INSTITUTO DE PESQUISAS ENERGÉTICAS E NUCLEARES Autarquia associada à Universidade de São Paulo

\author{
ESTUDO DE PRESSUPOSTOS TECNOLÓGICOS E COGNITIVOS \\ PARA APERFEIÇOAMENTO DE LABORATÓRIOS VIRTUAIS E \\ AMBIENTES COLABORATIVOS VIRTUAIS PARA RADIOFARMÁCIA
}

ROBERTO CORREIA DE MELO

Tese apresentada como parte dos requisitos para obtenção do Grau de Doutor em Ciências na Área de Tecnologia Nuclear - Aplicações.

Orientador:

Dr. João Alberto Osso Jr.

SÃO PAULO

2009 
Pacotes fechados de informações são tomados como fatos.

E fatos são tomados como verdades absolutas, a serem aprendidas e memorizadas como tal, restando pouco espaço para o raciocínio sobre elas.

Sem qualquer raciocínio para abrir o pacote, há poucas chances de que essas informações possam nos levar a qualquer insight, ou mesmo de que possam ser repensadas em outro contexto.

Ellen Langer 
À minha amada esposa Lourdes, incansável e bela companheira da vida inteira. Aos meus queridos filhos, Aline e Caio, que ampliaram meus sentidos. Aos meus pais, Antonio e Lodovina (in memorian). A todos os meus professores e professoras, desde o ensino fundamental até o doutorado. 


\section{Agradecimentos}

Ao Dr. João Alberto Osso Jr., do IPEN-CNEN/SP USP, pela orientação competente e disponibilidade constante para o diálogo.

Ao Dr. Alberto Saburo Todo, do IPEN-CNEN/SP USP, pela orientação decisiva nos primeiros passos dentro do Programa de Pós-Graduação da USP.

Ao colega Prof. Dr. Edmir Ximenes, que me colocou em contato com o capital humano do IPEN-CNEN/SP USP.

Ao Dr. Rodolfo Politano, do IPEN-CNEN/SP USP, por suas valiosas sugestões sobre o foco adequado para este trabalho.

Ao Dr. Afonso Rodrigues de Aquino, do IPEN-CNEN/SP USP, por sua análise e observações desde a fase de qualificação desse trabalho

À Dra. Ellen Jane Langer, da Harvard University (USA), por suas sugestões para a elaboração do instrumento para coleta de dados para o estudo de caso.

Ao colega Prof. Carlos Henrique Veríssimo Pereira, pela valiosa contribuição na coleta de dados e elaboração do protótipo apresentado neste trabalho.

Aos colegas bolsistas do Programa de Pós-Graduação do IPEN-CNEN/SP USP, pelo convívio humano e intelectual estimulante durante os anos (2005-2009) de desenvolvimento dos trabalhos desta tese. 


\section{LISTA DE TABELAS}

Página

Tabela 1. Tipos de nuclídeos ..................................................................

Tabela 2. Processos de desintegração do núcleo radioativo ......................... 10

Tabela 3. Radionuclídeos produzidos em reatores nucleares ..................... 14

Tabela 4. Radionuclídeos produzidos em cíclotrons ................................. $\quad 15$

Tabela 5. Radionuclídeos produzidos em geradores ................................. 16

Tabela 6. Principais radionuclídeos usados em medicina nuclear ............... 18

Tabela 7. Modos de uso do computador no ensino e aprendizagem .......... 22

Tabela 8. Características de ambientes construtivistas de aprendizagem ... 38

Tabela 9. Conceitos englobados em colaboração ..................................... $\quad 45$

Tabela 10. Taxonomia de Ohlsson ........................................................... 48

Tabela 11. Sumário das oito inteligências ............................................... 58

Tabela 12. Estilos de aprendizagem .................................................. 61

Tabela 13. Pensamento desatento (mindlessness) .................................. 63

Tabela 14. Pensamento atento (mindfulness) ......................................... 65

Tabela 15. Diferenças entre inteligência e mindfullnes .............................. 71

Tabela 16. Sete mitos penetrantes prejudiciais à cognição .......................... $\quad 72$

Tabela 17. Abordagem desatenta (mindless) versus abordagem atenta

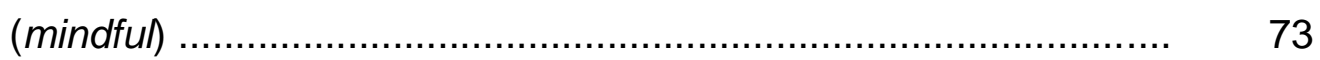

Tabela 18. Benefícios obtidos com o uso de LV ........................................ 77

Tabela 19. Classes de comunicação dentro de um LV .............................. $\quad 79$

Tabela 20. Benefícios do uso de LV ....................................................... 81

Tabela 21. Categoria geral dos LV ...................................................... 82

Tabela 22. Partes do ambiente VirRAD .................................................. 89

Tabela 23. Estrutura do questionário aplicado .......................................... 102

Tabela 24. Presença das oito inteligências nos usuários ........................... 124

Tabela 25. Visão dos usuários sobre mitos educacionais ........................... 125

Tabela 26. Visão dos usuários sobre abordagem mindful........................... 125

Tabela 27. Visão dos usuários sobre aspectos tecnológicos............................ 126 
Tabela 28. Recursos necessários por tipo de inteligência

Tabela 29. Ações para evitar os sete mitos negativos

Tabela 30. Ações para evitar abordagem mindless e favorecer abordagem mindful

Tabela 31. Características tecnológicas desejáveis no LV/CVE Proposto.... 132

Tabela 32. Funcionalidade completa do LV/CVE Proposto.

Tabela 33. Funcionalidade completa do LV/CVE Proposto - Menu 3D VR Lab.

Tabela 34. Finalidade das funções acrescentadas ao LV/CVE Proposto. 


\section{LISTA DE FIGURAS}

Página

Figura 1. Decaimento radioativo .................................................................



Figura 3. Arquitetura do LV VirRAD .......................................................... 92

Figura 4. LV em modo de estudo mono-usuário ....................................... 93

Figura 5. LV em modo de estudo multi-usuário ......................................... 96

Figura 6. Gênero dos usuários do LV/CVE VirRAD ................................. 104

Figura 7. Faixas etárias dos usuários do LV/CVE VirRAD ......................... 105

Figura 8. Formação acadêmica dos usuários do LV/CVE VirRAD ............... 105

Figura 9. Ocupações dos usuários do LV/CVE VirRAD ............................... 106

Figura 10. Anos de carreira dos usuários do LV/CVE VirRAD .................... 106

Figura 11. Inteligência verbal dos usuários do LV/CVE VirRAD ................. 108

Figura 12. Inteligência lógico-matemática dos usuários do LV/CVE VirRAD. 108

Figura 13. Inteligência visual-espacial dos usuários do LV/CVE VirRAD...... 109

Figura 14. Inteligência corpórea-cinestésica usuários do LV/CVE VirRAD ...... 109

Figura 15. Inteligência naturalística dos usuários do LV/CVE VirRAD.......... 110

Figura 16. Inteligência musical dos usuários do LV/CVE VirRAD................. 110

Figura 17. Inteligência intrapessoal dos usuários do LV/CVE VirRAD.......... 111

Figura 18. Inteligência interpessoal dos usuários do LV/CVE VirRAD.......... 111

Figura 19. Usuários do LV/CVE VirRAD que confirmam o mito 1................ 112

Figura 20. Usuários do LV/CVE VirRAD que confirmam o mito 2............... 112

Figura 21. Usuários do LV/CVE VirRAD que confirmam o mito 3................ 113

Figura 22. Usuários do LV/CVE VirRAD que confirmam o mito 4................ 113

Figura 23. Usuários do LV/CVE VirRAD que confirmam o mito 5................ 114

Figura 24. Usuários do LV/CVE VirRAD que confirmam o mito 6................ 114

Figura 25. Usuários do LV/CVE VirRAD que confirmam o mito 7............... 115

Figura 26. Usuários que criam novas categorias de conhecimentos .......... 115

Figura 27. Usuários abertos a novas informações ................................... 116

Figura 28. Usuários atentos a múltiplas perspectivas ............................... 116 
Figura 29. Freqüência de acesso dos usuários ao LV/CVE VirRAD.............. 117

Figura 30. Funções mais acessadas pelos usuários do LV/CVE VirRAD....... 118

Figura 31. Papel desempenhado pelos usuários do LV/CVE VirRAD........... 118

Figura 32. Modo como os usuários acessam o VR Lab do LV/CVE VirRAD... 119

Figura 33. Procedimentos mais executados no VR LAB do LV/CVE VirRAD.. 119

Figura 34. Importância do uso de avatares no VR LAB do LV/CVE VirRAD .. 120

Figura 35. Correção dos procedimentos do VR LAB do LV/CVE VirRAD,..... 120

Figura 36. Completeza dos procedimentos do VR LAB do LV/CVE VirRAD... 121

Figura 37. Usabilidade dos procedimentos do VR LAB do LV/CVE VirRAD, .. 121

Figura 38. Tempo de execução dos procedimentos do VR LAB do

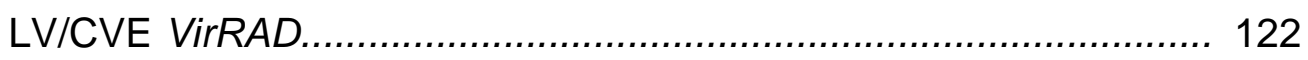

Figura 39. Variedade de procedimentos no 3D VR LAB do LV/CVE VirRAD.. 122

Figura 40. Utilidade do ambiente VirRAD como um todo.............................. 123 


\section{LISTA DE ABREVIATURAS E/OU SIGLAS}

$\begin{array}{ll}\text { ADHD } & \text { Síndrome de déficit de atenção e hiperatividade } \\ \text { a.m.u } & \text { Atomic Mass Unit } \\ \text { AVC } & \text { Ambiente Virtual Colaborativo } \\ \text { AVD } & \text { Ambiente Virtual Distribuído } \\ \text { AVI } & \text { Ambiente Virtual Imersivo } \\ \text { BBS } & \text { Bulletin Board } \\ \text { CAVE } & \text { Cave Automatic Virtual Environment } \\ \text { CMC } & \text { Computação Mediada por Computador } \\ \text { CODATA } & \text { Committee on Data for Science and Techonology } \\ \text { CORBA } & \text { Common Object Request Broker Architecture } \\ \text { CSCL } & \text { Computer Supported Collaborative Learning } \\ \text { CSCW } & \text { Computer Supported Collaborative Work } \\ \text { CVE } & \text { Collaborative Virtual Environment } \\ \text { DOS } & \text { Disk Operating System } \\ \text { EANM } & \text { European Association of Nuclear Medicine. } \\ \text { GC } & \text { Gestão do Conhecimento } \\ \text { HMD } & \text { Head Mounted Display } \\ \text { HTML } & \text { Hyper Text Markup Language } \\ \text { HTTP } & \text { Hyper Text Transmission Protocol } \\ \text { IHC } & \text { Interface Homem-Computador } \\ \text { IITP } & \text { International Institute of Theoretical and Applied Physics } \\ \text { IST } & \text { Information Society Technologies } \\ \text { IVE } & \text { Immersive Virtual Environment } \\ \text { JDBC } & \text { Java Database Connectivity } \\ \text { LCD } & \text { Liquid Crystal Display } \\ \text { LV } & \text { Laboratório Virtual } \\ \text { MI } & \text { Multiple Intelligences } \\ \text { ML } & \text { Mindful learning } \\ \text { ODBC } & \text { Open Database Connectivity } \\ \end{array}$




$\begin{array}{ll}\text { PC } & \text { Personal Computer } \\ \text { PET } & \text { Positron Emission Tomography } \\ \text { PHP } & \text { Hypertext Preprocessor } \\ \text { RBL } & \text { Resource-Based Learning } \\ \text { RMTP } & \text { Reliable Multicast Transport Protocol } \\ \text { RV } & \text { Realidade Virtual } \\ \text { SPECT } & \text { Single Photon Emission Computed Tomography } \\ \text { TIC } & \text { Tecnologias da Informação e da Comunicação } \\ \text { UNESCO } & \text { United Nations Educational, Scientific and Cultural Organization } \\ \text { VirRAD } & \text { Virtual Radiopharmacy } \\ \text { VL } & \text { Virtual Lab } \\ \text { VR Lab } & \text { Virtual Radiopharmacy Laboratory } \\ \text { WEB } & \text { World Wide Web }\end{array}$




\title{
ESTUDO DE PRESSUPOSTOS COGNITIVOS E TECNOLÓGICOS PARA APERFEIÇOAMENTO DE LABORATÓRIOS VIRTUAIS E AMBIENTES COLABORATIVOS VIRTUAIS PARA RADIOFARMÁCIA
}

\author{
Roberto Correia de Melo
}

RESUMO

\begin{abstract}
Neste trabalho foram estudadas características gerais de laboratórios virtuais e de ambientes colaborativos virtuais (que formam um ambiente LV/CVE), tanto em seus aspectos tecnológicos quanto com referência ao perfil cognitivo dos profissionais que os utilizam. Em seguida, estudou-se detalhadamente um ambiente LV/CVE - o VirRAD, que foi criado para capacitar profissionais de radiofarmácia, e estudou-se os aspectos cognitivos de seus usuários, analisados sob as perspectivas de duas teorias cognitivas de repercussão mundial: inteligências múltiplas, de Howard Gardner, e mindful learning, de Ellen Langer. As conclusões obtidas nesses estudos orientaram a proposição de aperfeiçoamentos ao LV/CVE focalizado, que foram incorporadas a um protótipo de aplicativo baseado no $\operatorname{VirRAD}$, cujas telas são apresentadas ao final deste trabalho, sendo que essas conclusões também são aplicáveis a qualquer ambiente LV/CVE.
\end{abstract}




\title{
STUDY OF COGNITIVE AND TECHNOLOGICAL PREREQUISITES FOR VIRTUAL LABORATORIES AND COLLABORATIVE VIRTUAL ENVIRONMENTS FOR RADIOPHARMACY
}

\author{
Roberto Correia de Melo
}

\begin{abstract}
This academic work explains a general view of virtual laboratories (VL) and collaborative virtual environments (CVE) (called, together, a VL/CVE set), focusing their technological features and analyzing the common cognitive features of their users. Also is presented a detailed description of VL/CVE VirRAD (Virtual Radiopharmacy), created specially to connect and support the international radiopharmacy community around the world, and is explained an analysis of their users' cognitive profile, under the perspective of two of the most important cognitive theories of the $20^{\text {th }}$ century: multiple intelligences, by Howard Gardner, and mindful learning, by Ellen Langer. Conclusions from this study has been incorporated, as feature enhancements, to a software prototype created based upon VirRAD software solution, and the hardcopy of their screens is exposed at the end of this work. It is also an essential idea that the conclusions of this work are relevant to any VL/CVE environment.
\end{abstract}




\section{SUMÁRIO}

Página

$1 \quad$ INTRODUÇÃO .....................................................................

1.1 Relevância deste trabalho.................................................................... 1

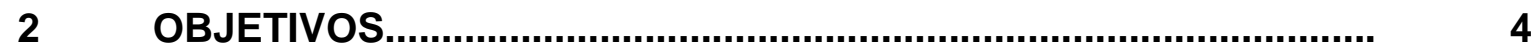

3 REVISÃO DA LITERATURA....................................................... 5

3.1 Radionuclídeos e radiofarmácia...................................................... 5

3.1.1 Modos de produção artificial de radionuclídeos.................................. 12

3.1.2 Radionuclídeos utilizados em diagnósticos e terapias......................... 17

3.1.3 Produção de radiofármacos no IPEN-CNEN/SP ................................. 18

3.2 Ambientes colaborativos virtuais - aspectos tecnológicos.................... 19

3.2.1 Pressupostos de TIC para criar um CVE................................................... 19

3.2.2 Comunicação mediada por computador............................................... 21

3.2.2.1 Tipos de CMC............................................................................ 23

3.2.2.2 CMC como uma ferramenta de pensar (mindtool) ............................. 24

3.2.2.3 CMC e CSCL............................................................... 25

3.3 Realidade virtual......................................................................... 28

3.3.1 Aspectos tecnológicos da RV.............................................................. 32

3.3.2 Uso educacional de RV...................................................................... $\quad 37$

3.4 Ambientes colaborativos virtuais - aspectos cognitivos....................... 39

3.4.1 Desenvolvimento cognitivo e aprendizagem....................................... 40

3.4.2 Aprendizagem colaborativa....................................................... 43

3.4.3 Formação de significados em colaboração........................................ 49

3.4.4 Aprendizagem em rede............................................................ 51

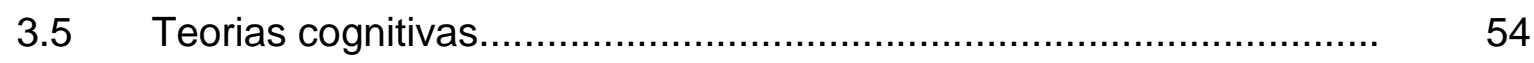

3.5.1 Elementos da teoria Inteligências Múltiplas, de Howard Gardner...... 56

3.5.2 Elementos da teoria Mindful Learning, de Ellen Langer...................... 61

3.6 Laboratórios virtuais...................................................................... 73

3.6.1 Contextualização de LV.......................................................................... 76 
3.6.2 Aspectos estratégicos da utilização de LV ............................................. 80

$3.7 \quad$ Origens do projeto VirRAD .................................................................... 84

3.7.1 Histórico do Projeto VirRAD ............................................................

3.7.2 Fundamentos do Projeto VirRAD....................................................... 86

3.7.3 Características do LV 3D VirRAD ........................................................ 90

3.8 Vantagens da utilização do VirRAD ................................................. 96

$4 \quad$ METODOLOGIA................................................................. 99

$5 \quad$ RESULTADOS DO ESTUDO DE CASO......................................... 104

5.1 Perfil pessoal dos usuários do LV/CVE VirRAD................................... 104

5.2 Perfil cognitivo dos usuários do LV/CVE VirRAD................................... 107

5.2.1 Sob a perspectiva de Inteligências Múltiplas....................................... 107

5.2.2 Sob a perspectiva de Mindful Learning............................................. 112

5.3 Aspectos da utilização do LV/CVE VirRAD...................................... 117

6 ANÁLISE E DISCUSSÃO DOS RESULTADOS.................................. 124

$7 \quad$ PROPOSTA DE UM LV/CVE APERFEIÇOADO.............................. 127

7.1 Características do LV/CVE proposto................................................ 128

$7.2 \quad$ Funcionalidade do LV/CVE proposto................................................. 132

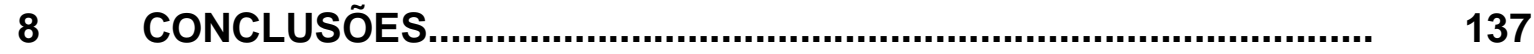

8.1 Sugestões para trabalhos futuros................................................. 139

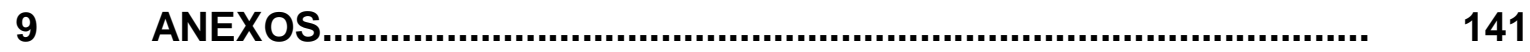

9.1 Questionário Mindful Learning...................................................... 143

9.2 Questionário Inteligências Múltiplas................................................ 147

9.3 Questionário aspectos da utilização do LV/CVE VirRAD....................... 149

9.4 Telas do LV/CVE proposto............................................................ 153

10 REFERÊNCIAS BIBLIOGRÁFICAS............................................. 161 


\section{INTRODUÇÃO}

A importância estratégica do tema laboratórios virtuais (LV) tem crescido de modo constante e consistente desde o início da década de 2000, em especial no caso em que LVs são utilizados associados a ambientes colaborativos virtuais (CVE), ou seja, quando o LV está contido e funciona sob um CVE.

Nesse período surgiram várias soluções eficazes integrando LV e CVE (a designação LV/CVE será aplicada para representar esta integração), voltadas para o atendimento a diferentes áreas científicas, uma das quais é a solução denominada Virtual Radiopharmacy - VirRAD, um ambiente virtual tridimensional (3D) dirigido para a comunidade internacional de radiofarmácia.

Os fatores intervenientes e que determinam as características e escopo do tema LV/CVE pertencem tanto à área de tecnologia da informação quanto à área de cognição, e apresentam uma relação de inter-dependência tal que, para o ambiente LV/CVE VirRAD ter sua eficácia aumentada como uma solução e interface tecnológica de comunicação, de ensino e aprendizagem, para usuários de qualquer área científica, propõe-se aqui que sua concepção deve basear-se na aplicação fortemente integrada tanto de pressupostos tecnológicos quanto de pressupostos cognitivos.

E não se encontra a aplicação integrada desses pressupostos na solução LV/CVE VirRAD, daí este trabalho no sentido de propor um LV/CVE aperfeiçoado que considere os aspectos tecnológicos e cognitivos apontados.

\subsection{RELEVÂNCIA DESTE TRABALHO}

A relevância potencial deste trabalho acadêmico decorre da abordagem integrada de três aspectos.

O primeiro aspecto é destacar a importância intrínseca do tema LV/CVE, relacionando-o com seus pressupostos tecnológicos, que são tecnologia da informação e comunicação (TIC), computação mediada por computador (CMC) e realidade virtual $(R V)$, e sua aplicabilidade na área de radiofarmácia hospitalar, e trazer para a comunidade científica brasileira de radiofarmácia o contato com essa 
nova modalidade de solução e interface tecnológica de pesquisa e de comunicação derivada das TIC, que é o próprio ambiente LV/CVE, cuja utilização pode acarretar vários benefícios, tais como: agilizar pesquisas, aprimorar procedimentos, reduzir prazos e custos e conduzir a novos resultados.

O segundo aspecto é apresentar o inter-relacionamento entre o tema LV/CVE com seus pressupostos cognitivos, aqui representados por duas teorias cognitivas de destaque do século $\mathrm{XX}$, analisadas de modo a compreender como essas teorias podem contribuir para aperfeiçoar os LV/CVE existentes e torná-los mais eficazes como ferramentas auxiliares de ensino, aprendizagem e de comunicação para cientistas, estudantes e profissionais.

O terceiro aspecto é propor e demonstrar um protótipo de software de LV/CVE incorporando sugestões para aperfeiçoar o LV/CVE estudado - o VirRAD, no qual foram aplicadas as conclusões das análises realizadas sobre as informações coletadas por meio de estudo de caso junto ao seus usuários.

Quanto aos pressupostos tecnológicos, tem-se como importante considerar o contexto formado pela junção tanto de conceitos inerentes às TIC, quanto a CMC e $\mathrm{RV}$, já que, associados, esses pressupostos criam e moldam o contexto de infraestrutura sobre o qual (e por meio do qual) são concebidos, implantados e utilizados os LV/CVE.

Quanto aos pressupostos cognitivos, GARDNER (1995) afirmou que existem, pelo menos, sete diferentes tipos de inteligências (anos depois ele acrescentou um oitavo tipo), o que permite hipotetizar que cada tipo de inteligência pode ser sensibilizado de um modo específico por características de aplicativos e interfaces de software como são os LV/CVE, e conduz a buscar evidências que comprovem ou neguem essa hipótese.

Quanto a práticas de ensino e aprendizagem, LANGER (1997) recomendou rejeitar modelos de ensino e aprendizagem baseados em certos conceitos largamente utilizados, e aceitos pela maioria das pessoas sem muita reflexão, porque, segundo ela, muitas dessas práticas são baseadas em sete mitos ou mentalidades penetrantes (pervasive, no original) que nos levam a resultados ineficazes na concepção e avaliação de processos de ensino e aprendizagem. 
Tendo em vista os fatores intervenientes mencionados, o presente estudo busca contribuir com a análise: 1) dos pressupostos tecnológicos que devem estar presentes em qualquer LV/CVE (TIC, CMC e RV), 2) dos perfis cognitivos dos seus usuários (de acordo com as inteligências múltiplas, de Howard Gardner), e os conceitos de ensino e aprendizagem presentes nos LV/CVE estudados (de acordo com os princípios da teoria mindful learning, de Ellen Langer), 3) das características que um LV/CVE deve ter para atender aos perfis cognitivos da maioria de seus usuários, e, 4) e busca incorporar características que atendam aos pressupostos apontados a um protótipo de aplicativo de software que aperfeiçoe o LV/CVE VirRAD.

A seqüência de assuntos deste trabalho foi realizada para, primeiramente, fornecer princípios sobre radionuclídeos e radiofarmácia, a fim de contextualizar o LV/CVE VirRAD em sua área de especialidade. Em seguida, fornece-se uma visão introdutória sobre os aspectos tecnológicos que cercam o tema LV/CVE (que são: TIC, CMC e RV) e fornece-se uma visão de aspectos cognitivos básicos (desenvolvimento cognitivo e aprendizagem, aprendizagem colaborativa, formação de significados em colaboração, aprendizagem em rede e elementos das duas teorias cognitivas abordadas).

Em seguida, conceituam-se laboratórios virtuais, seus fundamentos tecnológicos e aspectos estratégicos de sua utilização; finaliza-se com resultados de estudo de caso realizado sobre o LV/CVE VirRAD e sua comunidade usuária, estabelece-se conclusões e apresenta-se o protótipo de um aplicativo de software que propõe aperfeiçoamentos sobre o LV/CVE analisado. 


\section{OBJETIVOS}

O objetivo deste trabalho é demonstrar que, para qualquer ambiente LV/CVE ser eficaz como uma solução e interface tecnológica de comunicação, de ensino e aprendizagem, para qualquer área científica, sua concepção deve basear-se na aplicação integrada tanto de pressupostos tecnológicos quanto de pressupostos cognitivos, inter-relacionados.

No caso específico do LV/CVE do Projeto VirRAD, o objetivo é evidenciar que esse inter-relacionamento ainda não ocorre de modo eficaz, embora deva-se reconhecer seu alto nível de concepção e desenvolvimento, e isso deve-se, talvez, porque seus idealizadores desconheciam a importância da observância simultânea desses pressupostos em seu projeto ou talvez porque eles simplesmente não os considerassem essenciais.

Dentre os pressupostos tecnológicos envolvidos, destacam-se três grupos como os mais relevantes: TIC, CMC e RV.

Dentre os pressupostos cognitivos essenciais, este trabalho destaca: fundamentos de aprendizagem colaborativa e o conhecimento de teorias cognitivas, e dessas ressaltam-se duas teorias de grande influência contemporânea: inteligências múltiplas, de Howard Gardner, e mindful learning, de Ellen Langer.

Com referência aos pressupostos cognitivos, o modelo proposto nesta tese busca comprovar que um LV/CVE deve considerar em seu projeto e implantação as características do perfil cognitivo de seus usuários, a fim de produzir melhores resultados, sendo esse perfil analisado aqui sob a ótica das duas teorias cognitivas mencionadas.

Como não são encontradas evidências que comprovem que o desenvolvimento do LV/CVE VirRAD tenha levado em consideração de modo suficiente todos os pressupostos apontados, a contribuição do presente trabalho foca-se em: 
a) propor e demonstrar um modelo de LV/CVE que incorpore os pressu-postos tecnológicos e cognitivos apontados nesse estudo;

b) comparar o modelo proposto com o ambiente LV/CVE VirRAD;

c) apresentar sugestões de melhorias a serem incorporadas ao ambiente LV/CVE VirRAD.

Apresenta-se, na finalização dessa tese, um modelo de LV/CVE, na forma de um protótipo programado em Hyper Text Markup Language (HTML) e Hypertext Preprocessor (PHP) que incorpora as características gerais necessárias reveladas pelo estudo de caso, comparando-o com o LV/CVE VirRAD, bem como apresenta-se as conclusões do trabalho.

\section{REVISÃO DA LITERATURA}

Apresenta-se, neste tópico, aspectos sobre radionuclídeos e radiofarmácia, ambientes colaborativos virtuais - em termos tecnológicos e cognitivos, laboratórios virtuais. e as teorias cognitivas focalizadas.

\subsection{RADIONUCLÍDEOS E RADIOFARMÁCIA}

As primeiras experiências na obtenção de imagens dinâmicas do funcionamento do corpo humano (esses exames são chamados cintilografias) ocorreram na década de 1930, nos Estados Unidos, com o uso de radioisótopos acoplados a substâncias injetadas nos pacientes, inicialmente com a captação de imagens por meio de tomógrafos do tipo positron emission tomography (PET) e posteriormente com single photon emission computed tomography (SPECT).

Esse avanço tecnológico permitiu o surgimento da radiofarmácia, o ramo da ciência que estuda os aspectos químicos, farmacológicos, bioquímicos e fisiológicos relacionados ao desenvolvimento de substâncias marcadas (por sua combinação com radiofármacos) usadas para:

1) o tratamento de enfermidades (terapia); 
2) como traçadores radioativos em diagnósticos clínicos (in vitro e in vivo).

As imagens são obtidas por meio da administração de radiofármacos aos pacientes, medindo-se externamente a radiação emitida pelos radioisótopos, que atravessam o organismo de dentro para fora.

De acordo com THRALL e ZIESSMAN (2003), radiofármaco é um termo reservado para referenciar materiais radioativos que preenchem os requisitos para serem administrados a pacientes, e pode ser entendido como toda substância que tem em sua composição um radionuclídeo associado a uma molécula ou a um composto escolhido por sua capacidade de ser capturado por um determinado órgão, dentro de um processo fisiológico ou fisiopatológico, e que, devido à sua forma farmacêutica, quantidade e qualidade de radiação, pode ser utilizada no diagnóstico e no tratamento de diversas enfermidades dos seres vivos.

Suas características físico-químicas determinam sua fixação no órgão-alvo, forma de metabolização e de eliminação do organismo, enquanto que suas características físicas determinam a aplicação das substâncias em processos de diagnóstico e/ou terapêuticos (OLIVEIRA e SANTOS, 2006).

De acordo com THRALL e ZIESSMAN (2003), um radiofármaco possui dois componentes:

1) o radionuclídeo ou radionuclídeos associados e, acoplado a ele(s);

2) uma molécula bioquímica.

As principais características desejáveis em um radiofármaco, para sua utilização para fins de diagnóstico são:

1) sua meia-vida deve ser longa o bastante para a aplicação desejada;

2) não deve emitir radiações de partículas;

3) deve emitir fóton gama com energia e quantidade suficiente para a detecção externa, por meio de câmaras gama; 
4) sua atividade específica deve ser alta;

5) deve apresentar ausência de toxicidade e de efeitos secundários.

A produção de radionuclídeos em aceleradores de partículas iniciou-se antes de sua produção em reatores nucleares (construídos somente após a descoberta da fissão nuclear), e o ${ }^{32} \mathrm{P}$ foi o primeiro radiotraçador utilizado. (KNAPP e MIZRADEH, 2001)

A composição nuclear de um elemento, que considera seu número de massa $(A)$, seu número atômico $(Z)$ e o arranjo das partículas subatômicas no seu núcleo, distingue diferentes espécies, chamadas nuclídeos.

Nuclídeos são agrupados tendo em vista seus números de massa (A), números atômicos $(Z)$ e números de nêutrons $(N)$. Na TAB. 1 são mostrados os tipos de nuclídeos:

TABELA 1. Tipos de nuclídeos

\begin{tabular}{|c|c|c|c|}
\hline Denominação & Característica & Exemplo & Obs \\
\hline ISÓTOPOS & Mesmo número atômico (Z) & ${ }^{15} \mathrm{O},{ }^{16} \mathrm{O},{ }^{17} \mathrm{O},{ }^{18} \mathrm{O}$ & $\mathrm{Z}=8$ \\
\hline ISÓTONOS & $\begin{array}{c}\text { Mesmo números de nêutrons (N), } \\
\text { Diferentes números de massa (A) }\end{array}$ & ${ }^{59 / 26} \mathrm{Fe},{ }^{60 / 27} \mathrm{Co},{ }^{62 / 29} \mathrm{Cu}$ & $\mathrm{N}=33$ \\
\hline ISÓBAROS & $\begin{array}{c}\text { Mesmo número de massa (A), } \\
\text { Diferentes Z e N }\end{array}$ & ${ }^{67 / 29} \mathrm{Cu},{ }^{67 / 30} \mathrm{Zn},{ }^{67 / 37} \mathrm{Ga}$, & $\mathrm{A}=67$ \\
\hline ISÓMEROS & $\begin{array}{c}\text { Mesmo N e Z. } \\
\text { Diferentes estados de energia e spins }\end{array}$ & ${ }^{99} \mathrm{Tc},{ }^{99 \mathrm{~m}} \mathrm{Tc}$ & $\mathrm{A}=99$ \\
\hline
\end{tabular}

Fonte: (TUBIS e WOLF, 1976), adaptado pelo autor.

Radionuclídeos tendem a perder massa por meio de vários processos de decaimento radioativo, pela liberação de raios gama e/ou pelo desprendimento de partículas subatômicas, por meio dos quais o núcleo "busca" estabilidade.

Os radionuclídeos com núcleos menos estáveis são os que contem um número ímpar de prótons ou nêutrons, enquanto os com núcleos com números pares de prótons ou nêutrons são relativamente mais estáveis. A estabilidade de um núcleo pode ser vista por meio do quociente $\mathrm{N} / \mathrm{Z}$, número de nêutrons ( $\mathrm{N}$ ) pelo número atômico (número de prótons) (Z). Quanto mais esse quociente for próximo de 1, mais 
estável será o núcleo, e sua instabilidade cresce proporcionalmente ao crescimento do quociente.

Alguns radionuclídeos são denominados isótopos radioativos ou radioisótopos e são encontrados na natureza, o que é raro, e outros têm que ser produzidos artificialmente.

Decaimento radioativo é o processo de desintegração de um núcleo (e a conseqüente transformação do isótopo em outro) por meio de emissão de energia em forma de radiação, e pode ocorrer por emissão de partículas (radiação corpuscular), ou por emissão de ondas eletromagnéticas (radiação eletromagnética). Na FIG. 1 é representado o processo de decaimento:



FIGURA 1. Decaimento radioativo Fonte: (SAHA, 1998)

Os processos de desintegração do núcleo radioativo são seis, e podem ocorrer isoladamente ou combinados:

1) fissão espontânea: um núcleo pesado fragmenta-se (naturalmente ou por bombardeamento do núcleo por partículas de outros átomos) e emite dois ou três nêutrons; 
2) desintegração $\alpha$ : há a liberação de um núcleo de ${ }^{4} \mathrm{He}$ do núcleo do elemento; é mais comum nos elementos ${ }^{86} \mathrm{Rn},{ }^{235} \mathrm{U}$ e ${ }^{93} \mathrm{~Np}$; nesse tipo de decaimento, o número atômico do elemento pai é reduzido de 2 e o número de massa é reduzido de 4, e pode ser seguido por um decaimento por emissão $\beta^{-}$ou y ou ambos; um exemplo é a reação: ${ }^{235} \mathrm{U} \rightarrow{ }^{231} \mathrm{Th}+{ }^{4} \mathrm{He}$;

3) desintegração $\beta^{-}$: há a liberação de um elétron e um antineutrino do núcleo do radioisótopo, resultantes da transformação de um nêutron em um próton; ocorre quando um núcleo tem uma alta taxa $N / Z$ e é seguida por uma emissão $\gamma$; um exemplo é a reação: ${ }^{99} \mathrm{Mo} \rightarrow{ }^{99 \mathrm{~m}} \mathrm{Tc}+\beta^{-}+v$;

4) desintegração $\beta^{+}$: um próton se transforma em um nêutron por meio da emissão de uma partícula $\beta^{+}$e de um neutrino; um exemplo é a reação: ${ }^{64} \mathrm{Cu}$ $\rightarrow{ }^{64} \mathrm{Ni}+\beta^{+}+\mathrm{v}$;

5) captura eletrônica: um núcleo apresenta baixa taxa N/Z; o núcleo captura um elétron, transforma um próton em um nêutron e emite um neutrino; um exemplo é a reação: ${ }^{67} \mathrm{Ga}+\mathrm{e}^{-} \rightarrow{ }^{67} \mathrm{Zn}+\mathrm{v}$;

6) transição isomérica: um núcleo passa de um nivel excitado de energia mais alto para um nível mais baixo, normalmente liberando raios $\gamma$.

Na TAB. 2 são apresentados os processos de desintregração do núcleo radioativo: 
TABELA 2. Processos de desintegração do núcleo radioativo

\begin{tabular}{|c|c|}
\hline Processo & Característica \\
\hline FISSÃO ESPONTÂNEA & $\begin{array}{c}\text { Um núcleo pesado (o que contem maior quantidade de nêutrons do } \\
\text { que de prótons) fragmenta-se e emite dois ou três nêutrons. } \\
\text { Ocorre naturalmente ou por bombardeamento do núcleo do } \\
\text { radioisótopo por partículas oriundas de outros átomos. }\end{array}$ \\
\hline DESINTEGRAÇÃO $\alpha$ & $\begin{array}{c}\text { Liberação de um núcleo de }{ }^{4} \text { He do núcleo do radioisótopo em } \\
\text { processo de desintegração. }\end{array}$ \\
\hline DESINTEGRAÇÃO $\beta^{-}$ & $\begin{array}{r}\text { Liberação de um elétron e um antineutrino do núcleo do radioisótopo } \\
\text { em desintegração, resultantes da transformação de um } \\
\text { nêutron em um próton. }\end{array}$ \\
\hline DESINTEGRAÇÃO $\beta^{+}$ & $\begin{array}{c}\text { Um próton se transforma em um nêutron por meio da emissão de } \\
\text { umantícula } \beta^{+} \text {e de um neutrino no núcleo do radioisótopo. Ocorre } \\
\text { quando núcleo é "rico em prótons" (tem uma baixa taxa N/Z). }\end{array}$ \\
\hline CAPTURA & $\begin{array}{r}\text { Um núcleo que apresenta baixa taxa N/Z captura um elétron, } \\
\text { transforma um próton em um nêutron e emite um neutrino. }\end{array}$ \\
\hline ELETRÔNICA & $\begin{array}{c}\text { Um núcleo passa de um nivel excitado de energia mais alto para um } \\
\text { nível mais baixo, normalmente liberando raios } \gamma \text {. }\end{array}$ \\
\hline TRANSICCÃO \\
ISOMÉRICA
\end{tabular}

Fonte: (SAHA, 1998), adaptado pelo autor.

Atividade é a taxa de desintegração do núcleo e é designada por $A$. Cada radionuclídeo tem uma meia-vida ( $\left.T_{1 / 2}\right)$ específica, que é o tempo que ele demora a ter sua atividade reduzida à metade

Nos elementos químicos radioativos, se a razão entre nêutrons/prótons (n/p) do núcleo for instável por excesso de nêutrons, o radioisótopo decairá por emissão de partículas $\alpha$. Caso contrário, se a razão $\mathrm{n} / \mathrm{p}$ for instável por falta de nêutrons, $\mathrm{o}$ radioisótopo emitirá partículas $\beta^{+}$ou realizará a captura eletrônica para transformar um próton em um nêutron.

Traçadores radioativos são os radionuclídeos usados para diagnósticos e em processos como o de medição da velocidade de uma reação química ou da absorção de um elemento químico por algum órgão do corpo humano, e são substâncias às quais são adicionados radioisótopos associados a moléculas importantes no processo observado.

O interesse nos radionuclídeos deve-se também à sua capacidade de emissão de radiação ionizante, o que os potencializa para serem associados a traçadores e usados para diagnóstico por imagem. Imagens tridimensionais da dinâmica interna 
do corpo são obtidas usando-se câmaras PET, que usam radionuclídeos emissores de pósitrons com energia baixa, taxa de emissão alta e meia-vida curta, como ${ }^{18} \mathrm{~F}$, ${ }^{68} \mathrm{Ga},{ }^{11} \mathrm{C},{ }^{13} \mathrm{~N},{ }^{15} \mathrm{O}$, ou usando-se câmaras SPECT, que usam radionuclídeos emissores de raios-gama, que decaem por captura eletrônica ou por transição isomérica, que não emitem radiação corpuscular e possuem meia-vida adequada ao estudo fisiológico específico, como é o caso do ${ }^{99 \mathrm{~m}} \mathrm{Tc},{ }^{123} \mathrm{I},{ }^{131} \mathrm{I},{ }^{67} \mathrm{Ga},{ }^{111} \mathrm{In}$ e ${ }^{201} \mathrm{Tl}$.

PET e SPECT são gama-câmaras, e as primeiras têm vantagem sobre as câmaras SPECT por apresentarem sensibilidade e resolução maiores e maior flexibilidade em incorporar emissores de pósitrons em biomoléculas, enquanto que sua principal desvantagem é seu custo consideravelmente maior, além de exigir a proximidade de um ciclotron.

O sistema SPECT apresenta vantagens significativas quanto a preço, menor tamanho, facilidade de instalação e aplicabilidade em uma ampla variedade de procedimentos realizados em medicina nuclear. (THRALL e ZIESSMAN, 2003)

Radiofarmácia é "a ciência ou arte de preparar e dispensar componentes radioativos marcados de qualidade farmacêutica que são usados em medicina nuclear para diagnóstico e terapia." (TUBIS e WOLF, 1976)

A radiofarmácia compreende as etapas: estudar a preparação de radiofármacos; aplicar essas substâncias em pacientes; determinar doses; verificar o grau de toxicidade, e o nível de esterilidade (ausência de organismos vivos), tendo em vista as características/restrições dos radionuclídeos utilizados versus as especificidades das enfermidades a serem combatidas e da dinâmica dos organismos dos pacientes.

Os primeiros radionuclídeos artificiais $\left({ }^{128} \mathrm{I},{ }^{32} \mathrm{P},{ }^{14} \mathrm{C}\right)$ começaram a ser produzidos em cíclotrons ainda nos anos 30 , mas sua aplicação em maior escala iniciou-se nos anos 50, originando a área de estudos denominada medicina nuclear.

A biologia das radiações, área que estuda as interações e os efeitos das radiações ionizantes sobre os seres vivos, tornou-se de grande interesse para a radiofarmácia, sendo que os efeitos observados podem ser diretos ou indiretos. 
Efeitos diretos induzem moléculas à ionização, excitação ou formação de radicais livres (átomos ou moléculas altamente reativos com outros presentes nos tecidos e órgãos humanos devido à presença de um elétron livre).

Efeitos indiretos envolvem danos a moléculas situadas nas vizinhanças das moléculas-alvo, e o efeito indireto principal deve-se à radiólise da água, uma vez que a água atingida por radiações ionizantes libera vários produtos radiolíticos altamente reagentes com outras moléculas orgânicas, efeito agravado porque a água representa em torno de $80 \%$ da composição dos tecidos humanos. (TUBIS e WOLF, 1976)

\subsubsection{MODOS DE PRODUÇÃO ARTIFICIAL DE RADIONUCLÍDEOS}

Os radionuclídeos utilizados em medicina nuclear são os produzidos artificialmente, em reatores, cíclotrons ou geradores. Os que ocorrem na natureza não são adequados, pois têm meia-vida longa, são pesados e tóxicos, como $U, A c$, Th, Ra e Rd. (THRALL e ZIESSMAN, 2003)

Os radionuclídeos de maior interesse para a medicina nuclear são os de media-vida curta, como ${ }^{11} \mathrm{C}$ (de $\mathrm{T}_{1 / 2}$ de $20.5 \mathrm{~min}$.), ${ }^{15} \mathrm{O}$ (de $\mathrm{T}_{1 / 2}$ de $124 \mathrm{seg}$.), ${ }^{18} \mathrm{~F}$ (de $\mathrm{T}_{1 / 2}$ de $110 \mathrm{~min}$.), ${ }^{99} \mathrm{Mo}$ (de $\mathrm{T}_{1 / 2}$ de $66 \mathrm{~h}$ ), ${ }^{99 \mathrm{~m}} \mathrm{Tc}$ (de $\mathrm{T}_{1 / 2}$ de $6 \mathrm{~h}$ ), ${ }^{111} \mathrm{In}$ (de $\mathrm{T}_{1 / 2}$ de $67 \mathrm{~h}$ ), ${ }^{131}$ I (de $T_{1 / 2}$ de $193 \mathrm{~h}$ ), entre outros.

Quatro fatores combinados determinam a usabilidade de um radionuclídeo, e são: 1) suas características/facilidades de produção; 2) o custo/benefício de sua produção; 3) sua aplicabilidade em diagnósticos e terapias, e 4) suas propriedades físicas de decaimento. Os radionuclídeos produzidos artificialmente são obtidos pela:

a) irradiação em reatores nucleares, separando os produtos de processos de fissões nucleares ou por reações de captura de nêutrons. Como exemplo, a produção de ${ }^{131}$;

b) irradiação em aceleradores de partículas (cíclotrons), onde núcleos radioativos são bombardeados por feixes de partículas carregadas (ex:prótons) de diversos elementos. Como exemplo a produção de ${ }^{18} \mathrm{~F}$; 
c) separação de filhos de pais radioativos obtidos por um dos dois modos anteriores, processo denominado de gerador de radionuclídeos. Como exemplo o gerador de ${ }^{99} \mathrm{Mo}^{-}{ }^{99 \mathrm{~m}} \mathrm{Tc}$.

Um reator nuclear é um equipamento/instalação industrial ou de pesquisa que contém pastilhas de combustível físsil no interior de seu núcleo de tal modo que uma reação de fissão em cadeia auto-sustentável pode ser mantida nele de modo controlado. (TUBIS e WOLF, 1976)

O elemento físsil do núcleo é, geralmente, $0{ }^{235} \mathrm{U}$ enriquecido e alguns isótopos de ${ }^{235} \mathrm{U}$, e é acondicionado em bases de Al. Elementos de baixo peso molecular, tais como $\mathrm{C}, \mathrm{Be}$ ou $\mathrm{H}_{2} \mathrm{O}$, são distribuídos em torno e entre as pastilhas do combustível, a fim de capturar nêutrons livres liberados pela fissão, controlando o processo de fissão em cadeia, e são chamados moderadores.

Os radionuclídeos produzidos em reator são os que apresentam atividade $A$ alta (têm alta razão entre radioatividade e massa, e número atômico maior que 92). São produzidos por meio de três métodos (KNAPP e MIZRADEH, 2001):

1) separação dos produtos do processo de fissão nuclear: um exemplo é a fissão do ${ }^{235} \mathrm{U}$, que o divide em átomos de menor massa, que são isolados por meio de processos químicos, o constitui um método direto de produção de muitos radioisótopos úteis com peso atômico entre 100 e 130 a.m.u. (unidade de massa atômica). Exemplos: ${ }^{131} \mathrm{I}$, para tratamentos de tireóide, ${ }^{133} \mathrm{Xe}$, para estudos de ventilação dos pulmões e de perfusão cerebral, $\mathrm{e}^{99} \mathrm{Mo}$, que origina $\mathrm{o}^{99 \mathrm{~m}} \mathrm{Tc}$;

2) ativação direta de nêutrons de materiais-alvo: três tipos de reações de nêutrons são usadas para a produção de radionuclídeos para aplicações médicas: a) a reação elástica [n, $\gamma$ ]; b) a reação de captura de nêutrons [2n, $\gamma$ ]; c) a reação inelástica $\left[n, n^{\prime}, \gamma\right]$;

3) separação de filhos radioativos: de produtos obtidos por meio dos dois primeiros métodos, realizada em geradores de radionuclídeos. Quando o radionuclídeo pai produzido em reator decai, normalmente são produzidos 
radionuclídeos-filho de meia-vida curta, separados dos pais por processos como cromatografia de coluna de absorção.

Dentre os núcleos que sofrem fissionamento, os mais comuns são ${ }^{235} \mathrm{U},{ }^{239} \mathrm{Pu}$, ${ }^{237} \mathrm{~Np},{ }^{233} \mathrm{U},{ }^{232} \mathrm{Th}$, e os de maior interesse e aplicabilidade em radiofarmácia atualmente são: ${ }^{131} \mathrm{I},{ }^{99} \mathrm{Mo},{ }^{133} \mathrm{Xe}, \mathrm{e}{ }^{57} \mathrm{Co}$, que podem ser produzidos a partir da fissão de ${ }^{235} U$. Na TAB. 3 são mostrados os principais radionuclídeos produzidos em reator de fissão nuclear e as reações nucleares que os originam:

TABELA 3. Radionuclídeos produzidos em reatores nucleares

\begin{tabular}{lll}
\hline Fonte & Radionuclídeo & Reação nuclear \\
\hline Reator & ${ }^{131} \mathrm{I}$ & ${ }^{235} \mathrm{U}(\mathrm{n}, \mathrm{f})^{131} \mathrm{I}$ \\
& ${ }^{130} \mathrm{Te}(\mathrm{n}, \gamma)^{131} \mathrm{Te}{ }^{\mathrm{b}-} \rightarrow{ }^{131} \mathrm{I}$ \\
& ${ }^{32} \mathrm{P}$ & ${ }^{31} \mathrm{P}(\mathrm{n}, \gamma)^{32} \mathrm{P} /{ }^{62} \mathrm{~S}(\mathrm{n} \cdot \mathrm{p})^{32} \mathrm{P}$ \\
& ${ }^{67} \mathrm{Cu}$ & ${ }^{177} \mathrm{Zn}(\mathrm{n}, \mathrm{p}){ }^{67} \mathrm{Cu}$ \\
& $\left.{ }^{176} \mathrm{Lu}(\mathrm{n}, \gamma)\right)^{177} \mathrm{Lu}$ \\
& ${ }^{186} \mathrm{Re}$ & ${ }^{88} \mathrm{Sr}(\mathrm{n}, \gamma)^{89} \mathrm{Sr}$ \\
& ${ }^{153} \mathrm{Sm}$ & ${ }^{185}(\mathrm{n}, \gamma)^{186} \mathrm{Re}$ \\
& ${ }^{99} \mathrm{Mo}(\mathrm{n}, \gamma)^{153} \mathrm{Sm}$ \\
& & ${ }^{235} \mathrm{U}(\mathrm{n}, \mathrm{f})^{99} \mathrm{Mo} /$ \\
& ${ }^{98} \mathrm{Mo}(\mathrm{n}, \gamma)^{99} \mathrm{Mo}$
\end{tabular}

Fonte: (SAHA, 1998).

O cíclotron, ou acelerador de partículas, é o principal dispositivo para produção de radioisótopos, nos quais um feixe de íons passa através de uma série de cilindros não conectados, aos quais é aplicada uma corrente alternada de alta freqüência de uma freqüência de onda completa. Sua diferença com relação aos aceleradores lineares, é que, no cíclotron, os íons são capturados em um caminho circular obtido pela aplicação de campos magnéticos, nos ângulos adequados, no caminho da partícula. (TUBIS e WOLF, 1976)

De acordo com trabalhos de 14KNAPP e MIZRADEH (2001), o processo de produção de um radionuclídeo envolve três etapas: 1) preparação dos núcleos-alvo; 2) bombardeamento;3) tratamento químico. 
No ciclotron, partículas carregadas como prótons, deuterons, partículas $\alpha$ e partículas ${ }^{3} \mathrm{He}$ são aceleradas no vácuo por meio da ação de campos eletromagnéticos, produzindo-se radionuclídeos tais como: ${ }^{67} \mathrm{Ga},{ }^{123} \mathrm{I},{ }^{111} \mathrm{In},{ }^{201} \mathrm{TI},{ }^{11} \mathrm{C}$, ${ }^{13} \mathrm{~N},{ }^{15} \mathrm{O},{ }^{18} \mathrm{~F}$.

$\mathrm{Na}$ TAB. 4 são mostrados os radionuclídeos produzidos em cíclotrons e as reações nucleares que os originam:

TABELA 4. Radionuclídeos produzidos em cíclotrons

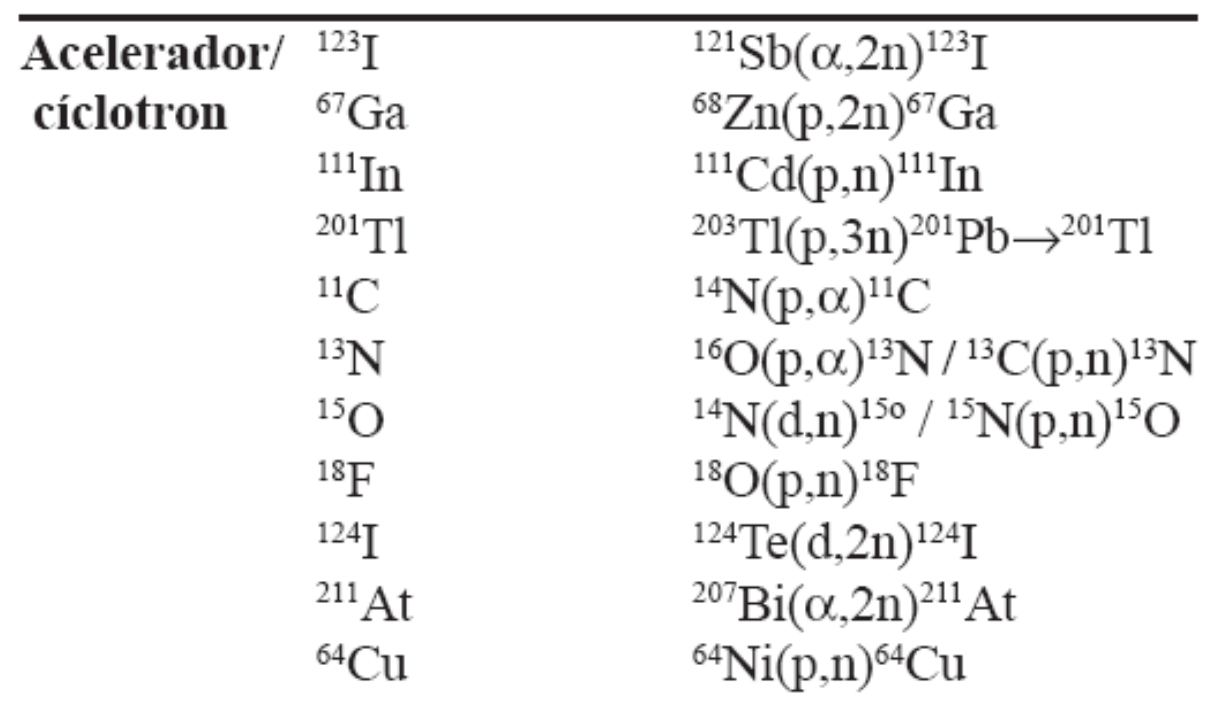

Fonte: (SAHA, 1998).

Geradores de radionuclídeos são dispositivos portáteis projetados para permitir a separação de radionuclídeos-filho, de meia-vida curta, a partir de radionuclídeos-pai, de meia-vida longa. Essa "extração" é uma operação de separação de elementos possibilitada pelo decaimento radioativo natural e característico do radionuclídeo "pai".

De acordo com KNAPP e MIZRADEH (2001), a separação do radionuclídeo-filho do radionuclídeo que the dá origem pode ser classificada em três tipos: 1) dependendo se o radionuclídeo-pai foi produzido em acelerador ou reator; 2) conforme os modos de decaimentos ou meias-vidas de pais e filhos; 3) baseado em suas aplicações em medicina nuclear. 
Na FIG. 2 é mostrado o esquema de funcionamento do gerador ${ }^{99} \mathrm{Mo} /{ }^{99 \mathrm{~m}} \mathrm{Tc}$, o mais importante dos geradores de radionuclídeos, exemplificando um esquema geral de todos eles.

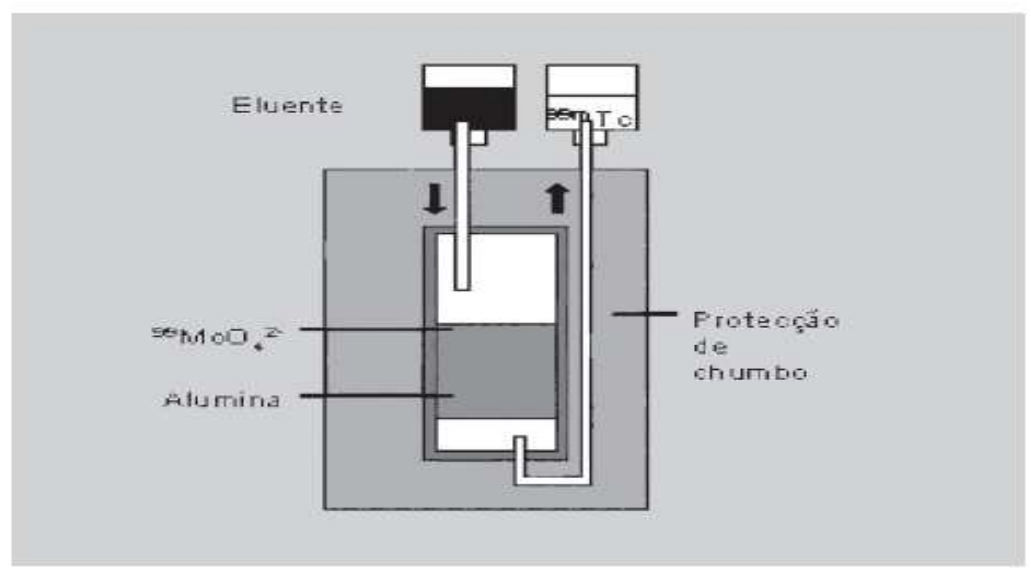

FIGURA 2. Gerador do radionuclídeo ${ }^{99 \mathrm{~m}} \mathrm{Tc}$

Fonte: (KNAPP e MIZRADEH, 2001)

$\mathrm{Na}$ TAB. 5 são mostrados os principais radionuclídeos produzidos em geradores e a reação nuclear que os origina:

TABELA 5. Radionuclídeos produzidos em geradores

\begin{tabular}{lll}
\hline Gerador & ${ }^{99 \mathrm{~m}} \mathrm{Tc}$ & ${ }^{99} \mathrm{Mo}^{\beta-} \rightarrow{ }^{99 m} \mathrm{Tc}$ \\
& ${ }^{68} \mathrm{Ga}$ & ${ }^{68} \mathrm{Ge}^{\mathrm{CE}} \rightarrow{ }^{68} \mathrm{Ga}$ \\
& ${ }^{90} \mathrm{Y}$ & ${ }^{235} \mathrm{U}(\mathrm{n}, \mathrm{f})^{90} \mathrm{Sr}^{\beta-} \rightarrow{ }^{90} \mathrm{Y}$ \\
& ${ }^{188} \mathrm{Re}$ & ${ }^{187} \mathrm{~W}(\mathrm{n}, \gamma)^{188} \mathrm{~W}^{\beta-} \rightarrow{ }^{188} \mathrm{Re}$ \\
& ${ }^{212} \mathrm{Bi}$ & ${ }^{228} \mathrm{Th} \rightarrow \ldots$. \\
& ${ }^{2124} \mathrm{~Pa} \rightarrow$ \\
& ${ }^{229} \mathrm{Th} \rightarrow \ldots{ }^{212} \mathrm{Bi}$ \\
& ${ }^{213} \mathrm{Bi}$ & $\mathrm{Ac}^{\alpha} \rightarrow{ }^{221} \mathrm{Fr}^{\alpha} \rightarrow$ \\
& ${ }^{217} \mathrm{At}^{\alpha} \rightarrow{ }^{213} \mathrm{Bi}$
\end{tabular}

Fonte: (SAHA, 1998)

THRALL e ZIESSMAN (2003) apontaram cinco fatores como importantes no controle de qualidade dos radionuclídeos produzidos em geradores: 
1) pureza radionuclídica: é a condição de não haver outro radionuclídeo no eluato do gerador além do radionuclídeo desejado (em geral, o radionuclídeo contaminante mais comum é o radionuclídeo-pai);

2) pureza química: é a condição de não haver no eluato a presença de impurezas químicas, como a alumina da coluna $\left(\mathrm{Al}_{2} \mathrm{O}_{3}\right)$;

3) pureza radioquímica: é a quantidade percentual do radionuclídeo-filho no eluato na valência especificada;

4) pureza física: representa a fração do radiofármaco total na forma física desejada;

5) pureza biológica: é a necessidade de ausência de microorganismos ou pirogênios.

\subsubsection{RADIONUCLÍDEOS UTILIZADOS EM DIAGNÓSTICOS E TERAPIAS}

São vários os radionuclídeos utilizados em diagnósticos e terapias, tendo-se iniciado a medicina nuclear com a aplicação do ${ }^{131} \mathrm{I}$, exclusivamente para estudos da glândula tireóide, e, posteriormente, tendo-se ampliado seu uso como marcador de vários radiofármacos.

Outro marcador bastante utilizado é o ${ }^{111} \mathrm{In}$, que permite a obtenção de imagens seqüenciais de alguns dias, importantes na avaliação de enfermidades inflamatórias (leucócitos marcados com ${ }^{111} \mathrm{In}$ ) e em imagens com anticorpos.

O ${ }^{67} \mathrm{Ga}$, inicialmente utilizado como marcador ósseo, é agora amplamente utilizado como agente marcador de tumores e de focos de infecção, enquanto que o ${ }^{201} \mathrm{Ta}$ é um agente para cintilografia miocárdica, constituindo-se em um excelente marcador do fluxo regional para miocárdio.

O radioisótopo mais utilizado em diagnóstico em Medicina Nuclear é o ${ }^{99 \mathrm{~m}} \mathrm{Tc}$ devido as suas características de decaimento favoráveis, ao fato de ser produzido na forma de um gerador e por marcar facilmente diversas moléculas, na forma de 
conjuntos de reativos liofilizados (kits), sendo que cada kit marcado é usado para um diferente órgão ou sistema no corpo humano.

$\mathrm{Na}$ TAB. 6 são mostrados os radionuclídeos mais importantes para a medicina nuclear:

TABELA 6. Principais radionuclídeos usados em medicina nuclear

\begin{tabular}{lcccc}
\hline Radionuclídeo & Tempo de meia-vida & Modo de decaimento & $\begin{array}{c}\text { Energia raios } \gamma \\
(\mathrm{keV})\end{array}$ & $\begin{array}{c}\text { Abundância da } \\
\text { emissão } \gamma(\%)\end{array}$ \\
\hline${ }^{99 \mathrm{~m} T \mathrm{Tc}}$ & $6 \mathrm{~h}$ & $\mathrm{TI}$ & 140 & 89 \\
${ }^{131} \mathrm{I}$ & $193 \mathrm{~h}$ & $\beta ; \mathrm{g}$ & 364 & 81 \\
${ }^{123} \mathrm{I}$ & $13 \mathrm{~h}$ & $\mathrm{CE}$ & 159 & 83 \\
${ }^{67} \mathrm{Ga}$ & $78 \mathrm{~h}$ & $\mathrm{CE}$ & $93,185,300,394$ & $37,20,17,5$ \\
${ }^{111} \mathrm{In}$ & $67 \mathrm{~h}$ & $\mathrm{CE}$ & 171,245 & 90,94 \\
${ }^{201} \mathrm{Tl}$ & $73 \mathrm{~h}$ & $\mathrm{CE}$ & 135,167 & 3,20 \\
${ }^{11} \mathrm{C}$ & $20,4 \mathrm{~min}$ & $\beta^{+}$ & 511 & 99,8 \\
${ }^{13} \mathrm{~N}$ & $10 \mathrm{~min}$ & $\beta^{+}$ & 511 & 100 \\
${ }^{15} \mathrm{O}$ & $2,07 \mathrm{~min}$ & $\beta^{+}$ & 511 & 99,9 \\
${ }^{18} \mathrm{~F}$ & $110 \mathrm{~min}$ & $\beta^{+}$ & 511 & 96,9 \\
${ }^{124} \mathrm{I}$ & $4,2 \mathrm{dias}$ & $\beta^{+}$ & 511 & 25 \\
${ }^{64} \mathrm{Cu}$ & $13 \mathrm{~h}$ & $\beta^{+}$ & 511 & 38 \\
\hline
\end{tabular}

Fonte: (KNAPP e MIZRADEH, 2001)

\subsubsection{PRODUÇÃO DE RADIOFÁRMACOS NO IPEN-CNEN/SP}

A Diretoria de Radiofarmácia do Ipen-Cnen/SP tem como missão a produção e distribuição de radioisótopos e radiofármacos para uso em Medicina Nuclear.

Ela produz mais de $95 \%$ da demanda brasileira deste tipo de produto, atendendo cerca de 260 clínicas espalhadas pelo território nacional. O seu catálogo de produtos atende a toda necessidade da classe médica nuclear brasileira, com produtos para uso em diagnóstico (pelas técnicas PET e SPECT) e terapia.

Além da produção rotineira, a DIRF atua também na área de pesquisa de novos radiofármacos e na formação de recursos humanos através do programa de pós graduação do IPEN. 


\subsection{AMBIENTES COLABORATIVOS VIRTUAIS - ASPECTOS TECNOLÓGICOS}

O tema CVE está no centro dos estudos relativos a LV por tratar-se de uma área que orienta o uso efetivo de computadores, seus aplicativos e o compartilhamento de dados e informações entre as pessoas. CHURCHILL et. al. (2001) definiram CVE como:

Um CVE é um espaço virtual ou conjunto de lugares distribuídos, baseados em computadores. Em tais lugares, pessoas podem encontrar-se e interagir com outras, com agentes ou objetos virtuais. CVEs podem variar em sua riqueza representacional, de espaços gráficos $3 \mathrm{D}, 2.5 \mathrm{D}$ e $2 \mathrm{D}$, a ambientes baseados em texto. O acesso a CVEs não é limitado a dispositivos desktop, mas pode incluir dispositivos móveis, quiosques públicos, etc.

Um CVE é uma ágora virtual disponibilizada em rede por meio da web, constituindo-se em um lugar para interação entre pessoas, criando uma comunidade de aprendizagem on-line voltada para 0 atendimento de necessidades de capacitação e troca de experiências entre membros de comunidades. Uma dessas comunidades, com escopo internacional, congrega de estudantes, docentes, pesquisadores e profissionais de radiofarmácia. Trabalhos de LAISTER e KOUBEK (2001) propuseram outra definição para CVE, relacionando-o com Computer Supported Collaborative Work (CSCW):

CVEs envolvem o uso de sistemas de RV em rede para suportar trabalho em grupo. O conceito-chave por trás de CVE é o de mundos virtuais compartilhados: espaços gerados por computador cujos ocupantes apresentam-se uns aos outros por meio de formas gráficas e podem controlar seus próprios pontos-de-vista e interagir uns com os outros usando várias representações de dados e programas de computadores.

\subsubsection{PRESSUPOSTOS DE TIC PARA CRIAR UM CVE}

De acordo com trabalhos de EARNSHAW et al. (1997), os aspectos referentes às TIC que devem ser observados para se criar um CVE eficaz para aprendizagem colaborativa são: 
a) uma representação $3 D$ do ambiente compartilhado: feita com o uso de softwares de RV, para representar objetos, superfícies, pessoas e situações dentro do CVE;

b) um banco de dados: que necessita ser mantido com dados de diferentes origens, para refletir com precisão suas sucessivas mudanças;

c) uma rede de comunicação de dados: confiável, rápida, consistente, que evite discrepâncias entre os participantes dos processos de aprendizagem colaborativa;

d) um alto grau de realismo: obtido por meio de representação fidedigna de tudo o que está contido no CVE, suas características e propriedades;

e) múltiplos pontos de vista: o CVE precisa garantir pelo menos um ponto de vista para cada usuário envolvido no processo;

f) uma representação de cada participante: de preferência no modo 3D, permitindo a todos os usuários envolvidos no processo perceberem as ações dos outros;

g) ferramentas de comunicação: recursos como voz, vídeo real-time e chat real-time, que permitam aos participantes interagirem em modo aberto e instantâneo;

h) primitivas de interação: são os recursos de movimentação e manipulação de objetos colocados à disposição dos usuários, tais como: mover o corpo, mover as mãos, pegar objetos, disparar procedimentos e ações, usar dispositivos;

i) alta velocidade de renderização: definida em, pelo menos, 15 frames por segundo, de modo a assegurar movimentos dentro do CVE similares aos que ocorrem na realidade. 
Os seres humanos relacionam-se com qualquer CVE utilizando-se de três sentidos (visão e audição, em maior grau, tato, em menor grau). Por meio da visão, os usuários têm a noção de sua presença - e a de outros usuários - dentro do CVE, então o CVE tem que prover imagens estereoscópicas, diferentes texturas de materiais, entre outras características.

Para o estímulo da percepção acústica, o CVE tem que prover som isotrópico, bem como simular a propagação de som e as alterações na acústica do ambiente provocadas por barreiras, levando em conta as propriedades de absorção e de reflexão do som que os objetos têm. O sentido tátil dos usuários pode ser estimulado pela simulação de colisões entre objetos dentro do CVE.

\subsubsection{COMUNICAÇÃO MEDIADA POR COMPUTADOR}

CMC facilita a comunicação entre indivíduos, é um dos pressupostos para a implantação de LV e de CVE, e sustenta-se sobre tecnologias de computadores, redes de computadores e soluções de software, como a internet.

Embora CMC seja freqüentemente associada com aprendizagem à distância, essa não é sua única aplicação: os recursos de CMC podem ser usados com grande eficácia mesmo no ensino presencial, de modo síncrono ou assíncrono, conectando desde apenas uma pessoa a outra até $n$ pessoas para $n$ pessoas.

De acordo com TAYLOR (1980), a invenção do computador de grande porte e sua disponibilização a partir de meados dos anos 50, mesmo ainda em caráter restrito dentro de empresas, permitiu aos interessados estudar utilizando essa nova ferramenta, inicialmente como se fosse um livro eletrônico, no qual se realizava as lições passo-a-passo, sob um modo conhecido como instrução programada.

Novas possibilidades educacionais surgiram na medida em que computador pessoal (PC) e as TIC tornaram-se commodities, apresentando condições para mudar o paradigma instrucionista até então vigente para o paradigma da construção do conhecimento, no qual o aluno teria condições de desempenhar um papel mais ativo, autônomo e responsável pela construção de seu próprio conhecimento. 
$\mathrm{Na}$ visão desses pesquisadores, os computadores poderiam ser usados de três modos no ensino, denominados "3Т": a) como professores (tutor): seriam programados por especialistas e os estudantes executariam os programas, que os ensinariam; b) como ferramenta (tool): quando realizariam tarefas auxiliares no processo de aprendizagem, como cálculos, editoração de textos, planilhamento de dados, análises estatísticas; c) como aluno (tutee): os estudantes teriam a missão de "ensinar o computador", colocando-se no papel de professores, aproveitando-se dos enormes benefícios potenciais de se aprender enquanto se ensina. (TAYLOR, 1980)

Observando-se o que aconteceu em larga escala nos anos 80/90, pode-se acrescentar atualmente um quarto "T": aprender usando o computador como brinquedo (toy), jogando-se games e afins, executando-se navegações sobre simulações de RV. Na TAB. 7 são mostrados os modos de uso do computador no ensino de aprendizagem:

TABELA 7. Modos de uso do computador no ensino e aprendizagem

\begin{tabular}{|c|c|}
\hline $\begin{array}{l}\text { Modos de uso do } \\
\text { computador no ensino }\end{array}$ & Características \\
\hline TUTOR & $\begin{array}{c}\text { Computadores são programados por especialistas e os } \\
\text { estudantes executam esses programas, e aprendem } \\
\text { com eles. }\end{array}$ \\
\hline TOOL & $\begin{array}{l}\text { Computadores realizam tarefas auxiliares no processo de } \\
\text { aprendizagem: executam cálculos, editoração de textos, } \\
\text { planilhamento de dados, análises estatísticas; }\end{array}$ \\
\hline TUTEE & $\begin{array}{l}\text { Caso em que os estudantes têm a missão de "ensinar o } \\
\text { computador", desempenhando o papel de professores, } \\
\text { aproveitando-se dos benefícios potenciais de se aprender } \\
\text { enquanto se ensina. }\end{array}$ \\
\hline TOY & $\begin{array}{c}\text { O estudante aprende usando o computador como } \\
\text { brinquedo (toy), jogando-se games e afins, executando-se } \\
\text { navegações sobre simulações de RV. }\end{array}$ \\
\hline
\end{tabular}

Fonte: (TAYLOR, 1980), adaptado pelo autor.

ROMISZOWSKI (1997) definiu CMC como "a comunicação entre diferentes partes separadas no tempo e no espaço, mediada por computadores interconectados", e observou que o computador, além de sua capacidade de processamento local, também representou um grande avanço como meio de comunicação, que é um processo essencial em todos os modelos educacionais. 
CMC facilita a comunicação entre indivíduos e grupos e é dependente das TIC, que possibilitaram o surgimento e a expansão de redes de computadores.

ROMISZOWSKI (1997) apontou que CMC envolve conhecimentos de vários assuntos (ambientes multimídia, aprendizagem colaborativa, RV, ferramentas de desenvolvimento) e representa um novo paradigma de comunicação.

\subsubsection{TIPOS DE CMC}

CMC pode ocorrer de modo síncrono (ligações que estão abertas simultaneamente para ambos os lados) ou assíncrono (ligações só abertas para um lado em determinado momento). Inicialmente, devido ao pouco desenvolvimento tecnológico das TIC, a maior parte das CMC dava-se de modo assíncrono. Gradativamente, com o desenvolvimento tecnológico e a redução de custos dos recursos de TIC, essa situação inverteu-se. Dentre os processos CMC, destacam-se:

a) E-mail: é o processo mais comumente utilizado, consiste em enviar/receber uma mensagem eletrônica de/para qualquer computador no mundo que esteja conectado à Internet; cada caixa postal de cada usuário reside no espaço de dados de um provedor de serviços de Internet, uma empresa com infraestrutura de TIC e serviços direcionados para esse fim;

b) Bulletin-boards (BBS): permite ao usuário postar mensagens em um quadro de avisos, que é acessado por $n$ usuários; BBS suporta grandes grupos de usuários com interesses comuns e têm seis funções: e-mail, sala de conferências, sala de chat, questionários ou enquetes, acesso a arquivos, acesso a bancos de dados; e podem ser usados tanto por indivíduos quanto por grandes corporações;

c) Computer conferencing: permite disponibilizar salas virtuais para contato entre dois ou mais lugares, para compartilhamento de conhecimentos e para atividades gerais de ensino e aprendizagem. 


\subsubsection{CMC COMO UMA FERRAMENTA DE PENSAR (MINDTOOL)}

O uso educacional de recursos de CMC apresenta características que reforçam os princípios cognitivistas e construtivistas de ensino e aprendizagem, porque, enquanto usam recursos de CMC, os participantes tendem a refletir mais e a observar mais seus pensamentos e ações do que quando estão envolvidos em alguma atividade cara-a-cara com seus interlocutores, pessoalmente ou por telefone.

De acordo com trabalhos de HARASIM (1990) apud JONASSEM (1995), a necessidade de verbalizar todos os aspectos da interação dentro de um ambiente baseado em textos pode ampliar as habilidades metacognitivas de reflexão e de revisão durante a aprendizagem.

CMC facilita o processo construtivista porque suporta a reflexão sobre o que cada pessoa sabe, sua comunicação com outras pessoas e o confronto de idéias, o que pode conduzir a mudanças conceituais em qualquer das pessoas envolvidas.

Por intermédio de CMC, grupos de pessoas expõem diferentes perspectivas e interpretações, promovem debates, questionamentos, seus comprometimentos com significados de idéias e, ao fazerem isso, estão profundamente engajados em processos de construção de conhecimento.

JONASSEM (1995) avaliou CMC como uma ferramenta de pensar, que compreende os seguintes aspectos:

a) CMC é baseado em computador: por meio das TIC e da Internet, incorpora milhões de usuários interconectados;

b) os serviços CMC estão permanentemente disponíveis: e-mail, salas de conferências, quadros de avisos, bancos de dados, publicações;

c) é acessível: a maior parte dos softwares necessários para navegar na Internet é de acesso livre e grátis, obtidos em sites da própria Internet; o hardware necessário também sofreu grandes reduções de preço; 
d) é uma representação do conhecimento: embora CMC não seja uma forma direta de representação do conhecimento, é um meio para transmissão dessas representações, permitindo o intercâmbio delas entre os interessados;

e) é aplicável a diferentes domínios: praticamente todos os assuntos estão disponibilizados na internet;

f) induz ao raciocínio crítico: por meio das atividades básicas de CMC, que são recuperação de informações, e-mail e computer conferencing;

g) facilita a aprendizagem: porque permite a aquisição e negociação de significados e conhecimentos;

h) apresenta um formalismo simples e poderoso: os recursos de CMC são simples de usar, altamente disponível e com grande alcance;

i) fáceis de aprender. os assuntos estão disponíveis diretamente para o aprendiz e são altamente atraentes: aprende-se enquanto se usa; usa-se enquanto se aprende.

\subsubsection{CMC E CSCL}

CMC e Computer Supported Collaborative Learning (CSCL) são assuntos interligados: enquanto $\mathrm{CMC}$ cria as condições tecnológicas e de infra-estrutura para o uso colaborativo de computadores e redes, CSCL agrega uma visão de como trabalhar os conteúdos para otimizar as práticas colaborativas viabilizadas por CMC. Conforme trabalhos de KOSCHMANN (2002) apud STAHL (2003):

CSCL é um campo de estudo centralmente ocupado com significados e práticas de formação de significados no contexto de atividades coletivas, e os modos como essas práticas são mediadas por intermédio de artefatos desenvolvidos.

A formação de significados, um assunto-chave em CMC e CSCL, é uma atividade essencialmente social, conduzida coletiva e colaborativamente dentro de uma comunidade. E a transmissão dos significados é feita por intermédio de 
artefatos (tecnológicos, sociais, culturais) e das práticas desenvolvidas em determinado contexto, e que são formadoras esse contexto.

STAHL (2003) propôs que, "particularmente em contextos de colaboração, significados existem em um mundo intersubjetivo e são interpretados a partir de perspectivas pessoais." Ele destacou que Hegel descreveu a emergência da consciência do indivíduo por intermédio do processo de mútuo reconhecimento de si mesmo e do outro, e que é o trabalhador que produz determinado artefato quem tem melhores condições de perceber que seu trabalho foi externalizado e tornado persistente por meio do artefato que ele produziu.

STAHL (2003) definiu que a autoconsciência desse indivíduo trabalhador emerge por intermédio de sua atividade no mundo físico e social, onde ele vê a si mesmo por meio de seus produtos e através dos olhos dos outros.

O trabalho dá forma ao seu objeto. As relações de transformação aplicadas ao objeto são transformadas nas formas do objeto e tornam-se algo persistente porque, para o trabalhador, o objeto ganha auto-suficiência. Essa mediação transformadora - a atividade de dar forma - é também a individualidade da consciência ou a consciência pura para si mesma, a qual, no processo de trabalho, aflora e assume um caráter persistente. A consciência do trabalhador, portanto, migra da percepção da auto-suficiência do artefato para a percepção de seu próprio eu. (STAHL, 2003)

Marx propôs que os significados são socialmente produzidos e interpretados e que, embora a interpretação de um significado esteja ligada à subjetividade individual, o significado em si é observado e compartilhado coletivamente.

VIGOTSKI (1999) apontou que a mente dos indivíduos, que era considerada anteriormente como situada dentro de suas cabeças, depende de suas atividades dentro de seu mundo físico e social. Para ele, por exemplo, o gesto de apontar ilustra uma primeira experiência típica de formação de significado para a criança, e é criado num mundo intersubjetivo e internalizado no repertório próprio de elaboração de sentido da criança.

Nós chamamos de internalização a reconstrução interna de uma operação externa. Um bom exemplo desse processo pode ser encontrado no desenvolvimento do apontar. Inicialmente, esse gesto de apontar nada mais é que uma tentativa mal sucedida da criança de pegar algo, um movimento na direção de um objeto que significa o interesse em fazer algo com ele. ... Quando 
a mãe percebe que o movimento da criança indica algo, a situação muda fundamentalmente. $O$ apontar transforma-se em um gesto para os outros. A tentativa mal-sucedida da criança provoca uma reação não no objeto que ela tenta pegar mas em outra pessoa. Conseqüentemente, o significado primário de um movimento de pegar mal-sucedido é estabelecido por outros. O movimento de pegar muda para um ato de apontar. Como resultado dessa mudança, o movimento em si é então fisicamente simplificado, e o que resulta é a forma de apontar, que nós podemos chamar um verdadeiro gesto. (VYGOTSKY, 1998, apud STAHL, 2003)

A observação de Vygotsky é essencial para a compreensão da geração de significados e, por extensão, da geração daquilo que os seres humanos consideram como realidade:

O que se vê aqui é que o apontar é a gênese do significado. O gesto é um artefato: ele incorpora significados no mundo real. O significado é uma referência ao que se aponta. $O$ bebê objetiva algum objeto; a mãe reconhece que o bebê objetiva aquele objeto; o bebê reconhece que a mãe reconhece isso. $O$ reconhecimento mútuo múltiplo conduz a que a mãe e o bebê reconheçam um ao outro como pessoas que têm intenções e que podem reconhecer as intenções dos outros. (VYGOTSKY, 1998, apud STAHL, 2003)

STAHL (2003) propôs que o apontar desencadeia um processo social fundamental de orientação para um determinado objeto, coordenando a orientação imediata de vários indivíduos para uma mesma direção, fornecendo a base, ainda sem o uso de palavras, para a colaboração. E que a linguagem surge em uma etapa posterior, a partir do gesto, e é em seguida internalizada, e não se limita a nomes de objetos, mas a outras ferramentas lingüísticas mais sofisticadas que executam outras funções sintáticas e semânticas.

$\mathrm{Na}$ evolução das formas e usos de gestos, esses são transformados em discurso e esses discursos são transformados em pensamentos. Significados e referências a objetos e fenômenos do mundo material são internalizados em formas mentais que ainda preservam embutidas algumas funções originais dos artefatos físicos ou dos gestos corporais.

VIGOTSKI (1999) propôs que as atividades humanas são mediadas sempre por artefatos, que são nomeados e podem ser usados para mediar atividades futuras, e que os significados emergem essencialmente no mundo externo, observável e intersubjetivo de outras pessoas e de objetos físicos. Um gesto, um som, um caractere, um texto, uma imagem, um objeto físico, pode tornar-se um 
artefato pleno de significados para um grupo, podendo ser utilizado em uma atividade colaborativa. Inclusive, a natureza do artefato transcende o dualismo mente-corpo pensado por Descartes, integrando o físico e o conceitual e conduzindo o significado para sua origem na interação social.

Após o processo do apontar e do compartilhamento de significados na criança, gradativamente ela é introduzida no mundo da linguagem e a linguagem falada a conduz à "falar para si mesma", primeiramente de modo audível e, depois, de modo silencioso e internalizado. Ele também defendeu que a habilidade da criança em falar para si mesma é uma poderosa ferramenta para controlar suas ações e para internalização das influências dos outros.

STAHL (2003) concluiu que a mente não era, portanto, uma capacidade cognitiva pré-existente, como pensava Descartes, nem um esquema universal para estruturação da realidade, como queria Kant, nem um grupo de recursos biologicamente desenvolvidos, como argumentava Piaget, mas sim o resultado da internalização e transformação de artefatos que surgem nas interações sociais.

\subsection{REALIDADE VIRTUAL}

As TIC voltadas para ambientes de RV permitem ao usuário interagir com ambientes simulados por computadores, representem eles ambientes reais ou imaginários. Aplicativos que usam RV têm o potencial de agregar processos de exploração, descoberta, observação e construção de uma nova visão sobre objetos, conceitos e situações de ensino, gerando, dessa forma, um descortíneo inédito do conhecimento para o aprendiz.

KIRNER e TORI (2004) concluíram que o que se convencionou chamar, até aqui, de realidade virtual, é uma interface avançada que permite aos usuários acessarem aplicações em um computador. E que essas interfaces podem ser classificadas como sendo de três gerações:

a) interfaces textuais: nas quais o usuário interage com o aplicativo por meio de comandos escritos no teclado (como no sistema operacional DOS); 
b) interfaces gráficas: com menus e janelas, nas quais o usuário, utilizando-se de teclado, mouse ou recursos semelhantes, pode escolher opções, ativar menus (como no sistema operacional Windows);

c) interfaces gráficas tridimensionais: que são as que permitem ao usuário adentrar em ambientes tridimensionais e executar ações.

KIRNER e TORI (2004) definiram que "RV é uma interface avançada para aplicações computacionais, onde o usuário pode navegar e interagir, em tempo real, em um ambiente tridimensional gerado por computador, usando dispositivos multisensoriais." Essa definição vale-se de alguns conceitos e metáforas, que são:

a) interface: é qualquer meio interposto entre o usuário de um aplicativo ou equipamento e o aplicativo ou equipamento em si, para que o usuário possa visualizar o aplicativo funcionando e comunicar-se com ele;

b) navegar em um aplicativo: é passar de uma tela (ou ambiente) à outra, manter telas abertas, por exemplo, na barra de tarefas do Windows, e, ao longo dessa alternância de telas, interagir com o sistema operacional e com os aplicativos e com os dados rodando nele. A navegação mais avançada que se pode realizar dentro de aplicativo 3D é a do tipo "6 graus de liberdade", executando-se nela seis tipos de movimentos: para frente/para trás, acima/abaixo, esquerda/direita, inclinação para cima/para baixo, angulação à esquerda/à direita, rotação à esquerda/à direita;

c) em tempo real (realtime): significa que a interação do usuário com o aplicativo ou sistema é síncrona, ou seja, as entradas, processamentos e saídas são feitas em seqüência, sem atraso na resposta;

d) ambiente tridimensional gerado por computador: são visualizações gráficas geradas pelos aplicativos, na tela ou em um ambiente 3D, que dão ao usuário a sensação de "estar dentro" dos programas e ambientes gerados por ele; 
e) dispositivos multisensoriais: são periféricos que o usuário usa para interagir com o aplicativo e que se adaptam aos sentidos humanos, tais como: luvas, óculos estereoscópicos, capacetes, entre outros.

ISDALE (1998) definiu RV, referindo-se ao seu aspecto de sistemas mediados por computador, do seguinte modo: "RV é um modo para humanos visualizarem, manipularem e interagirem com computadores e com dados extremamente complexos". A expressão "realidade virtual" contem dois conceitos opostos (é um oximoro), uma vez que "realidade" diz respeito a fatos e fenômenos existentes no mundo físico real e "virtual" diz respeito a fatos e fenômenos que não existem nessa instância. Apesar disso, tornou-se a expressão pela qual são conhecidas as pesquisas, as teorias, os produtos e os conceitos a respeito desse assunto. Segundo trabalhos de ISDALE (1998), sistemas de RV compreendem:

a) o ambiente virtual: que pode assumir várias formas, para representar entidades ou objetos reais ou abstratos e seus atributos, também reais ou abstratos: formas geométricas, cores, texturas, efeitos de iluminação. $O$ ambiente virtual é a base para a realização de simulações de várias ordens: físicas, químicas, geométricas, humanas, e precisa ser capaz de representar com o máximo de fidedignidade as propriedades de entidades ou objetos do mundo real ou abstrato;

b) o ambiente computacional: que é a infra-estrutura de hardware e software de TIC usada para suportar o processamento dos sistemas de RV, variando de instalações simples e econômicas até extremamente complexas e caras. Sua capacidade de processamento deve ser tal que permita uma degradação máxima de $100 \mathrm{~ms}$ no tempo de resposta de transações e assegure a exposição de um mínimo de 10 quadros por segundo na seqüência de telas que apresentar. Para qualquer aplicativo RV é essencial ter-se disponível um ambiente computacional realtime que realize tarefas típicas como: gerenciamento do banco de dados, controle dos canais de E/S, tratamento da detecção de colisões, gerenciamento dos recursos da rede e dos servidores. 
$\mathrm{O}$ (s) computador(es) usado(s) deve(m) ter a maior quantidade possível de processadores e o sistema operacional e os aplicativos devem ter condições de trabalhar no modo multitarefa, executando várias tarefas simultaneamente;

c) a tecnologia $R V$ : que abrange recursos tecnológicos auxiliares para que o usuário participe do ambiente virtual, tais como rastreadores, capacetes, navegadores 3D, luvas, óculos estereoscópicos, monitores, telas panorâmicas, mesas virtuais, CAVE Automatic Virtual Environment (CAVE), mouse 3D, fones de ouvido, dispositivos de reação e geradores de imagens, entre outros;

d) formas de interação do usuário com o ambiente virtual: que podem ser imersivas ou desktop. Interações imersivas dão ao usuário a sensação de "estar dentro" do ambiente gerado pelo aplicativo, por meio da utilização de ambientes tipo CAVE (ambiente que consiste de uma sala, na qual se situa o usuário, e em que cada parede é usada como uma tela de projeção), ou de Head Mounted Display (HMD), ou de dispositivos hápticos (que incorporam sensores e atuadores, permitindo ao usuário a sensação táctil e/ou de força), entre outros. Interações desktop apresentam-se ao usuário normalmente por intermédio de telas, Liquid Cristal Display (LCD) ou não.

Os aplicativos de RV pertencem a três tipos, em função das relações entre os recursos virtuais e os recursos reais presentes neles:

a) realidade misturada: é a que ocorre quando o aplicativo realiza uma combinação ou sobreposição de objetos virtuais tridimensionais gerados por computador com objetos reais do ambiente físico e exibe esse resultado ao usuário em tempo real. Esses aplicativos dão ao usuário a sensação de ir alem do real, tanto em escala macroscópica quanto em escala microscópica;

b) realidade aumentada: é a que suplementa o mundo real incluindo nele objetos virtuais gerados por computador, combinando entidades ou objetos reais e virtuais; a diferença para a realidade misturada é que aqui o ponto de partida é sempre real. $O$ aplicativo permite a manipulação de objetos 
virtuais por meio de dispositivos reais de entrada de dados, e essa tecnologia deverá ter grande impacto nas formas de relacionamento entre as pessoas, prevendo-se grandes mudanças conceituais e procedurais em áreas como ensino, aprendizagem e ambientes de trabalho coletivos;

c) virtualidade aumentada: é a que suplementa o mundo virtual incluindo nele outros objetos, reais ou mesmo virtuais gerados por computador.

Os aplicativos de virtualidade aumentada permitem, por exemplo, a criação de avatares humanóides realistas dentro de ambientes tridimensionais de ensino e aprendizagem, permitindo que os usuários interajam dentro do ambiente virtual por intermédio deles, criando, desse modo, perspectivas de grandes avanços para a aprendizagem colaborativa, troca de idéias, em atividades como fazer compras, estudar e interagir com grupos de muitas e novas maneiras. Avatar é um humano virtual, uma representação gráfica do usuário dentro do ambiente de RV, que o usuário "incorpora" e por meio do qual ele age dentro dele.

De acordo com trabalhos de HOFFMAN (2004), dentre as utilizações de aplicativos RV, algumas atualmente são da área médica e destinam-se, por exemplo, para o tratamento de fobias ou amenização de dor de pacientes queimados. Enquanto o paciente está engajado na utilização de simuladores de RV, como o Snowworld (um simulador de ambientes e paisagens geladas), sua atenção não se concentra mais na dor, mas sim no mundo virtual.

\subsubsection{ASPECTOS TECNOLÓGICOS DA RV}

Os recursos tecnológicos de RV ajudam a gerar ambientes virtuais distribuídos (AVD). RODRIGUES et al. (2004) definiram AVD como:

AVDs são caracterizados como um ambiente virtual interativo em que os usuários dispersos geograficamente têm como objetivos a cooperação e o compartilhamento dos recursos computacionais em tempo real usando um suporte de redes de computadores para melhorar o desempenho coletivo por meio da troca de informações. 
Quando vários usuários podem interagir dentro de um AVD, caracteriza-se um ambiente virtual colaborativo (AVC), baseado nos princípios de CSCW, e as propriedades desses ambientes são referentes a: espaço, presença e tempos compartilhados; comunicação entre os participantes; interação dos participantes com o ambiente.

Um AVC torna-se um CVE quando são utilizados paradigmas de aprendizagem colaborativa cujos efeitos são potencializados quando se utiliza avatares humanóides para representar os participantes.

No caso de haver a utilização de avatares, nem todos precisam ser controlados por participantes: pode haver os que são controlados por modelos de simulações dirigidos por eventos e disparados dentro dos aplicativos.

De acordo com trabalhos de SEMENTILLE (1999), apud RODRIGUES et al. (2004), um AVD é composto por quatro componentes básicos:

a) displays gráficos: periféricos que permitem ao usuário visualizar (selecionar uma perspectiva de visualização ao navegar pelo aplicativo) o ambiente virtual de modo tridimensional, o que inclui: monitores, HMD e CAVEs.

b) dispositivos de comunicação e controle: periféricos que permitem ao usuário manipular objetos dentro do ambiente virtual, bem como comunicar-se com outros participantes; incluem: teclado e mouse, comunicação textual, dispositivos hápticos como luvas (datagloves) e microfones.

c) sistema de processamento: processadores para computar o efeito das entradas dos participantes e suas conseqüências para o ambiente virtual.

d) a rede de comunicação: os recursos de processamento associados a um servidor de rede e os serviços que ele provê, para manter para todos os participantes do ambiente virtual a sincronização no compartilhamento do AVD. 
Segundo trabalhos de SEMENTILLE (1999), apud RODRIGUES et al. (2004), os participantes de um AVD podem comunicar-se de acordo com os seguintes modelos de comunicação:

a) cliente-servidor: é o modelo mais comum e ocorre quando o computadorcliente comunica-se diretamente com o computador-servidor e vice-versa, não havendo troca de dados entre os computadores-clientes;

b) peer-to-peer: que liga dois computadores-cliente diretamente, independentemente do servidor; apresenta a vantagem de independer do servidor, porém tem a desvantagem de trazer o processamento da comunicação para cada computador-cliente;

c) computação distribuída orientada a objetos: em que a comunicação do computador-cliente ocorre com um computador intermediário que realiza serviços de disponibilização de objetos (por exemplo, a arquitetura CORBA);

d) híbrido: ocorre quando se combina os modelos cliente-servidor e o peer-topeer, nesse caso o servidor realiza algumas tarefas de administração do ambiente de comunicação entre dois clientes, mas a sessão de comunicação entre eles se desenvolve sem depender todo o tempo do servidor.

A comunicação entre os computadores que suportam os participantes dentro de um AVD pode dar-se de acordo com três estruturas básicas:

a) unicast: "um-para-um", realizada diretamente entre dois clientes;

b) broadcast: "um-para-vários", em que um computador-cliente envia seus dados sempre para todos os outros, e esses os ignoram caso os dados não Ihes digam respeito;

c) multicast: "um-para-vários" ou "vários-para-vários", onde os dados trafegam de/para um grupo pré-determinado de computadores de participantes do AVD. 
Avatares são humanos virtuais representados dentro do CVE, são modelos de pessoas/usuários criados por software feitos para atuar como substitutos desses. Inicialmente foram criados para enfrentar testes ergométricos em veículos baseados em computador, em simulações prévias à construção de veículos e máquinas, bem como para utilização em tutoriais de ensino e aprendizagem.

Os avatares incluem a proposta de representarem um ser humano, não apenas por meio de seus sinais e atributos exteriores, mas também suas emoções, interação e tomada de decisão.

Para WILCOX (1998) apud KIRNER e TORI (2004), há diferentes conceituações envolvendo representações de humanos em CVEs, tais como: "avatar é toda a representação de personagem controlado por alguém do mundo real" ou "avatar é uma representação gráfica de uma pessoa real no ambiente virtual, junto com seu comportamento". Agente virtual é uma aplicação que tem comportamento autônomo, não necessariamente precisa ser representado por uma entidade gráfica.

Para THALMANN et al. (1999) apud KIRNER e TORI (2004), "agente virtual é um humano virtual que é criado e controlado por software e avatar é o humano virtual controlado por um participante vivo". KIRNER e TORI (2004) defenderam que humanos virtuais, agentes virtuais ou avatares, que são três modos como essas representações são denominadas, possuem cinco aspectos que as distinguem:

1) aparência: eles podem ser representados por ícones 2D, desenho animado, objetos 3D ou outro meio, porém sempre buscando obedecer aos princípios ditados pela antropometria;

2) movimento: que podem ser armazenados ou parametrizados e que têm como objetivo aproximar o comportamento do avatar ao comportamento observado no usuário humano;

3) interatividade: usada para controlar o avatar, que pode ser obtida por rastreamento de sensores, rastreamento de resultado final, invocadores externos (p.ex., menus), sintetizadores de voz, comando de fala, entre outros; 
4) comunicação: o avatar se comunica com o usuário por fala, movimentos labiais, dos olhos, das mãos ou outros movimentos corpóreos;

5) gestos descritos: utilizando os braços dos humanos virtuais, por meio de movimentos de buscar e segurar objetos e da comunicação por meio de gestos e sinais.

Um AVD transforma-se em um ambiente virtual imersivo (AVI) quando se constitui em "um cenário tridimensional dinâmico armazenado em computador e exibido através de técnicas de computação gráfica, em tempo real, de tal forma que faça o usuário acreditar que está imerso neste ambiente." (KIRNER e TORI, 2004)

O grau de interação do usuário dentro de um AVI será maior ou menor dependendo da classe do sistema de RV utilizado (realidade virtual imersiva, não imersiva, realidade aumentada, telepresença), bem como dos dispositivos presentes na interação. De acordo com os trabalhos de KIRNER e TORI (2004), as formas básicas de interação dentro de um AVI são três:

a) interação direta: quando o usuário utiliza seu corpo na interação, tocando os objetos do sistema. Metáforas de interação direta podem ser: 1) interação com a mão, diretamente sobre o objeto do aplicativo; 2) extensão do braço, quando o usuário estende seu braço (de seu avatar ou humano virtual) dentro do aplicativo; 3) ray-casting, apontamento de objetos por meio de um raio controlado pelo usuário; 4) image-plane, apontamento por raio, mas desta vez controlado pelo olho do usuário juntamente com sua mão ou outro dispositivo.

b) interação com controles físicos: quando o usuário se vale de botões, joysticks, pedais, entre outros.

c) controles virtuais: quando são usados controles de software criados dentro do aplicativo para permitir a interação com ele. 
Outro aspecto importante na utilização de um AVI é a navegação, ou seja, o processo de deslocamento do usuário dentro do ambiente virtual, que pode ser dividida, segundo seus objetivos, em três categorias:

a) navegação exploratória: são os movimentos sem destino específico.

b) navegação de busca: é a que ocorre quando se busca um objeto ou posição-alvo onde alguma tarefa será realizada.

c) navegação de manobra: aquela quando o objetivo do deslocamento é encontrar uma nova posição para o usuário realizar uma tarefa.

\subsubsection{USO EDUCACIONAL DE RV}

A tecnologia RV acrescenta possibilidades estimuladoras para que os estudantes visualizem conceitos abstratos, para que observem eventos que ocorrem em escala atômica ou cósmica, acontecimentos de dimensões extremamente reduzidas ou inimaginavelmente grandes, para que visitem ambientes que estão fora do alcance de nossa realidade física ou deslocados no tempo, passado ou futuro, ou nos quais condições de segurança impediriam a aproximação humana.

As atividades suportadas pela tecnologia RV permitem situações em que os estudantes terão melhores condições de entender, reter e generalizar novos conhecimentos, porque estarão ativamente envolvidos na construção de seu próprio universo de conhecimentos, dentro de uma situação/condição de "aprender-fazendo" (learning-by-doing). CHEE e HOOI (2002), afirmaram que:

O poder potencial de aprendizagem baseada em RV é especialmente forte com relação à mudança de uma educação baseada em uma perspectiva despersonalizada e na terceira pessoa, para uma perspectiva incorporada, usando a tecnologia para reificar conceitos a serem aprendidos, e provendo o apoio da tecnologia para auxiliar os estudantes em sua transição de uma aprendizagem baseada na experiência para aprendizagens baseadas em modos mentais mais reflexivos, abstratos e simbólicos.

Os estudantes interagem na maioria dos aplicativos de RV de modo exploratório, sozinhos no ambiente virtual, porém há muitos aplicativos nos quais é 
possível a colaboração com outros estudantes (como no 3D VR LAB do Projeto VirRAD), o que o caracteriza como um ambiente construtivista de ensino e aprendizagem.

Segundo JONASSEN (1995) apud YOUNGBLUT (1998), um ambiente construtivista apresenta as características mostradas na TAB. 8:

TABELA 8. Características de ambientes construtivistas de aprendizagem

- Provêem múltiplas representações da - Mantém seu foco na construção do realidade, evitando uma simplificação conhecimento, não em sua reprodução. excessiva da realidade e apresentando a complexidade natural do mundo real.

- Apresentam tarefas autênticas (contex- • Estimulam práticas reflexivas. tualizando a instrução, ao invés de abstraí-la).

- Permitem a construção de conhecimentos contextualizada e dependente de conteúdos.

- Suportam a construção colaborativa de conhecimentos por meio da negociação social e não da competição por reconhecimento entre os aprendizes.

Fonte: Jonassem (1995) apud Youngblut (1998), adaptado pelo autor.

YOUNGBLUT (1998) estudou aspectos sobre a eficácia potencial do uso educacional de RV, tais como:

a) todos os ambientes virtuais permitem ao aluno vivenciar uma experiência diante/dentro dele: porém a experiência em um ambiente virtual vai além do caminhar dentro dele; ela permite atuar sobre esse mundo virtual, se não o modificando de verdade (porque, afinal, trata-se de um mundo virtual), modificando-o virtualmente e, como conseqüência dessas ações, o aluno pode construir seu próprio conhecimento acrescentando novas estruturas de conhecimento às que possui, completando assim as fases “piagetianas” de adaptação, acomodação e equilibração.

b) o termo "classe de aula virtual", inerente a ambientes $R V$, implica em mais do que seus aspectos tecnológicos referentes às TIC: porque reforça os novos paradigmas de educação centrada no aluno e de educação para a vida toda. Nesses paradigmas, colaboradores de todas as idades participam 
remotamente de atividades educacionais, e podem formatar seus currículos adaptados às suas necessidades; classes não são limitadas à disponibilidade de tempo de seus professores, de espaço ou de localização geográfica; e o acesso a bibliotecas e laboratórios não são limitados a horários, entre outras características.

c) estudantes menos privilegiados em princípio, em termos de conhecimentos anteriores, são os mais beneficiados em aprendizagem com o uso de RV: $\mathrm{e}$ estudantes se dão igualmente bem com RV, independentemente de sua habilidade geral (os estudantes com maior habilidade espacial se destacam); bem como há algumas evidências de que os meninos apresentam melhores resultados com o uso de RV do que as meninas, em especial em jogos ou simuladores de montar objetos (cenários, video-games).

d) estudantes com problemas motores ou mentais podem ser beneficiados com o uso educacional de RV: como comprovam pesquisas realizadas envolvendo crianças autistas ou com outros problemas neurológicos.

e) o papel do professor em sala de aula parece alterar-se quando se usa RV como recurso de ensino e aprendizagem: nesse caso, eles tornam-se mais mediadores do processo de descoberta e aprendizagem de seus alunos do que meros transmissores de informações, como tende a ser o caso das aulas em que nenhuma tecnologia RV é empregada.

\subsection{AMBIENTES COLABORATIVOS VIRTUAIS - ASPECTOS COGNITIVOS}

Aborda-se neste tópico os conceitos que são pressupostos cognitivos para o estudo do tema LV/CVE: uma visão de desenvolvimento cognitivo e aprendizagem, aprendizagem colaborativa, formação de significados em colaboração, aprendizagem em rede e, em especial, teorias cognitivas. 


\subsubsection{DESENVOLVIMENTO COGNITIVO E APRENDIZAGEM}

O desenvolvimento cognitivo foi estudado por Piaget com foco voltado para a infância, período que ele aponta como compreendido entre o nascimento e os onze anos de idade, e também por Vygotsky, embora esse não se refira a uma cronologia de desenvolvimento numericamente tão precisa.

De acordo com WOOLFOLK (1996) apud CASAS (1999), o desenvolvimento cognitivo é dependente do desenvolvimento humano, ou seja, constrói-se sobre as bases biológicas dos seres humanos.

O conceito de desenvolvimento, porém, não se aplica a todas as mudanças pelas quais passa o ser humano ou ser cognitivo, mas somente àquelas que se dão de forma ordenada e por um lapso de tempo significativo. Compreende-se também que "as mudanças que podem ser qualificadas como desenvolvimento seriam as que resultam em uma conduta mais adaptativa, organizada, efetiva e complexa"

Para CASAS (1999), as mudanças biológicas são as que nos conduzem ao desenvolvimento e têm os seguintes aspectos observáveis: 1) Seqüência: é a ordem cronológica em que as mudanças ocorrem; 2) Ritmo: a velocidade com que as mudanças ocorrem; 3) Forma: é o aspecto resultante ou aparência externa causada pela mudança. Ele destacou que:

Desenvolvimento é um termo que pode referir-se tanto à mente e às emoções quanto ao corpo, é uma progressão ordenada em níveis cada vez mais altos, tanto de diferenciação quanto de integração dos componentes de um sistema.

O conceito de desenvolvimento humano compreende os seguintes aspectos gerais: 1) Físico: referente às mudanças que ocorrem no corpo; 2) Pessoal: relativo às mudanças na personalidade do indivíduo; 3) Social: os que dizem respeito às mudanças que se apresentam nas interações do indivíduo com os outros; 4) Cognitivo: referentes às mudanças das capacidades de aprendizagem e de pensamento do indivíduo.

De acordo com os trabalhos de WOOLFOLK (1996) apud CASAS (1999), o desenvolvimento cognitivo apresenta três características: 1) ocorre em ritmos distintos de uma pessoa para outra; 2) segue a mesma seqüência em todos os 
indivíduos, independentemente da pessoa; 3) ocorre sempre de modo gradual, ou seja, passa por transições lentas.

A linguagem, outro fator-chave para o desenvolvimento cognitivo, apresenta aspectos estruturais, que é o conhecimento dos elementos da frase (a gramática), bem como pressupõe conhecimentos sobre como combiná-los (a sintaxe); e aspectos funcionais, que se referem aos usos que a criança faz da linguagem para comunicar-se, pensar e resolver problemas.

Enquanto Piaget propôs que o pensamento precedia a linguagem, VIGOTSKI (1999) concebeu o contrário: para ele, a linguagem desempenha o aspecto cognitivo mais crítico no processo de aprendizagem. A linguagem precederia o pensamento e contribuiria para sua formação. Além de a linguagem originar o próprio pensamento, ela é também vista por Vygotsky como um elemento constitutivo do humano, ou seja, sua concepção é tal que a linguagem cria o humano.

De acordo com trabalhos de GOOD e BROPHY (1997) apud CASAS (1999), a aprendizagem é um conceito-chave para os estudos da cognição, podendo dar-se de seis maneiras:

a) Intencional: é a aprendizagem conscientemente direcionada para um objetivo. Por exemplo, quando o indivíduo quer aprender sobre instalações elétricas e procura fazê-lo objetivamente.

b) Incidental: a que ocorre geralmente de maneira passiva, quando não há uma intenção prévia e deliberada de aprender.

c) Memorística: é a aprendizagem que ocorre quando a pessoa não elabora ou relaciona o conteúdo aprendido com outros conteúdos prévios; apenas o retém, isolado, na memória.

d) Significativa: a que ocorre quando o indivíduo constrói coerentemente seu aprendizado através de raciocínio sobre o conteúdo aprendido, ao invés de somente memorizá-lo. 
e) Por recepção: quando o conhecimento apresentado é retido em sua forma final, tipicamente através de instruções a serem seguidas.

f) Por descoberta: a que ocorre quando os estudantes estão empenhados em uma pesquisa, por meio de explorações e experiências, que os conduzem à descoberta de conceitos ou princípios-chave.

Já o conceito de conhecimento pode ser entendido como o resultado que se obtém do processo de aprendizagem. É com ele que o pensamento trabalha, e são três os tipos de conhecimentos:

a) declarativos: que são os conhecimentos intelectuais, o conhecimento "do quê", dos fatos e conceitos, e que resultam do armazenamento de proposições verbais que refletem um conceito ou um fato;

b) procedurais: que são os conhecimentos "do como", ou seja, as instruções de como realizar tarefas e solucionar problemas;

c) condicionais: que são os conhecimentos referentes a "onde e porque", para que $o$ indivíduo tenha o discernimento que utiliza para aplicar os outros dois tipos de conhecimentos.

Pouco adianta para uma pessoa deter apenas conhecimentos declarativos, se ela não tiver conhecimentos procedurais sobre como aplicá-los, e também se não tiver conhecimentos condicionais que regulem essas aplicações.

Os dois primeiros tipos de conhecimentos podem ser estimulados através da utilização de recursos de simulações, CVE e LV, com a ajuda de tutores ou de modo autônomo, ficando o desenvolvimento do terceiro tipo de conhecimentos dependente exclusivamente da orientação de professores e de experiências reais ou virtuais, tratando-se de uma situação educacional em que simulações, CVE ou LV podem auxiliar menos. 


\subsubsection{APRENDIZAGEM COLABORATIVA}

DILLENBOURG (1999) propôs que "aprendizagem colaborativa é uma situação na qual duas ou mais pessoas aprendem ou tentam aprender alguma coisa juntos". Ele mesmo, no entanto, julga essa definição limitada, porque argumenta que:

a) a idéia de "dois ou mais" pode englobar desde um par até milhares de pessoas, o que seria uma grande mudança de escala e que traria outros efeitos agregados.

b) o conceito de "aprender algo" pode ser interpretado de diversas maneiras, tendo em vista diferentes teorias cognitivas e seus postulados.

c) a condição de "juntos" também poderia ter diferentes sentidos temporais e/ou espaciais.

Há vários significados para aprendizagem e, conseqüentemente, para aprendizagem colaborativa, e duas perspectivas podem ser lembradas: a primeira é que aprendizagem colaborativa pode ser vista como um método pedagógico, a outra perspectiva é a que a trata como um processo psicológico.

O sentido pedagógico é prescriptivo: tenta explicar os motivos para que exista a aprendizagem colaborativa, onde se argumenta que duas ou mais pessoas colaboram porque esperam que assim consigam melhores resultados. $O$ sentido psicológico é descritivo: tenta reportar como o processo de aprendizagem ocorre, no qual se observa que duas ou mais pessoas aprendendo em colaboração é visto como um mecanismo que causa aprendizagem.

Segundo DILLENBOURG (1999), os indivíduos não aprendem porque estudam juntos ou individualmente, mas porque executam certas atividades (como ler, construir, pesquisar) que disparam certos mecanismos de aprendizagem (como, por exemplo, indução, dedução, compilação). Portanto, o aspecto colaborativo dessa situação de estudarem juntos é apenas um tipo de contrato social entre os aprendizes ou entre os aprendizes e o professor, e esse não é a causa da aprendizagem. 
Aprendizagem colaborativa descreve uma situação na qual se espera que ocorram formas particulares de interações entre pessoas e que, uma vez ocorrendo, vão disparar mecanismos de aprendizagem, mas que não implicam em garantia de que as interações esperadas vão ocorrer.

Um benefício de realizar atividades de aprendizagem em grupo é que isso certamente gera situações cognitivas extras (como ter que explicar, discordar, acordar, entre outros) que disparam mecanismos cognitivos extra (elicitação de conhecimento, internalização, assimilação, entre outros), que representam um grande benefício potencial quando comparados aos obtidos quando a aprendizagem é feita com o indivíduo isolado. Outro benefício que surge em atividades de aprendizagem em grupo é a necessidade da explicitação, para o grupo, de conhecimentos tácitos das pessoas, conhecimentos não expressos por meio de palavras e que subsistem na mente das pessoas.

Segundo DILLENBOURG (1999), o substantivo colaboração engloba conceitos com quatro aspectos:

a) Uma situação pode ser caracterizada como mais ou menos colaborativa. Por exemplo, é mais provável ocorrer colaboração entre pessoas de status similares do que entre um chefe e um funcionário, ou entre um professor e um aluno.

b) Refere-se às interações que ocorrem entre os membros do grupo, que podem ser mais ou menos colaborativas. Por exemplo, uma negociação tem um aspecto colaborativo maior do que simplesmente dar instruções.

c) Alguns mecanismos de aprendizagem são intrinsecamente colaborativos, como receber um embasamento inicial em qualquer assunto tem um aspecto colaborativo maior do que a indução de procurar esse embasamento sozinho.

d) O quarto aspecto refere-se aos efeitos da aprendizagem colaborativa, não porque isso seja usado para definir colaboração, mas porque diferentes visões sobre como medir os efeitos de aprendizagem colaborativa contribuem para acrescentar dificuldades de terminologia nessa área. 
Na TAB. 9 são resumidos os conceitos englobados em colaboração:

TABELA 9. Conceitos englobados em colaboração

\begin{tabular}{|c|c|}
\hline Conceito & Significado \\
\hline Situação & Que envolve pessoas de status similares \\
\hline Interações & $\begin{array}{c}\text { Ações recíprocas entre os membros de um } \\
\text { grupo }\end{array}$ \\
\hline $\begin{array}{c}\text { Mecanismos de } \\
\text { aprendizagem }\end{array}$ & $\begin{array}{c}\text { São disparados em situações colaborativas } \\
\text { Efeitos da } \\
\text { aprendizagem }\end{array}$ \\
\hline
\end{tabular}

Fonte: (DILLENBOURG, 1999), adaptado pelo autor.

As situações descritas como colaborativas, referenciadas no conceito "Situação" acima prevêem que os participantes na colaboração:

a) tenham aproximadamente o mesmo nível e possam realizar as mesmas ações: o que implica dizer que os colaboradores devem ter simetria de ações (são permitidas as mesmas ações a todos), simetria de conhecimentos (todos têm que ter o mesmo nível de conhecimentos a respeito do assunto no qual colaboram, para poder haver interação entre eles) e simetria de status (todos têm que ter as mesmas possibilidades e autoridade para interagir).

b) tenham um objetivo em comum: eles não podem estar em processo de competição porque, nesse caso, não haveria interações entre eles visando atingir metas conjuntas.

c) trabalhem juntos: deve existir um critério de divisão de tarefas entre eles. Aqui é feita uma distinção entre colaboração e cooperação, embora às vezes sejam usados como sinônimos. Na colaboração, os parceiros trabalham necessariamente juntos, quase sempre simultaneamente, e na cooperação os parceiros dividem o trabalho em sub-tarefas, as executam separadamente (e mesmo assincronamente) e juntam os resultados no final. 
Segundo os trabalhos de DILLENBOURG (1999), outro modo de definir colaboração é como uma situação na qual aprendizes interagem de um modo colaborativo, envolvendo os conceitos de interatividade, sincronicidade e negociabilidade.

A interatividade entre os colaboradores não é definida pela freqüência das interações, mas pela intensidade com que as interações influenciam o processo cognitivo dos envolvidos.

A sincronicidade é um critério que implica em comunicação síncrona, com a cooperação associada a essa comunicação. O sincronismo é freqüentemente associado ao uso de TIC, mas não depende delas. Um aspecto, no entanto, que precisa estar presente para assegurar o bom sincronismo é o baixo tempo de demora na resposta de um dos colaboradores a qualquer pergunta colocada por outro, já que o sincronismo depende de uma ação rápida do receptor a todo e qualquer estímulo recebido.

A negociabilidade significa que cada colaborador não está sujeito a restrições hierárquicas, ou seja, não está sob as ordens de qualquer outra pessoa, podendo argumentar, colocar sua posição e tentar convencer a outra parte, em igualdade de condições.

Os mecanismos de aprendizagem envolvidos em aprendizagem colaborativa são os mesmos presentes na aprendizagem individual, até porque são os que ocorrem primeiramente nas pessoas, que são sempre os agentes individuais de qualquer processo, sendo eles: indução, carga cognitiva, auto-explicação e conflito.

Indução é o processo em que um colaborador influencia a concepção e representação de uma solução de outro colaborador, e é influenciado pelo outro, de modo que essa troca de influências pode alterar as concepções e representações presentes em ambos.

Carga cognitiva é o conceito de que, no processo de colaboração, a divisão horizontal do trabalho reduz a carga de processamento realizada por cada indivíduo, dentro do grupo, para as tarefas já determinadas; mas aumenta a carga cognitiva dependendo de uma nova tarefa. 
Auto-explicação é a idéia relacionada com situações sociais, são os acréscimos de conhecimentos que a pessoa faz, confirmando para si mesma suas novas descobertas, e pode ser comparado aos processos de adaptação/acomodação propostos por Piaget.

Conflito é um conceito intrinsecamente social trazido para a ciência cognitiva por Piaget, que descreve que uma discrepância entre os conhecimentos ou os pontos de vista de dois colaboradores pode levar a confrontações entre ambos e a tomadas de posições com relação aos assuntos em debate.

Segundo DILLENBOURG (1999), as teorias da aprendizagem colaborativa devem, necessariamente, abordar quatro grandes assuntos, e o fazem, na maioria dos casos, que são: a) critérios para definir a situação cognitiva (simetria, grau de divisão do trabalho); b) as interações (simetria, negociabilidade), c) os processos de interação; d) os efeitos da aprendizagem colaborativa.

Para ele, uma situação gera padrões de interação e dispara mecanismos cognitivos, que conduzem a efeitos cognitivos. Essa linearidade sucessiva de causa e efeito, entretanto, é uma simplificação, porque muitas relações são recíprocas: há uma ligação bi-direcional entre situações e interações, entre interações e processos, entre processos e os efeitos cognitivos.

Um aspecto recorrente nas teorias da aprendizagem é o que significa "entender algo", principalmente entender o discurso online, o que é relacionado a ter fluência epistêmica sobre tarefas epistêmicas. Na TAB. 10 são descritas as tarefas epistêmicas apontadas por Ohlsson: 
TABELA 10. Taxonomia de Ohlsson

\begin{tabular}{|c|c|}
\hline $\begin{array}{c}\text { Tarefa } \\
\text { epistêmica }\end{array}$ & Significado \\
\hline DESCREVER & $\begin{array}{c}\text { Desenvolver um discurso referenciando um objeto/evento tal que } \\
\text { uma pessoa que participe do discurso adquira uma concepção } \\
\text { acurada do objeto/evento. }\end{array}$ \\
\hline EXPLANAR & $\begin{array}{c}\text { Desenvolver um discurso em relação a um evento tal que uma } \\
\text { pessoa que participe do discurso entenda porque aquele } \\
\text { evento aconteceu. }\end{array}$ \\
\hline PREVER & $\begin{array}{c}\text { Desenvolver um discurso tal que uma pessoa que participe dele } \\
\text { entenda que tal evento acontece/acontecerá sob determinadas } \\
\text { circunstâncias, ou seja, entenda as relações de causa-e-efeito } \\
\text { envolvidas no evento. }\end{array}$ \\
\hline ARGÜIR & $\begin{array}{c}\text { Argumentar a favor (ou contra) uma posição ou questão em } \\
\text { particular, portanto aumentando (ou diminuindo) no receptor a } \\
\text { certeza de que a posição ou questão esteja certa. }\end{array}$ \\
\hline CRITICAR & $\begin{array}{c}\text { Desenvolver um discurso sobre algo (especialmente um produto } \\
\text { cultural) tal que uma pessoa que participe do discurso fique ciente } \\
\text { dos aspectos positivos e negativos envolvidos no assunto. }\end{array}$ \\
\hline EXPLICAR & $\begin{array}{c}\text { Explicar um conceito é desenvolver um discurso tal que uma pessoa } \\
\text { que participe do discurso adquira um claro entendimento de } \\
\text { seu significado. }\end{array}$ \\
\hline DEFINIR & Definir um termo é propor um uso para ele. \\
\hline
\end{tabular}

Fonte: (GOODYEAR, 2001), adaptado pelo autor.

De acordo com GOODYEAR (2001), há um ciclo de aprendizagem relacionado a jogos epistêmicos que descreve atividades de compartilhamento de conhecimentos observados em programas de ensino e aprendizagem.

Esse ciclo é composto pelas atividades:

a) externalização: processo pelo qual o conhecimento tácito contido em práticas é explicitado, por exemplo, por meio de descrições escritas.

b) compartilhamento: atividades de disseminação dessas descrições e compartilhamento com a comunidade.

c) refinamento: processo de propor sugestões de melhorias nas práticas descritas, ou re-elaborações do conhecimento explicitado nelas. 
d) internalização: processo por meio do qual as descrições do conhecimento são reapropriadas pelo aprendiz, resultando em mudanças de suas práticas de trabalho.

\subsubsection{FORMAÇÃO DE SIGNIFICADOS EM COLABORAÇÃO}

Significado é o conteúdo ou idéia que palavras, sons, gestos, imagens e/ou símbolos possuem (conduzem ou sugerem), ao serem trocados por pessoas quando essas se comunicam por meio da linguagem (verbal, sonora, textual, visual, gestual). São idéias sobre fatos e fenômenos, do mundo real ou imaginário; são representações mentais de algo visto, concebido, lembrado, imaginado, proposto, planejado ou estudado.

Representações mentais são modelos mentais internos que as pessoas criam (ou que são criados nelas, independentemente de sua vontade) para entender/ representar o mundo físico, psíquico e cultural onde vivem.

De acordo com BOEREE (1997), com base em trabalhos de Jung, a formação de significados na mente de uma pessoa está relacionada a arquétipos, ou seja, um conceito que representa uma tendência não-aprendida, portanto, inata, a perceber os fatos de certo modo, anterior à própria formação da consciência do individuo em contato com a realidade que o cerca.

Dentre os vários arquétipos apontados por Jung, pode-se exemplificar com o arquétipo da mãe, que relata que todos os seres humanos nascem prontos para procurar sua mãe, reconhece-la, interagir com ela, constituindo-se o arquétipo em um tipo de conhecimento prévio embutido nas mentes de todas as pessoas, talvez fruto da evolução (e da experiência acumulada) de nossa espécie.

Exemplos de outros arquétipos citados por Jung são: do pai, da família, do herói e o arquétipo de Deus, esse último representando nossa necessidade de compreender o universo, de dar um significado a tudo o que acontece, de tentar descobrir o propósito dos fatos e sua direção. Ou seja, é muito extensa e complexa a gênese do conceito de significado e a cadeia de ligações desse conceito com os demais que interessam ao estudo das atividades de colaboração. 
STAHL (2003) apontou que, no contexto de CSCL, "a elaboração de sentido pode ser tratada como uma atividade essencialmente social, que é conduzida juntamente - colaborativamente - por uma comunidade, ao invés de ser conduzida por indivíduos isoladamente."

Ele propôs que, em contextos de colaboração, significados existem no mundo intersubjetivo e que são interpretados sob perspectivas pessoais, e destacou que a natureza dos significados tem um papel preponderante nas ciências, que remonta às origens da filosofia ocidental, com os diálogos de Sócrates e lembrou que, posteriormente, devido às idéias de Kant e Hegel, a formação de significados tornouse ainda mais relevante para as ciências da aprendizagem, frisando que tanto a ontologia quanto a epistemologia são centrais para as ciências de aprendizagem construtivistas e sócio-culturais.

Segundo STAHL (2003), Kant e Hegel trabalharam no sentido de superar a dualidade mente-corpo introduzida por Descartes, na qual os significados eram considerados puramente mentais, dissociados ontologicamente e epistemológicamente dos fatos e fenômenos do mundo real.

As ciências da aprendizagem contemporâneas, em especial a partir de Vygotsky, reconhecem o comprometimento das idéias (e da aprendizagem) com a realidade material do homem, e sua dependência (e relacionamento dialético) com as condições materiais e sociais em que são geradas.

De acordo com VIGOTSKI (1999), Hegel demonstrou que a consciência humana emergeria por meio da atividade do homem no mundo social e material, dentro de um processo de reconhecimento do eu e do outro.

STAHL (2003) lembrou que a formação de significados, para Vygotsky, tem sua gênese no gesto de apontar, e que este gesto é um artefato, porque incorpora significados dentro do mundo real.

Com relação à linguagem, para VIGOTSKI (1999), ela nasce a partir do gesto é, posteriormente, internalizada. Durante as fases de evolução cognitiva da criança, os gestos primais são transformados em discurso, e o discurso transformado em pensamento. Para ele, a natureza e a importância do artefato, nessa concepção, superam a dualidade proposta por Descartes, porque integram o mundo conceitual 
com o mundo físico, e também transcendem a visão individualista do significado, situando sua origem nas interações sociais.

A linguagem falada leva a pessoa a falar consigo mesma, em seu discurso interno silencioso, e essa habilidade mostra-se uma poderosa ferramenta para controlar as ações da pessoa e influenciar os outros.

De acordo com trabalhos de SANTAELLA (2001), citando Peirce, pensamento é linguagem e linguagem é pensamento, de modo indissociável, bem como não há pensamentos sem signos $\mathrm{e}$, consequentemente, nem haveria linguagem independentemente de signos, visão essa que aprofunda as questões sobre linguagem e pensamento abordadas por Vygotsky.

\subsubsection{APRENDIZAGEM EM REDE}

GOODYEAR (2001) argumentou que o objetivo das atividades de ensino é fazer com que os estudantes desenvolvam competências e habilidades que podem ser divididas em três categorias:

a) genéricas: são as competências gerais adquiridas pelos estudantes, usadas por eles como meios para sua interação com os outros e com seu ambiente (e para aquisição de novos conhecimentos), também chamados de habilidades nucleares ou habilidades transferíveis, que são: alfabetização, domínio de números, comunicação em língua nativa, comunicação em língua estrangeira, liderança, capacidade de trabalho em equipe, habilidades em TIC.

b) acadêmicas: são as referentes ao domínio do discurso acadêmico, fortemente ancorado em: 1) conhecimentos conceituais declarativos, 2) formas contemplativas de análise, e 3) uso de representações textuais. Os conhecimentos acadêmicos manifestam-se por meio das habilidades da pessoa em recuperar conhecimentos conceituais declarativos e aplicá-los na construção de argumentos ou na solução de problemas. Esses são metaconhecimentos, ou seja, conhecimentos sobre como adquirir conhecimentos. 
c) reflexivas: são as competências e habilidades de análise de fatos e fenômenos, de idéias complexas, de efetuar comparações, sínteses, compreender teorias do campo do pensamento, de entender as relações entre as idéias e as ações.

Outro fator importante é a fluência epistêmica, que é a habilidade de se reconhecer e praticar bem uma variedade de jogos epistêmicos, que são um conjunto de estratégias que guiam a construção do conhecimento em torno de estruturas epistêmicas - estruturas características de construção de conhecimentos tornadas disponíveis por meio da cultura. GOODYEAR (2001) destacou que:

O desenvolvimento de fluência epistêmica - a habilidade para reconhecer e praticar uma variedade de jogos epistêmicos - ocorre através da participação em jogos epistêmicos, não apenas observando-os ou ouvindo a respeito deles. Desenvolve-se fluência epistêmica por meio da interação com outras pessoas que já sejam relativamente mais fluentes.

$\mathrm{Na}$ aprendizagem em rede as TIC são usadas para promover todos os tipos de conexões de aprendizagem dentro de uma comunidade de aprendizagem: entre tutores $(T)$ e aprendizes (A), em todas as quantidades de cada lado (1T:1A, 1T:nA, $1 A: 1 A, 1 A: n A)$, entre comunidades de aprendizagem e recursos de aprendizagem.

Segundo trabalhos de SHUELL (1992), o conhecimento é pessoal, construído ativamente dentro de uma comunidade de aprendizagem, mas é de fundamental importância o contexto social que provê condições para a aprendizagem.

O simples fato de o aprendiz estar envolto por uma comunidade de aprendizagem não assegura que ocorrerá sua construção pessoal de conhecimento. A aprendizagem é uma jornada pessoal, mas, como ela se dá normalmente dentro do grupo, é fundamental verificar-se o que o aprendiz está fazendo, porque a aprendizagem depende das atividades do aprendiz, físicas e mentais.

Segundo os trabalhos de SHUELL (1992) apud GOODYEAR (2001), há quatro modelos de aprendizagem:

a) aprendizagem como recepção passiva: modelo que implica na visão da aprendizagem como algo que pode ser segmentado e transmitida do tutor 
para o aluno; é uma visão do tutor como ativo e do aluno como passivo; é o modelo mais consagrado até hoje nas escolas.

b) aprendizagem como descoberta: é o oposto do modelo anterior; o aluno tem que trabalhar ativamente em experimentar, interpretar suas experiências, construir seus próprios significados e compreensões através de uma jornada de descobertas pessoais; ocorre com menor freqüência que o modelo anterior e altera os papéis desempenhados por tutores e alunos.

c) aprendizagem como preenchimento de déficit de conhecimento: nesse modelo, o aprendiz move-se de um estado de novato para a condição de expert em determinado assunto, passo-a-passo, cumprindo metas de aprendizagem estabelecidas pelo tutor ou pelo programa de instrução; é um modelo semelhante ao de recepção passiva.

d) aprendizagem como uma construção orientada: modelo que confere ao aluno uma participação ativa, encarregando-o como responsável pela construção de seus conhecimentos.

Segundo trabalhos de GOODYEAR (2001), há maiores possibilidades de sucesso em atividades de aprendizagem caso essa seja:

a) ativa: o aluno deve realizar uma variedade de operações cognitivas baseado em novas informações, a fim de fazê-las significativas para si mesmo; os processos cognitivos em que 0 aluno engaja-se serão determinantes para o quê e quanto o aluno aprenderá.

b) cumulativa: o que o aluno já sabe desempenha um papel importante sobre o que ele pode aprender, particularmente seu conhecimento ativo anterior, porque é sobre ele que sedimentam-se os novos conhecimentos.

c) individual: cada aprendiz constrói seu próprio conhecimento de um modo idiossincrático, usando experiências e conhecimentos anteriores para dar 
sentido às novas experiências e conhecimentos; isso significa que não há dois conhecimentos iguais e que cada pessoa constrói um conhecimento que tem característica única e só é observado nela.

d) auto-regulável: aprendizagem efetiva é caracterizada por dois fatores: o aluno precisa estar ciente de que está engajado em um processo reflexivo de aprendizagem; e a habilidade do aluno em agir baseado nessa reflexão.

e) orientada a objetivos: objetivos claros são imprescindíveis para tornar efetivas as atividades de aprendizagem, e precisam estar claros para os alunos, professor e durante o processo de negociação que envolve ambas as partes.

\subsection{TEORIAS COGNITIVAS}

LOCK e PETERS (1999) apontaram que Piaget e Vygotsky desenvolveram, de modo independente, importantes pesquisas sobre os processos de ensino e aprendizagem, tendo o primeiro criado o arcabouço da teoria que passou a ser denominada epistemologia genética, e o segundo o responsável pelo desenvolvimento de uma teoria denominada sócio-cultural.

De acordo com RIVARD (1996) apud HOLLADAY (2000), os estudos sobre cognição, desde fins do século XIX, resultaram na formação de duas grandes famílias de teorias:

a) behaviorista: as que vêem o aprendizado como um processo que envolve basicamente uma série de associações entre estímulos e respostas, e que pode ser percebido por meio de mudanças na forma ou na freqüência de comportamentos externos.

b) cognitivista: teorias que relacionam o processo de aprendizado com a aquisição de conhecimentos como resultado de ações externas e de processos internos que os aprendizes usam para organizar e armazenar as informações. 
Os trabalhos de Piaget refutaram enfoques eminentemente behavioristas de aprendizagem, até então vigentes, nos quais se admitia que aprendizagem era o resultado da reação do individuo aos estímulos do ambiente e da transformação dessas reações em ações, e iniciaram o estudo de um enfoque cognitivista, entendendo-se que as pessoas aprendem, ao invés de apenas reagirem a estímulos, e o fazem como resultado de etapas sucessivas de análise dos assuntos e objetos estudados e da interação com outras pessoas.

Os trabalhos Vygotsky, também cognitivista, têm características que os distanciaram dos trabalhos de Piaget. Enquanto Piaget privilegiou aspectos biológicos, propondo que o amadurecimento do organismo leva o indivíduo a ter condições de cumprir estágios sucessivos de desenvolvimento cognitivo cada vez mais complexos, Vygotsky focalizou prioritariamente aspectos da linguagem e da interação social, colocando-os em um patamar de importância superior à do amadurecimento do organismo e desvinculando a aprendizagem como simples conseqüência desse amadurecimento orgânico.

O conhecimento, em especial o tecnológico, e seus meios de aquisição e reprodução, é reconhecido atualmente como a principal fonte de riqueza dos homens, das empresas e das nações, fazendo com que o estudo das teorias cognitivas, entendido como o estudo de como se adquire e transmite conhecimento, continue prioritário, e seu interesse desloque-se dos centros acadêmicos para todas as áreas de conhecimentos, em todas as áreas da sociedade, empresas, cultura e da economia.

As teorias behavioristas não se aprofundaram em explicar a complexidade envolvida nos fenômenos do aprendizado: não explicam como as pessoas aprendem a elaborar idéias consideradas complexas e que, principalmente, não decorrem de suas necessidades, mas partem de algum ponto abstrato. $E$ também não conseguem explicar como é possível a criação de conceitos complexos a partir de uma simbologia também complexa, que muitas vezes é criada juntamente com os conceitos que busca representar.

As teorias cognitivistas, em contrapartida, estão mais interessadas que as behavioristas em desvendar as estratégias usadas pelos seres humanos quando 
confrontados com problemas, quer sejam reais, referentes às necessidades imediatas, quer sejam virtuais, fruto, em princípio, de suas inquietações intelectuais, sem um vínculo imediato com os estímulos do meio.

\subsubsection{ELEMENTOS DA TEORIA DAS INTELIGÊNCIAS MÚLTIPLAS DE HOWARD GARDNER}

Gardner interessou-se pelos trabalhos de Piaget e, no início dos anos 80, publicou suas primeiras conclusões sobre sua teoria, na qual ele nega que a inteligência humana seja uma entidade única e a propõe como tendo, pelo menos, oito tipos de instâncias independentes.

Ele define inteligência como um potencial biopsicológico que o indivíduo tem para processar informações, que pode ser ativado em um determinado contexto para resolver problemas ou criar produtos que são valorizados em um ou mais ambientes culturais.

De acordo com os trabalhos de GARDNER (1995), os oito tipos de inteligências são:

1) lingüística: capacidade para as linguagens falada e escrita, para aprender idiomas e usar a linguagem a fim de atingirem objetivos;

2) lógico-matemática: capacidade para analisar e resolver problemas logicamente, utilizando matemática e princípios científicos;

3) musical: habilidade para compor e/ou executar músicas, reconhecer padrões sonoros, tons, ritmos, que são, segundo Gardner, habilidades estruturalmente paralelas à inteligência lingüística;

4) corpóreo-cinestésica: que se manifesta por meio da facilidade no uso do próprio corpo, para expressar-se e/ou resolver problemas;

5) espacial: reconhecida por meio da facilidade que o indivíduo tem em reconhecer e usar áreas espaciais; 
6) inter-pessoal: capacidade que o indivíduo tem de entender intenções, motivações e desejos de outras pessoas, facilitando o seu relacionamento com os outros;

7) intra-pessoal: capacidade que o indivíduo tem de entender a si mesmo, seus sentimentos, medos, motivações e, desse modo, manter equilibrada sua própria vida;

8) naturalística: capacidade de distinguir entre elementos da natureza, favorável à sobrevivência de nossa espécie;

$\mathrm{Na}$ TAB. 11 é apresentado um sumário das características das oito inteligências propostas por Gardner: 
TABELA 11. Sumário das oito inteligências

\begin{tabular}{|c|c|c|c|c|}
\hline Inteligência & Pontos fortes & Preferências & $\begin{array}{l}\text { Aprende melhor } \\
\text { por meio de }\end{array}$ & Necessita de \\
\hline $\begin{array}{l}\text { VERBAL/ } \\
\text { LINGUIS- } \\
\text { TICA }\end{array}$ & $\begin{array}{c}\text { Escrita, leitura, } \\
\text { Memorização de } \\
\text { datas, pensar em } \\
\text { palavras, contar } \\
\text { estórias }\end{array}$ & $\begin{array}{l}\text { Escrever, ler,contar } \\
\text { estórias, conversar, } \\
\text { memorizar, resol- } \\
\text { ver charadas }\end{array}$ & $\begin{array}{c}\text { Ouvir e ver } \\
\text { palavras, } \\
\text { falando, lendo, } \\
\text { escrevendo }\end{array}$ & $\begin{array}{l}\text { Livros, cadernos, } \\
\text { instrumentos de } \\
\text { escrita, diálogos, } \\
\text { discussões. }\end{array}$ \\
\hline $\begin{array}{l}\text { LÓGICO/ } \\
\text { MATEMÁ- } \\
\text { TICA }\end{array}$ & $\begin{array}{l}\text { Matemática, lógica, } \\
\text { resolução de } \\
\text { problemas, } \\
\text { raciocínio, padrões }\end{array}$ & $\begin{array}{l}\text { Questões, trabalho } \\
\text { com números, } \\
\text { experimentos, } \\
\text { resolver problemas }\end{array}$ & $\begin{array}{l}\text { Relacionamen- } \\
\text { tos e padrões, } \\
\text { classificando, } \\
\text { abstrações. }\end{array}$ & $\begin{array}{c}\text { Fatos e } \\
\text { fenômenos para } \\
\text { pensar e } \\
\text { explorar, } \\
\text { materiais } \\
\text { científicos, } \\
\text { museus. } \\
\end{array}$ \\
\hline $\begin{array}{l}\text { VISUAL/ } \\
\text { ESPACIAL }\end{array}$ & $\begin{array}{l}\text { Mapas, leitura, } \\
\text { gráficos, desenhos, } \\
\text { visualizações, } \\
\text { abstrações }\end{array}$ & $\begin{array}{l}\text { Desenhar, construir, } \\
\text { desenvolver, criar, } \\
\text { apreciar pinturas }\end{array}$ & $\begin{array}{l}\text { Trabalho com } \\
\text { cores e } \\
\text { pinturas, } \\
\text { visualizações, } \\
\text { imaginação }\end{array}$ & $\begin{array}{l}\text { LEGO, vídeos, } \\
\text { filmes, slides, } \\
\text { arte, jogos, } \\
\text { quebra-cabeças }\end{array}$ \\
\hline $\begin{array}{l}\text { CORPÓ- } \\
\text { REO- } \\
\text { CINESTÉ- } \\
\text { SICA } \\
\end{array}$ & $\begin{array}{c}\text { Esportes, dança, } \\
\text { competições, uso de } \\
\text { ferramentas, atuação }\end{array}$ & $\begin{array}{l}\text { Mover-se, tocar e } \\
\text { falar, linguagem } \\
\text { corporal }\end{array}$ & $\begin{array}{c}\text { Toque, } \\
\text { movimento, } \\
\text { conhecimento } \\
\text { por sensações }\end{array}$ & $\begin{array}{l}\text { Atuação, objetos } \\
\text { para construir, } \\
\text { movimento, } \\
\text { esportes }\end{array}$ \\
\hline MUSICAL & $\begin{array}{l}\text { Sons, lembrar-se de } \\
\text { melodias, ritmos, } \\
\text { canto }\end{array}$ & $\begin{array}{l}\text { Cantar, tocar um } \\
\text { instrumento, ouvir } \\
\text { música }\end{array}$ & $\begin{array}{l}\text { Ritmo, melodia, } \\
\text { ouvindo } \\
\text { músicas e } \\
\text { melodias }\end{array}$ & $\begin{array}{c}\text { Tempo para } \\
\text { cantar concertos, } \\
\text { instrumentos }\end{array}$ \\
\hline $\begin{array}{l}\text { INTER- } \\
\text { PESSOAL }\end{array}$ & $\begin{array}{c}\text { Liderança, } \\
\text { organização, resolver } \\
\text { conflitos, vender }\end{array}$ & $\begin{array}{l}\text { Falar a pessoas, ter } \\
\text { amigos, unir grupos }\end{array}$ & $\begin{array}{l}\text { Comparando, } \\
\text { relacionando, } \\
\text { compartilhando }\end{array}$ & $\begin{array}{c}\text { Amigos, jogos } \\
\text { coletivos, eventos } \\
\text { sociais, clubes } \\
\end{array}$ \\
\hline $\begin{array}{l}\text { INTRA- } \\
\text { PESSOAL }\end{array}$ & $\begin{array}{l}\text { Reconhecer pontos } \\
\text { fortes e pontos } \\
\text { fracos, estabelecer } \\
\text { metas, compreender- } \\
\text { se }\end{array}$ & $\begin{array}{l}\text { Trabalhar sozinho, } \\
\text { refletir interesses }\end{array}$ & $\begin{array}{l}\text { Trabalhando } \\
\text { sozinho, } \\
\text { refletindo, } \\
\text { criando projetos }\end{array}$ & $\begin{array}{l}\text { Lugares secretos, } \\
\text { tempo sozinho, } \\
\text { projetos próprios, } \\
\text { escolhas }\end{array}$ \\
\hline $\begin{array}{l}\text { NATURA- } \\
\text { LIISTICA }\end{array}$ & $\begin{array}{c}\text { Compreender a } \\
\text { natureza, fazer } \\
\text { distinções, identificar } \\
\text { fauna e flora }\end{array}$ & $\begin{array}{c}\text { Estar envolvido com } \\
\text { a natureza, tomar } \\
\text { decisões }\end{array}$ & $\begin{array}{l}\text { Trabalhando } \\
\text { com a natureza, } \\
\text { explorando } \\
\text { seres vivos }\end{array}$ & $\begin{array}{l}\text { Ordem, padrões } \\
\text { de iguais/dife- } \\
\text { rentes, conexões } \\
\text { com a vida real }\end{array}$ \\
\hline
\end{tabular}

Fonte: (GARDNER, 1995), adaptado pelo autor. 
Gardner utilizou oito critérios para distinguir os tipos de inteligências e para caracterizá-las, que são:

1) o isolamento de cada tipo de inteligência dentro do cérebro, que é detectado quando, por exemplo, alguém sofre danos físicos cerebrais que afetam um tipo de inteligência enquanto outros tipos permanecem intactos;

2) a hipótese da colaboração de cada tipo de inteligência no processo evolucionário humano, como, por exemplo, ao se analisar como a inteligência espacial colaborou para as migrações de grupos humanos, ao longo de sua história, colaborando com sua sobrevivência;

3) a idéia da presença de um núcleo central de operações inerente a cada tipo de inteligência, como no caso da inteligência lingüística, cujas operações centrais são o reconhecimento e a discriminação de fonemas, o comando da sintaxe e a aquisição dos significados das palavras;

4) a observação de cada tipo dentro de sistemas simbólicos, como, por exemplo, a linguagem escrita ou os símbolos matemáticos;

5) a descoberta do diferente ritmo de evolução de cada tipo de inteligência dentro da espécie humana e mesmo dentro de cada indivíduo;

6) a constatação de que existem pessoas que são, ao mesmo tempo, limitadas para certos tipos de inteligência e bem dotadas em outros tipos;

7) evidências suportadas pela psicologia experimental, como a vista em autistas, que exibem notável domínio de números e estatísticas, por exemplo, sem compreender seus significados;

8) evidências encontradas pela psicometria, como, por exemplo, diferentes resultados em observações sobre se a realização de determinadas atividades do indivíduo depende do uso de uma ou mais inteligência. 
De acordo com trabalhos de SMITH (2002), são premissas básicas da teoria das inteligências múltiplas:

a) todas os indivíduos possuem todas as oito inteligências, em diferentes graus de intensidade;

b) cada indivíduo tem um perfil único de inteligência (com um percentual específico de cada uma);

c) processos educacionais podem ser implantados tomando-se por base os diferentes tipos de inteligência;

d) cada inteligência ocupa uma região diferente do cérebro (pacientes com danos em diferentes regiões cerebrais mostram conseqüências diferentes em seus tipos de inteligência);

e) as inteligências podem operar em conjunto com as outras ou independentemente;

f) as inteligências, reunidas, definem as características globais da espécie humana.

GARDNER (1995) argumentou que os seres humanos podem aprender de diferentes maneiras: por meio da exploração do ambiente com suas mãos e seus sentidos, por meio da observação das outras pessoas, de conversações, de leituras, desenvolvendo e utilizando uma infinidade de símbolos, ou pintando, dançando, enfim, por meio de uma longa lista de modos e meios de captação e de expressão de significados.

GILES (2007) definiu a expressão "estilo de aprendizagem" como a característica composta por fatores cognitivos, afetivos e psicológicos, que servem de indicadores sobre como um aprendiz percebe, interage com e responde a um ambiente de aprendizagem, que é usado em vários campos educacionais e decorre da aplicação da teoria das inteligências múltiplas. 
$\mathrm{Na}$ TAB. 12 são apresentados os quatro estilos de aprendizagem propostos por ele:

TABELA 12. Estilos de aprendizagem

\begin{tabular}{|c|c|}
\hline $\begin{array}{c}\text { Estilo de } \\
\text { aprendizagem }\end{array}$ & $\begin{array}{c}\text { Como possuidores desse estilo de aprendizagem processam } \\
\text { informaçôes }\end{array}$ \\
\hline VISUAL & $\begin{array}{c}\text { Mais efetivamente quando as vêem, por meio de: mapas, } \\
\text { gráficos, fluxos, símbolos. Essas pessoas pensam por meio de } \\
\text { figuras e têm uma imaginação vívida. }\end{array}$ \\
\hline AURAL & $\begin{array}{c}\text { De modo mais eficaz quando elas são faladas ou ouvidas; } \\
\text { respondem bem a aulas e discussões e são excelentes } \\
\text { ouvintes. Ao tentarem relembrar informações, essas pessoas o } \\
\text { fazem "ouvindo-as" novamente. }\end{array}$ \\
\hline LER / & $\begin{array}{c}\text { Melhor quando apresentados a um texto escrito; aproveitam } \\
\text { muito esquemas, resumos, diagramas, fluxos. Ao tentarem } \\
\text { relembrar informações, eles as "relêem" mentalmente. }\end{array}$ \\
\hline $\begin{array}{c}\text { CORPÓREO/ / } \\
\text { CINESTÉSICA }\end{array}$ & $\begin{array}{c}\text { Ativamente por meio do corpo. São ricos em gestual, em } \\
\text { exemplos, em práticas e simulações, porém são leitores } \\
\text { deficientes. }\end{array}$ \\
\hline
\end{tabular}

Fonte: (GILES, 2007), adaptado pelo autor.

Esses estilos de aprendizagem podem orientar a criação e implantação de ambientes LV/CVE mais adequados às características cognitivas de seus usuários, tornando-os mais eficazes.

\subsubsection{ELEMENTOS DA TEORIA MINDFUL LEARNING DE ELLEN LANGER}

O trabalho desenvolvido por Ellen Langer e seus colaboradores focalizou inicialmente pesquisas sobre as limitações do que ela denominou aprendizagem desatenta (mindlessness learning), que se refere à aprendizagem (com características quase behavioristas) que se dá quando da aquisição de hábitos, que se desenrola e se consolida no indivíduo desacompanhada de uma reflexão e da consciência de que a aprendizagem está ocorrendo.

LANGER (1989) apontou que "quando nós seguimos cegamente rotinas ou executamos ordens desatentamente, nós estamos agindo como autômatos, com potenciais graves conseqüências para nós e para os outros." 
Segundo seus trabalhos, o pensamento desatento (mindless thought) pode ser caracterizado inicialmente pela presença de três fatores observáveis no indivíduo:

a) comprometimento com categorias pré-existentes: usualmente parte-se de conceitos e categorias pré-existentes, criadas anteriormente para compreender o mundo; o pensar desatento ocorre quando se prende rigidamente às categorias já criadas no passado, o que nos impede de ampliar nossos conceitos e idéias.

b) comportamento automático: tendência das pessoas em agir conforme hábitos antigos, ou seja, dado um determinado estímulo, já conhecido, a pessoa reage de determinado modo, repetidas vezes utilizado. Dessa forma, as pessoas respondem desatentamente a um contexto familiar ao invés de prestar atenção ao conteúdo de uma situação.

c) agir a partir de uma perspectiva única: age-se normalmente sem introduzir variações nas ações, sem considerar alternativas que poderiam ser mais eficazes dependendo da situação que se apresenta; se alguém pede determinado tipo de ajuda, procura-se oferecer exatamente o que está sendo pedido, sem agregar expertise ao assunto.

Na TAB. 13 estão resumidas essas características: 
TABELA 13. Pensamento desatento (mindlessness)

\begin{tabular}{|c|l|}
\hline Fator & \multicolumn{1}{|c|}{ Característica } \\
\hline 1 & $\begin{array}{l}\text { Comprometimento com categorias pré-existentes. Fica-se } \\
\text { rigidamente comprometido com categorias criadas no passado. }\end{array}$ \\
\hline 2 & $\begin{array}{l}\text { Comportamento automático. Compreende a tendência em } \\
\text { repetir as mesmas ações na presença dos mesmos estímulos. }\end{array}$ \\
\hline 3 & $\begin{array}{l}\text { Agir a partir de uma perspectiva única. Compreende responder } \\
\text { somente à causa apresentada, sem considerar outras variáveis } \\
\text { que possam enriquecê-la. }\end{array}$ \\
\hline
\end{tabular}

Fonte: (LANGER, 1989), adaptado pelo autor.

Para LANGER (1989), há diferentes raízes para o pensar desatentamente, que nos conduzem a fazê-lo sob a influência de um ou mais dos fatores restritivos enumerados por ela e que são:

a) repetição: a execução freqüente das mesmas tarefas pode nos conduzir a pensar desatentamente em qualquer profissão; as pessoas incorporam os procedimentos e os executam sem qualquer esforço cognitivo; os novatos podem perceber melhor pequenas modificações feitas em tarefas muito repetidas do que aqueles que as executam rotineiramente.

b) comprometimento cognitivo prematuro: o indivíduo desatento é normalmente comprometido com um modo pré-determinado e único de pensar, fazer algo ou usar uma informação; não explora variações possíveis nos usos de objetos, conhecimentos ou aplicações das mesmas informações com as quais lida; o modo com que inicialmente assimilou a informação (se foi atenta ou desatenta) determina com ele vai utilizá-la no futuro.

c) aprendizagem desatenta e inconsciência: se se aprende algo desatentamente, não nos ocorrerá pensar a respeito posteriormente, e nem mesmo cogitar que isso deva ser feito; porém se formos alertados para isso, aceita-se sem dificuldades novas perspectivas sobre assuntos antigos. 
d) crença na limitação dos recursos: cria-se categorias rígidas, mutuamente exclusivas, e limita-se a classificação de fatos a essas categorias; com isso, restringe-se as possibilidades de descobertas e de novas soluções.

e) noção linear do tempo: concepção restritiva do recurso tempo, que nos conduz a desperdiçar possíveis esforços devido à falsa noção de que o tempo não pode ser compartilhado entre diferentes atividades.

f) educação para os resultados: desde o ensino fundamental, o foco da escolarização é colocado nos resultados, ao invés de nos processos por meio dos quais eles são obtidos; essa concepção conduz a apresentar os fatos incondicionalmente, o que contribui para um pensar desatento.

g) o poder do contexto: o modo como se age tem forte influência do contexto e nossa mentalidade determina como se interpreta cada contexto; além disso, a idéia de contexto é formada continuamente por nós; o contexto não existe como uma realidade externa, independente das pessoas, o que provoca constantes confusões: muitas pessoas assumem que as motivações e intenções das outras pessoas são as mesmas delas, embora o mesmo comportamento possa ter diferentes significados.

Em oposição à aprendizagem desatenta, LANGER (1989) apresentou as características da aprendizagem atenta (mindfulness), que são:

a) criação de novas categorias: processo natural que as crianças têm de categorizar e re-categorizar, rotular e re-rotular os fatos e fenômenos do mundo freqüentemente, sobrevivendo de modo adaptativo e dinâmico.

b) abertura para novas informações: de modo semelhante à capacidade para criar novas categorias, uma mentalidade atenta percebe novos estímulos, nota as variações no contexto e nos detalhes, tornando sua aprendizagem mais efetiva. 
c) percepção de mais de uma perspectiva: ter diferentes perspectivas sobre determinado ponto tem um efeito libertador da criatividade, aumentando nossas opções de ações.

$\mathrm{Na}$ TAB. 14 estão resumidas as características do pensamento atento (mindfulness):

TABELA 14. Pensamento atento (mindfulness)

\begin{tabular}{|c|l|}
\hline Fator & \multicolumn{1}{c|}{ Característica } \\
\hline 1 & $\begin{array}{l}\text { Criação de novas categorias. Processo cognitivo natural, } \\
\text { espontâneo, adaptativo e evolutivo que as crianças têm. }\end{array}$ \\
\hline 2 & $\begin{array}{l}\text { Abertura para novas informações. Processo de recepção } \\
\text { de novos estímulos, melhorando a aprendizagem. }\end{array}$ \\
\hline 3 & $\begin{array}{l}\text { Percepção de mais de uma perspectiva simultânea- } \\
\text { mente; amplia a criatividade e estimula diferentes } \\
\text { reações. }\end{array}$ \\
\hline
\end{tabular}

Fonte: (LANGER, 1989), adaptado pelo autor.

O pensar desatento é caracterizado pela aceitação e prática de idéias baseadas em pequenos comprometimentos cognitivos prematuros, e acaba formando uma mentalidade negativa que interfere diretamente nas ações da pessoa. Pensar de modo atento impede que prevaleçam as limitações decorrentes da aceitação de comprometimentos cognitivos prematuros.

Existem sete mitos penetrantes (do inglês pervasive) que se agregam negativamente em todos os aspectos da vida cognitiva da pessoa, enfraquecendo aspectos da aprendizagem, sufocando a criatividade, silenciando eventuais questionamentos e reduzindo a auto-estima.

De acordo com LANGER (1989), esses mitos são:

1) os assuntos básicos têm que ser aprendidos tão bem a ponto de tornaremse automáticos para a pessoa: esse aspecto pode ser melhor compreendido desdobrando-o em: 
1a) aprender muito cedo pode tornar-se um problema para a pessoa, na medida em que ela pode consolidar uma forma de pensar e agir inadequada para toda a vida, adquirida sob uma visão parcial da coisa aprendida.

1b) se a aprendizagem ocorrer de forma incondicional, o aprendiz pode perder (ou reduzir sensivelmente) sua capacidade futura de vislumbrar e testar alternativas para o assunto aprendido, tornando-se refém de pseudo-verdades que, dessa forma, podem the parecer imutáveis e absolutas. A aprendizagem ocorrida em momento mais maduro certamente envolverá incertezas, o que se constitui em uma aprendizagem mais aderente à realidade.

1c) o aprendiz precisa manter sua capacidade de aprendizagem aberta às novidades, alerta para eventuais distinções, sensível à possibilidade de mudança para outros contextos.

1d) o aprendiz precisa manter sua consciência, explicita ou implícita, das múltiplas perspectivas envolvidas em cada assunto, bem como uma orientação para o momento presente dos fatos, ou seja, deve estar ciente de que a solução encontrada pode ser a melhor até agora, mas pode não valer indeterminadamente no futuro.

2) prestar atenção significa permanecer focado em uma coisa de cada vez: essa é, para Langer, uma verdade altamente discutível, uma vez que a atenção do indivíduo pode ser positivamente desviada para outro fato ou conceito, que se interpõe com mais urgência para ela, e que merece ser levado em conta antes que ela retorne ao assunto inicial. LANGER (1997) destacou em seus trabalhos que:

Desde o jardim da infância, senão antes, nós todos somos alertados para prestarmos atenção. Embora ninguém sinta necessário explicar o que isso significa, nós gradualmente aprendemos que significa estar focalizado em um único assunto a cada vez. Se o nosso foco mudar, chamamos a isso distração.

Ao mesmo tempo, prestar atenção a vários fatos e fenômenos simultaneamente não é visto como uma desvantagem em outras situações. Pelo contrário, é considerado absolutamente normal, como quando se está dirigindo, ouvindo rádio, 
lendo outdoors, vendo os outros carros e a rodovia, conversando com alguém, tudo simultâneo e sem distração aparente.

Realizam-se várias ações simultaneamente e sempre, e essa é uma característica positiva de aparelho cognitivo humano, mas, por razões ainda pouco explicadas, comportar-se assim em salas de aulas tradicionais é encarado como um problema. Para LANGER (1989), as pessoas estão sempre em busca de novidades, daí a necessidade de uma aula variar os focos de atenção, seja para um novo objeto, seja para um novo assunto, para que a atividade seja bem sucedida.

Ela também argumenta que se espera dos alunos, erroneamente, um estado de hipervigilância ideal, havendo grandes problemas relacionados à síndrome de deficit de atenção e hiperatividade (ADHD), um distúrbio de comportamento detectado em até $7 \%$ das crianças e até $4 \%$ dos adultos, problemas esses que podem ser minimizados por meio adoção de uma perspectiva atenta (mindful) nas atividades de ensino e aprendizagem;

3) é importante retardar as gratificações: ela explica que trabalhar e estudar são vistos normalmente como atividades desagradáveis, e que são acompanhados também da idéia da gratificação ocorrendo apenas no futuro; a idéia normalmente presente é que, caso a pessoa aceite exercer agora atividades áridas ou árduas, tais como estudar ou trabalhar, uma recompensa virá no futuro, imediato ou remoto. $\mathrm{O}$ comportamento de buscar recompensas, gerado nas crianças, pode ser altamente decepcionante para elas, uma vez que é baseado em expectativas de que elas vão receber o que merecem, em um mundo que não se caracteriza por ser previsível.

Um exemplo é o de que, quando alguém se aproxima de uma atividade caracterizada como um jogo, o faz em geral de modo não avaliativo e mais agradável. E o que torna a atividade mais agradável é exatamente o processo de ir do desconhecido para o conhecido. Quanto mais opções existirem para percorrer esse caminho, mais agradável e atraente torna-se o jogo. Por outro lado, quando a mesma atividade é encarada como trabalho, tende a ser encarada como tediosa e, consequentemente, tende a ser rejeitada. 
4) memorizar é necessário em educação: esse mito é altamente prejudicial para atividades de ensino e aprendizagem e para a vida como um todo: estudantes pensam em passar em provas e testes desse modo, mas são incapazes de contextualizar o conteúdo aprendido por esse meio. E contextualizar é imprescindível. LANGER (1997) destacou em seus trabalhos que:

Pacotes fechados de informações são tomados como fatos. $E$ fatos são tomados como verdades absolutas, a serem aprendidas tal como são e a serem memorizadas, restando pouco espaço para raciocínio sobre eles. Sem qualquer raciocínio para "abrir o pacote", há poucas chances de que esses pacotes de informações vão conduzir a qualquer insight conceitual ou mesmo de que possam ser repensadas em outro contexto.

A escolha do caminho da memorização, no entanto, parece sobreviver nas escolas por diferentes razões:

a) os professores preferem avaliar seus alunos com base em material memorizado porque facilita suas avaliações;

b) acredita-se que certos assuntos (os considerados básicos) precisam ser aprendidos (memorizados) antes que outros;

c) há um sentido geral de que a aceitação das verdades básicas do mundo é necessária para manter a situação de estabilidade do mundo, o que quer que isso venha significar;

d) os atuais professores também foram ensinados por meio de memorizações, portanto consideram-na naturais, e tendem a ensinar do mesmo modo como foram ensinados.

LANGER (1997) argumentou que a memorização é uma tentativa de se aprender informações consideradas irrelevantes pelas pessoas, e defende que tornar as informações relevantes para a pessoa removeria a necessidade de memorização: assim elas seriam naturalmente incorporadas ao acervo de conhecimentos do aluno; 
5) esquecer é um problema: há uma verdade geralmente aceita de que esquecer algo é negativo e deve ser evitado. Para LANGER (1997), esquecer algo nos dá o prazer de re-experenciá-lo, e esquecer detalhes leva os indivíduos a recriá-los, às vezes com melhorias, a partir de cenários novamente concebidos. Mas também o "lembrar" pode ocorrer de dois modos:

a) atentamente (mindfully): caso em que a pessoa se habilita a ser sensível ao contexto e a notar as particularidades das circunstâncias presentes:

b) desatentamente (mindless/y): caso em que, por aceitar os fatos e fenômenos de modo desatento ou por tê-los apenas memorizado, tem-se mais dificuldades em encará-las como livres do contexto apresentado.

Quando lembramos de algo sem qualquer trabalho construtivo, quando meramente acessamos as informações na forma exata em que as arquivamos, há menor chances de nos sentirmos competentes. Isso está mais próximo da idéia de que satisfizemos algo no passado do que de nos sentirmos capazes de satisfazê-lo no momento presente. (LANGER, 1997)

A questão da memorização (e do esquecimento) tem ainda outra conotação negativa na mentalidade vigente: esquecer é visto como uma falha, como falta de inteligência ou como sinal de envelhecimento. Porque se aceita que o envelhecimento leva a condições orgânicas degradadas que conduzem ao esquecimento, o que é mais uma mentalidade do que uma verdade cientificamente comprovada. E, ela observa, as mentalidades são assim: uma vez aceito como tal, um fato dificilmente retorna para um processo de reconsideração e de reavaliação.

As rígidas mentalidades que se aceita sobre si mesmo afetam os desempenhos das pessoas, e as informações que thes dão forma são aceitas por elas despercebidamente em um período de suas vidas em que elas parecem ser irrelevantes para suas preocupações imediatas. De acordo com trabalhos de LANGER (1997): 
Crianças que não dão importância à escola podem aceitar avaliações negativas de suas habilidades. Mais tarde, quando se tornam cientes da importância dessas habilidades, aquelas avaliações já estão fixas em suas mentes. Nesse ponto, o dano já está concretizado. Essa mentalidade não é mais testada: ela é tratada como necessariamente verdadeira. E essa pode ser a forma como aceitamos o assim chamado inevitável declínio da memória que vem com a idade. Se formos levados a acreditar que temos memória frágil ou que somos estudantes fracos, essa mentalidade pode tornar-se uma profecia auto-realizável.

6) inteligência é conhecer o que já existe (ou conhecer os fatos como eles são): há um consenso de que se pode medir a inteligência pelo conhecimento que a pessoa tem sobre o que já está colocado, ou seja, pelo seu conhecimento da realidade externa já estabelecida. Muitas teorias da inteligência (senão todas) assumem que há uma realidade absoluta colocada, e, portanto, tanto maior a inteligência de alguém quanto maior sua consciência (ou adaptação) sobre essa realidade. LANGER (1997) afirmou que:

Uma visão alternativa, que é a base da pesquisa atenta (minduful), é que o indivíduo sempre pode definir sua relação com o ambiente de diversas maneiras, essencialmente criando a realidade externa. "O que já existe" é formatado pelo modo como o vemos.

A inteligência humana, vista por ela sob uma perspectiva evolucionária, é uma habilidade de reter e organizar percepções, que aumenta nossas chances de sobrevivência, e que as perspectivas impostas à nossa percepção não são construtos arbitrariamente criados, mas uma resposta adaptativa determinada pela evolução natural. Quanto mais nossos mapas conceituais correspondem às contingências de nosso meio ambiente, maiores nossas chances de sobrevivência.

Segundo trabalhos de LANGER (1997):

Em um estado atento (mindful), nós reconhecemos implicitamente que não existe uma perspectiva ótima que explica uma determinada situação. Portanto, nós não procuramos por uma resposta que corresponda à situação, mas reconhecemos que há mais de uma perspectiva em uma informação dada e realizamos uma escolha dentre elas.

7) somente há respostas corretas ou erradas: isso decorre da crença generalizada de que existem claramente o certo e o errado, de que a inteligência repousa na ênfase de que há experts que sabem tudo e que respondem 
sucintamente a qualquer pergunta. Há teóricos que assumem que o objetivo do processo educacional é equipar os estudantes para que atinjam uma meta préestabelecida e pré-especificada, o que é um equívoco, já que as metas dependem dos contextos, e um bom resultado em um determinado contexto pode não sê-lo em outro.

O mais importante é ensinar ao aluno um perfil de aprender a aprender, e que essa meta-habilidade pode ser percebida no estudante por meio de sua velocidade em aprender novas tarefas e sua habilidade em transferir um aprendizado específico para outras tarefas relacionadas.

Na TAB. 15 estão resumidas as diferenças entre inteligências e mindfullness:

TABELA 15. Diferenças entre inteligência e mindfullnes

\begin{tabular}{|l|l|}
\hline \multicolumn{1}{|c|}{ Inteligência } & \multicolumn{1}{|c|}{ Mindfullness } \\
\hline $\begin{array}{l}\text { Corresponde à realidade, por meio da } \\
\text { identificação de um ajuste ótimo entre o } \\
\text { indivíduo e o ambiente. }\end{array}$ & $\begin{array}{l}\text { Controla a realidade por meio da } \\
\text { identificação de várias perspectivas possíveis } \\
\text { a partir das quais qualquer situação pode ser } \\
\text { revista. }\end{array}$ \\
\hline $\begin{array}{l}\text { Um processo linear que se move do } \\
\text { problema para a resolução o mais rápido } \\
\text { possível. }\end{array}$ & $\begin{array}{l}\text { Um processo de dar um passo atrás a partir } \\
\text { tanto da perspectiva do problema quanto da } \\
\text { solução vislumbrada, para ver as situações } \\
\text { como novidade. }\end{array}$ \\
\hline $\begin{array}{l}\text { Um meio de se atingir resultados } \\
\text { desejados. }\end{array}$ & $\begin{array}{l}\text { Um processo por meio do qual significados } \\
\text { são atribuídos aos resultados. }\end{array}$ \\
\hline $\begin{array}{l}\text { Desenvolvida a partir da perspectiva de } \\
\text { observação de um expert, que focaliza } \\
\text { categorias estáveis. }\end{array}$ & $\begin{array}{l}\text { Desenvolvida a partir da habilidade de um } \\
\text { ator em exercitar controle pessoal sobre } \\
\text { perspectivas em mudança. }\end{array}$ \\
\hline $\begin{array}{l}\text { Depende dos fatos lembrados e das } \\
\text { habilidades aprendidas em contextos } \\
\text { que são percebidos, às vezes, como } \\
\text { novos. }\end{array}$ & $\begin{array}{l}\text { Depende da fluidez do conhecimento e das } \\
\text { habilidades em reconhecer as vantagens e } \\
\text { desvantagens de ambos. }\end{array}$ \\
\hline
\end{tabular}

Fonte: (LANGER, 1997), adaptado pelo autor.

O pensamento flexível é a essência da abordagem atenta (mindufulness), flexibilidade essa que também pode ser considerada uma qualidade do pensamento inteligente. Para ela, a inteligência consistiria em identificar as estratégias e procedimentos que refletem otimamente o contexto de um problema em particular, e a resposta de alguém a um problema não é uma tentativa de realizar a melhor escolha entre várias opções disponíveis, mas de criar opções. 
Os métodos de ensino tradicionais valorizam a resolução de problemas, ao invés de valorizarem a aquisição da meta-habilidade de aprender-a-aprender. Testes de inteligência continuam a ser aplicados com foco concentrado primeiramente nas habilidades de seccionar linhas ou avaliar diferentes volumes e, mais tarde, aplicálos à solução de problemas, mas melhor seria se enfatizassem a habilidade em adquirir novas habilidades.

Quando estudantes são avaliados dessa forma, não tem a oportunidade de escolher seus próprios objetivos, nem são autorizados a explorar processos que estão fora do repertório de processos apresentados pelos experts.

LANGER (1997) destacou que o processo de decisão atento (mindful), em oposição à tomada de decisões feita passivamente baseada em dados montados por outros, é um processo ativo de auto-definição, evitando as categorias fixas préestabelecidas por experts.

O processo atento (mindful) acolhe as incertezas, para aumentar as chances de pensamento criativo, ao contrário dos processos de ensino tradicionais, nos quais os estudantes são ensinados a ver os fatos como imutáveis, representantes de verdades incondicionais.

$\mathrm{Na}$ TAB. 16 estão resumidas características dos sete mitos penetrantes prejudiciais à cognição:

TABELA 16. Sete mitos penetrantes prejudiciais à cognição

\begin{tabular}{|c|c|}
\hline Mito & Característica \\
\hline 1 & $\begin{array}{c}\text { Os fundamentos devem ser aprendidos tão profundamente a ponto } \\
\text { de tornarem-se uma segunda natureza da pessoa }\end{array}$ \\
\hline 2 & Prestar atenção significa estar focado em uma coisa de cada vez \\
\hline 3 & É importante retardar as gratificações \\
\hline 4 & $\begin{array}{c}\text { Memorização é um fator essencial no processo de ensino e } \\
\text { aprendizagem }\end{array}$ \\
\hline 5 & Esquecer é um problema \\
\hline 6 & Inteligência é conhecer as coisas "exatamente como elas são" \\
\hline 7 & Existem somente respostas certas ou erradas \\
\hline
\end{tabular}

Fonte: (LANGER, 1997), adaptado pelo autor. 
A teoria mindful learning considera ainda que há três características inerentes a uma abordagem desatenta (mindless, no original), comumente presente em atividades de ensino e aprendizagem, prejudicando-as, e que devem ser combatidas. Também considera que há três características inerentes a uma abordagem atenta (mindful, no original) que são altamente desejáveis em atividades de ensino e aprendizagem, favorecendo-as, e que devem ser estimuladas.

Essas características são relacionadas na TAB. 17.

TABELA 17. Abordagem desatenta (mindless) versus abordagem atenta (mindfu)

\begin{tabular}{|c|c|c|}
\hline $\mathrm{N}$ & $\begin{array}{c}\text { Abordagem desatenta } \\
\text { (mindless) }\end{array}$ & $\begin{array}{c}\text { Ações para evitar abordagem desatenta } \\
\text { (mindless) }\end{array}$ \\
\hline 1 & $\begin{array}{c}\text { Classificação de novos } \\
\text { assuntos em categorias } \\
\text { antigas }\end{array}$ & $\begin{array}{c}\text { Lembrar sempre que novos assuntos } \\
\text { podem se enquadrar em novas categorias }\end{array}$ \\
\hline 2 & $\begin{array}{c}\text { Comportamento automático } \\
\text { que exclui atender a novos } \\
\text { sinais }\end{array}$ & $\begin{array}{c}\text { Reforçar sempre quais são os novos } \\
\text { sinais/fatores dos assuntos apresentados. } \\
\text { Apresentar links dinâmicos para assuntos } \\
\text { afins, criados semanalmente a partir de } \\
\text { pesquisas via Google. }\end{array}$ \\
\hline 3 & $\begin{array}{c}\text { Adoção de ações que } \\
\text { operam sob uma perspectiva } \\
\text { única }\end{array}$ & $\begin{array}{c}\text { Reforçar sempre quais são os novos } \\
\text { sinais/fatores dos assuntos apresentados. } \\
\text { Apresentar sempre diferentes perspectivas } \\
\text { simultaneamente. }\end{array}$ \\
\hline
\end{tabular}

Fonte: [LANGER, 1997], adaptado pelo autor.

\subsection{LABORATÓRIOS VIRTUAIS}

A partir da década de 90, as necessidades de aprendizagem ao longo de toda a vida, associadas às oportunidades criadas por novas mídias, como a Internet, levaram tanto educadores quanto desenvolvedores de materiais de aprendizagem a buscar alternativas que atendessem à crescente demanda de uma população heterogênea de alunos e, ao mesmo tempo, fizessem uso das facilidades da Internet.

De acordo com trabalhos de GUIMARÃES et al. (2003), os processos de ensino e aprendizagem adotados desde então têm buscado permitir acesso às experiências práticas para os educandos, mas um obstáculo nesse caminho é o alto requerimento 
de tempo e dinheiro para o planejamento e construção de laboratórios reais na maioria das instituições.

Lugares virtuais de aprendizagem, ou laboratórios virtuais, independentes de localização espacial e temporal, começaram então a ser desenvolvidos, a fim de complementar os laboratórios reais, especialmente visando economia de tempo e de investimento de recursos financeiros.

De acordo com CERNIAN et al. (2003), as funções principais dos LV são:

a) conectar alunos, aprendizes, professores, mentores (de universidades, instituições, empresas), formando grupos,

b) prover recursos individuais de tutoriais e de ajuda,

c) permitir o acesso a materiais de ensino e aprendizagem atualizados,

d) permitir acesso a dispositivos virtuais para realizar simulações experimentais virtuais, com fins de aprendizagem e/ou de pesquisa.

A importância estratégica do tema LV tem sido apontada em vários estudos e corroborada pela UNESCO desde os anos 90 como um fator crítico para um desenvolvimento científico sustentável, conforme indicado no Report of the Expert Meeting on Virtual Laboratories, organizado pelo International Institute of Theoretical and Applied Physics (IITP), no qual registrou-se os motivos, oportunidades e desafios englobados pelo tema. CANESSA et al. (2004) afirmou que esse relatório apontou para a importância internacional do assunto LV, em especial ao:

a) aferir o estado-da-arte e as tendências para o tema LV, identificando primordial-mente sua aplicabilidade para os países em desenvolvimento.

b) identificar como o conceito e recurso LV pode ser usado para apoiar diferentes atividades de capacitação e pesquisa que ocorrem em diversos lugares, a fim de extrair os melhores resultados possíveis do tema LV, tanto em atividades de nível teórico quanto de características práticas. 
c) identificar a relevância potencial das técnicas de LV aplicadas nas pesquisas e na solução de problemas ocorridos no desenvolvimento dos LV.

d) efetuar recomendações para ações em nível internacional para implantação de LV, em particular as relativas a países em desenvolvimento.

A UNESCO forneceu recursos ao Committee on Data for Science and Technology (CODATA), a fim de fomentar o interesse pelo tema LV e coordenar esforços de todas as regiões do planeta para disseminá-los, o que resultou em experiências bem sucedidas na implantação de vários LV.

O objetivo principal da implantação de um LV é criar uma alternativa tecnológica e metodológica para os estudantes e pesquisadores de países que não dispõem de laboratórios reais para assuntos equivalentes (e nunca substituir um laboratório real por um LV; no máximo, complementá-lo), levando-se em conta as dificuldades financeiras e orçamentárias dos países em desenvolvimento e iniciar novas formas de resolver problemas de desenvolvimento tecnológico.

Para CODATA (2000), "o LV representa um potencial para um novo paradigma (e uma nova cultura) da ciência, que pode produzir avanços inesperados entre pessoas quando elas compartilham funções cognitivas." Os fatores interrelacionados que determinam a eficácia e orientam a criação e implantação de LV, são:

a) as necessidades que os usuários têm de aprender os assuntos abordados pelo LV.

b) a definição dos parâmetros de controle dos experimentos a serem realizados.

c) haver disponibilidade da infra-estrutura de TIC para viabilizar e suportar a criação e o acesso ao LV.

d) o desenvolvimento de pessoal com capacitação técnica para implantação, utilização e manutenção dos LV. 


\subsubsection{CONTEXTUALIZAÇÃO DE LV}

CANESSA et al. (2004) definiram LV como "um espaço de trabalho eletrônico para colaboração à distância e experimentação em pesquisa ou outras atividades, para gerar e distribuir resultados usando tecnologias distribuídas de informação e de comunicação." UNESCO (2000) enfatizou que o tema laboratórios virtuais representa um potencial para um novo paradigma - e uma nova cultura - da ciência, que pode produzir conclusões antecipadas quando suas funções cognitivas são compartilhadas.

Os usuários de um LV podem ser agrupados sob três categorias: membros de comunidades médicas e científicas (profissionais que trabalham em hospitais ou assessoram médicos), cientistas da computação (em geral, desenvolvedores de soluções de TIC) e usuários da indústria, do comércio ou de instituições de ensino (detentores dos mais variados perfís).

Segundo trabalhos de FROITZHEIM e SIMIONI (1999), a implantação de LVs encontra-se em franca expansão atualmente, por vários motivos, dentre os quais eles citam que LV:

a) permitem o aumento de escala dos esforços de equipes de pesquisa;

b) favorecem a combinação de esforços de diferentes origens e fomentam participações regionais vindas de diferentes áreas do globo;

c) potencializam os benefícios decorrentes das junções de recursos humanos e expertises disponíveis;

d) permitem acesso compartilhado a instrumentos únicos ou exclusivos e fomentam a integração de países em desenvolvimento a esforços científicos internacionais, permitindo-Ihes investir esforços para evitar ou minimizar seu isolamento e/ou atraso tecnológico.

Na TAB. 18 são apresentados os benefícios obtidos com o uso de LV: 
TABELA 18. Benefícios obtidos com o uso de LV

\begin{tabular}{|c|c|}
\hline Benefício & Descrição \\
\hline $\begin{array}{c}\text { Alteração de escala de esforços } \\
\text { de equipes de pesquisa }\end{array}$ & $\begin{array}{c}\text { A colaboração simultânea de vários membros da equipe } \\
\text { faz com que o esforço individual seja minimizado. }\end{array}$ \\
\hline $\begin{array}{c}\text { Favorecimento à combinação de } \\
\text { esforços dentro das equipes } \\
\text { A presença de diferentes perfis favorece a sinergia } \\
\text { entre eles e colabora para maximizar os resultados. } \\
\text { Aumento nos benefícios na } \\
\text { formação de equipes de } \\
\text { pesquisadores }\end{array}$ & $\begin{array}{c}\text { Diferentes experiências acumuladas de diferentes } \\
\text { pesquisadores somam-se, aumentando o poder de } \\
\text { obter resultados. }\end{array}$ \\
\hline $\begin{array}{c}\text { Quebra de barreiras geográficas } \\
\text { Compartilhamento de equipa- } \\
\text { mentos }\end{array}$ & $\begin{array}{c}\text { A colaboração entre os membros das equipes dá-se de } \\
\text { modo online e real-time, superando limitações } \\
\text { geográficas. }\end{array}$ \\
\hline $\begin{array}{c}\text { É possível a interligação remota de equipamentos, } \\
\text { permitindo seu compartilhamento por mais } \\
\text { pesquisadores. }\end{array}$ \\
$\begin{array}{c}\text { participação de equipes e países/ } \\
\text { instituições de diferentes origens }\end{array}$ & $\begin{array}{c}\text { Quebra-se barreiras organizacionais e institucionais, } \\
\text { agilizando-se as pesquisas e ampliando-se a } \\
\text { capacidade de obtenção de resultados. }\end{array}$ \\
\hline
\end{tabular}

Fonte: (ALEXIOU et. al, 2006), adaptado pelo autor.

A necessidade de compartilhamento de dados científicos possibilitada pelos LV requer a disponibilização de uma infra-estrutura física que engloba computadores, redes de comunicação e diferentes tipos de hardwares e softwares, como equipamentos de telecomunicações e programas de bancos de dados.

Os princípios que orientam a criação e implantação de LV ancoram-se em uma vertente conceitual, que refere-se aos conteúdos disponibilizados por meio dos LV e à forma de usá-los; são princípios que apontam para os conceitos das principais teorias cognitivas, como teorias precursoras, de Piaget (epistemologia genética), de Bruner (construtivismo) e de Vygotsky (sócio-cultural), bem como apontam para teorias de Gardner (inteligências múltiplas) e de Ellen Langer (mindful learning), e para o tema CVE. A segunda vertente é a da infra-estrutura tecnológica requerida para implantar e usar um LV, que abrange conceitos relacionados a três temas:

a) sistemas colaborativos de documentos, com acesso a bancos de dados distribuídos disponíveis sobre a web. 
b) um sistema avançado de tele-conferência, integrando voz e vídeo em um sistema multi-usuário, com browsers e motores de pesquisa que facilitem a colaboração entre usuários e agentes inteligentes de software.

c) uma interface desktop avançada com acesso a diferentes sistemas operacionais e que possa representar elementos dos ambientes virtuais do mesmo modo para todos os usuários.

De acordo com os trabalhos de FROITZHEIM e SIMIONI (1999), um LV é baseado na comunicação envolvendo pesquisadores e na comunicação entre pesquisadores e seus objetos de pesquisa, podendo essa dar-se sob três classes:

1) de pessoa para pessoa: que incluem cenários muitos-para-muitos, que são tipicamente modelados sobre técnicas de interações humanas convencionais, tais como conversações, chamadas telefônicas, conferências, um livro, TV ou uma carta. Há vários serviços suportados por computador equivalentes a esses modelos. Alguns são síncronos, outros são assíncronos.

2) de pessoa para equipamento: ou de pessoa para experimento, nos casos em que os experimentos são operados por pessoas e as operações podem ser controladas remotamente. $O$ controle do equipamento pode ser executado interativamente, direta e sincronamente, por dispositivo ou execução de programa (denominado tele-operação) ou indireta ou assincronamente, por meio de programa ou rotina pré-definida (denominado teleprogramação).

3) de pessoa para metamáquina: metamáquina é o conceito de que projetos científicos serão, gradativamente, baseados em grandes bancos de dados distribuídos controlados por algoritmos e processados em computadores com acesso aos dados de uma biblioteca digital e sob controle computacional de uma infra-estrutura de comunicação embutida em um LV. Os dados residirão em grandes bancos de dados e serão explorados por algoritmos de extração sofisticados operando em ambientes distribuídos. 
Várias técnicas de comunicação e de manuseio de dados já estão em operação relativas à exploração de ambientes metamáquinas, tais como:

a) computação cliente-servidor, tais como o Common Object Request Broker Architecture (CORBA), Open Database Connectivity (ODBC) e Java Database Connectivity (JDBC).

b) operação remota de computadores e compartilhamento de aplicativos para operar supercomputadores remotamente.

c) tecnologias de agentes de software inteligentes, uma abordagem para operações de extração e filtragem de dados.

Na TAB. 19 são apresentadas as classes de comunicação dentro de um LV:

TABELA 19. Classes de comunicação dentro de um LV

\begin{tabular}{|c|l|}
\hline Classe de Comunicação & \multicolumn{1}{|c|}{ Conceito } \\
\hline DE PESSOA PARA PESSOA & $\begin{array}{l}\text { Envolvem comunicação entre pessoas, desde 1:1 até N:N, } \\
\text { utilizando várias técnicas de comunicação e vários suportes } \\
\text { e serviços. }\end{array}$ \\
\hline DE PESSOA PARA & $\begin{array}{l}\text { Envolvem a interação de pessoas com equipamentos, } \\
\text { direta ou remotamente, por meio alguma interface lógica ou } \\
\text { física, síncrona ou assincronamente. }\end{array}$ \\
\hline DEUIPAMENTO & $\begin{array}{l}\text { Envolvem pessoas, de um lado, e ambientes } \\
\text { metamáquinas, de outro, que são grandes bancos de dados } \\
\text { controlados por técnicas de comunicação e manipulação de } \\
\text { dados, como: CORBA, ODBC, JDBC. }\end{array}$ \\
\hline
\end{tabular}

Fonte: (CANESSA et al., 2005), adaptado pelo autor.

A segunda classe de comunicação, de pessoa para equipamento, ou de pessoa para experimento, abrange duas modalidades:

a) teleoperação: é uma abordagem síncrona e que pode dar-se de dois modos. No primeiro, o pesquisador transmite comandos, por intermédio da internet, para um computador que vai controlar equipamentos e experimentos e receber feedback desses e controlar o processo. No segundo modo, os comandos para os computadores que controlam os equipamentos e 
experimentos são de baixo nível (como: mova para a direita, coloque fluido, pare), caso em que o feedback torna-se mais importante para o controle do experimento;

b) teleprogramação: é uma abordagem assíncrona para a operação de equipamentos dentro de um LV, na qual os equipamentos usados no experimento usam programas previamente escritos (usando diversas linguagens de programação) e carregados neles, e os resultados da execução são analisados posteriormente pelos cientistas.

\subsubsection{ASPECTOS ESTRATÉGICOS DA UTILIZAÇÃO DE LV}

De acordo com trabalhos de KHALIFA e LAM (2002), a atividade de ensinar não está mais confinada no tempo e no espaço, porque, com o uso das TIC, professor e alunos podem estar em contato assincronamente e dispersos geograficamente.

A busca pela experiência prática quando se ensina/aprende é uma meta importante em qualquer processo educacional, porque, nesses casos, o aprendiz está diretamente envolvido com seu objeto de estudo, e consegue uma relação de conhecimento "na primeira pessoa", diferentemente de quando apenas ouve um professor falar a respeito de um assunto, sem poder "vivenciá-lo" na prática.

Um LV não resolve essa necessidade, mas, por intermédio dos recursos de simulações de RV, provê meios para que a experiência educacional do aprendiz seja de alto nível de "realismo" e de contextualização, criando nele a visualização de um modelo do assunto estudado.

Modelos são recortes da realidade, simulados por outras mídias e em outra escala, que fornecem ao aprendiz a possibilidade de serem percorridos ilimitadas vezes, permitindo-lhe aprender sobre o fenômeno que os modelos representam.

ALEXIOU et al. (2005) destacaram que, entre os vários benefícios disponibilizados pelos LV, tem-se que: 1) eles tornam real o compartilhamento de recursos, ampliando possibilidades de acesso a equipamentos caros; 2) facilitam o acesso a material educacional e de pesquisa tanto para profissionais quanto para estudantes; 3) ajudam a estabelecer padrões de pesquisa científica em áreas nas 
quais a experimentação é requerida; 4) reduzem os custos de locomoção e reduzem as ausências dos pesquisadores de seus locais de trabalho.

Para ALEXIOU et al. (2006), os benefícios do uso de LV são:

a) redução significativa de custos de montagem, quando comparados a laboratórios reais;

b) eventuais erros na operação de um LV não causam catástrofes, preservando os investimentos realizados e a vida de estudantes e profissionais;

c) a interação com o ambiente virtual motiva os usuários, especialmente os aprendizes, quando comparado com o ambiente real;

d) determinadas pesquisas e experimentos somente podem ser realizados em um LV, porque são simulações, pois não têm contrapartida real.

Na TAB. 20 estão resumidos esses benefícios:

TABELA 20. Benefícios do uso de LV

\begin{tabular}{|c|c|}
\hline Benefícios do uso de LV & Descrição \\
\hline REDUÇÃO DE CUSTOS & $\begin{array}{l}\text { Os investimentos para criação, operação e manutenção de um } \\
\text { LV são significativamente menores que para um laboratório real, } \\
\text { além da facilidade da troca de componentes, que são virtuais. }\end{array}$ \\
\hline $\begin{array}{l}\text { MINIMIZAÇÃO DOS } \\
\text { EFEITOS DE ERROS }\end{array}$ & $\begin{array}{c}\text { Alguns laboratórios reais podem representar altos riscos quanto } \\
\text { à integridade física dos pesquisadores, bem como quanto aos } \\
\text { efeitos danosos nas instalações, em caso de erros em processos } \\
\text { e acidentes. Esses riscos não existem em um LV. }\end{array}$ \\
\hline $\begin{array}{c}\text { MOTIVAČÃO DOS } \\
\text { USUARRIOS }\end{array}$ & $\begin{array}{c}\text { A redução de custos e eliminação dos efeitos em caso de erros, } \\
\text { além da possibilidade ilimitada de repetições, motiva os usuários } \\
\text { a interagirem continuamente com os LV. }\end{array}$ \\
\hline $\begin{array}{l}\text { VIABILIZA CERTAS } \\
\text { PESQUISAS }\end{array}$ & $\begin{array}{l}\text { Muitos estudos somente podem ser feitos por meio de } \\
\text { simuladores, devido ao seu alto custo, ou a sua escala de tempo } \\
\text { ser infinitamente pequena ou grande, ou devido ao grau de risco } \\
\text { envolvido. Além disso, o uso de LV elimina, em grande parte, a } \\
\text { burocracia normalmente envolvida em projetos reais. }\end{array}$ \\
\hline
\end{tabular}

Fonte: (CANESSA et al., 2005), adaptado pelo autor. 
LV podem ser implantados para três diferentes propósitos, constituindo três categorias gerais, que são:

a) LV grandes instalações: a motivação para sua implantação é ampliar as condições gerais para se realizar pesquisas científicas, provendo-se um local independente para acesso a instrumentos, manuseio de dados e processamento de análises.

b) LV científico geral: cuja meta de implantação é prover um local geral para pesquisa, comunicação e colaboração científica. Muitos desenvolvimentos científicos dependem mais do encontro de pessoas, para ensino e aprendizagem, do que de equipamentos, por isso a importância dos aspectos de comunicação dos LV.

c) LV orientado a projeto: o tipo de LV criado especificamente para atender um projeto, com cronograma e orçamento fixos. Nesse caso, após atingir as metas estabelecidas no início, o LV será fechado.

$\mathrm{Na}$ TAB. 21 estão resumidas as categorias dos LV:

TABELA 21. Categoria geral dos LV

\begin{tabular}{|c|c|}
\hline Categoria geral do LV & Descrição / Objetivo \\
\hline GRANDES INSTALAÇÕES & $\begin{array}{c}\text { Implantar condições para a realização de pesquisas } \\
\text { científicas pelo maior contingente possível de pesquisadores. }\end{array}$ \\
\hline CIENTÍFICO GERAL & $\begin{array}{c}\text { Prover local para pesquisa, comunicação e } \\
\text { colaboração contínua. }\end{array}$ \\
\hline ORIENTADO A PROJETO & $\begin{array}{c}\text { Atender projetos com características de cronograma e } \\
\text { orçamento fixos, independentemente do porte do projeto. }\end{array}$ \\
\hline
\end{tabular}

Fonte: (CANESSA et al., 2005), adaptado pelo autor.

Há dois tipos de abordagens para ambientes de treinamento baseados em recursos de TIC, em especial os focados nos recursos da Internet: 
a) laboratórios baseados em hardware: os que provêm acesso remoto a equipamentos reais, e são de particular interesse em áreas da engenharia, como mecânica, elétrica, sistemas de força, entre outros.

b) laboratórios baseados em software: os que devem efetivamente ser chamados de virtuais; são baseados em simulações, realizadas com recursos de software e de especial aplicabilidade em ciências da computação, tecnologias de computadores e engenharia de software.

No primeiro tipo, usuários acessam laboratórios reais a partir de outros locais usando controle remoto e sistemas de telepresença para executar os experimentos. No segundo, são usados simuladores de experimentos baseados em recursos de RV ou de instrumentos de laboratório.

Os LV são estratégicos especialmente para os países em desenvolvimento, porque podem ajudar a modelar como construir, divulgar e usar conhecimentos científicos. O processo de sua implantação leva esses países a enfrentarem e terem que desenvolver meios para superar dificuldades como as de:

a) infra-estrutura: especialmente as referentes a infra-estrutura de TIC, redes públicas e serviços públicos e privados de telecomunicações, quantidade de computadores per capita, largura de banda de transmissão de dados, backbones nacionais ou continentais, conexões de satélites e uma ampla gama de softwares necessários para criar ambientes avançados de RV.

b) habilidades técnicas: tanto nas áreas específicas de estudos quanto em TIC precisam ser fortemente desenvolvidas em países em desenvolvimento. Ainda que estejam presentes dentro das empresas comerciais particulares, esses conhecimentos precisam tornar-se mais disponíveis em instituições de ensino e de pesquisa.

c) acesso a informação: em que são críticos tanto os acessos quanto a compreensão de conteúdos tecnológicos em TIC e em ferramentas de geração de LV (predominantemente escritas em inglês), e as metas a serem atingidas 
são baixar o custo de acesso à informação, ampliar seu alcance e eliminar barreiras econômicas e culturais para acesso a informações científicas abertas.

De acordo com trabalhos de ALEXIOU et al. (2006), os LV são preferíveis aos laboratórios reais nos casos em que:

a) O processo de aprendizagem em um laboratório real possa colocar em risco a saúde ou a segurança dos envolvidos;

b) Alguns experimentos não possam ser realizados devido a limitações de tempo, de orçamento ou similares;

c) O custo de construção ou de manutenção do laboratório real seja proibitivo, ou seja, impossível alocar profissionais experientes;

d) Existam experimentos que apenas podem ser simulados em computadores, como decaimento radioativo, crescimento populacional, entre outros.

\subsection{ORIGENS DO PROJETO VIRRAD}

O consórcio VirRAD iniciou seus trabalhos com o suporte financeiro e o apoio estratégico da UNESCO, tendo por objetivo criar e manter um LV/CVE com recursos para fomentar atividades virtuais de comunicação, ensino e aprendizagem para a comunidade mundial de radiofarmácia.

Devido à disseminação das atividades relacionadas a pesquisas e a utilização médica de radioisótopos por vários países, nas últimas décadas, a comunidade de pessoas ligadas a esses assuntos está dispersa geograficamente ao redor do globo, e apresenta a característica marcante de congregar diferentes níveis de conhecimentos, habilidades, competências, formações culturais e acadêmicas, tais como: farmacêuticos, biólogos, radiofarmacêuticos, químicos, físicos, médicos, engenheiros nucleares, engenheiros em radiologia e técnicos de diversas áreas. 


\subsubsection{HISTÓRICO DO PROJETO VIRRAD}

As atividades para criação do portal web contendo recursos para ensino e aprendizagem em radiofarmácia por meio do VR LAB foram iniciadas dentro do projeto europeu VirRAD, em fevereiro de 2002, com a finalidade de cumprir as metas estabelecidas no programa de 2001 da Information Society Technologies (IST), um grupo de trabalho da Comunidade Européia, e visando atender às especificações técnicas da European Association of Nuclear Medicine (EANM).

O objetivo do Projeto VirRAD é prover um website, uma ágora virtual eletrônica utilizando intensivamente as TIC, e um LV 3D. Nesse website a comunidade internacional de profissionais e interessados em radiofarmácia pode encontrar-se virtual e ininterruptamente para aprender, ensinar, pesquisar bibliografias, identificar eventuais parceiros, trocar experiências, comunicar planos e realizações, publicar resultados, discutir melhores práticas e aperfeiçoar-se tecnicamente, visando desenvolver continuamente o campo de radiofarmácia. (VIRRAD, 2006)

A comunidade de radiofarmácia, como outras que congregam membros acadêmicos e científicos altamente especializados, é ainda pouco numerosa, além de estar geograficamente distribuída entre poucas instituições mas em vários países, o que the acarreta dificuldades de vários tipos, principalmente quanto às limitações de expansão da disseminação de conhecimentos originados por seus especialistas, dificuldades de contatos diretos entre especialistas e aprendizes e limitações de comunicação, motivos pelos quais a equipe do Projeto VirRAD buscou prover meios e recursos para solucionar os problemas causados por esses fatores.

Conforme estabelecido na missão do projeto, de acordo com o exposto em VIRRAD (2006), os objetivos básicos da plataforma VirRAD são:

a) prover meios para o compartilhamento de idéias e para a disseminação de melhores práticas de radiofarmácia;

b) permitir meios e recursos para facilitar a superação de obstáculos práticos enfrentados pela comunidade de radiofarmácia para aprender e comunicar-se e servir como suporte para a resolução de dificuldades rotineiras nessa área; 
c) suportar meios que ensejem e permitam o desenvolvimento de soluções inovadoras para problemas universais de radiofarmácia;

d) criar e manter uma plataforma de recursos para modalidades de ensino/aprendizagem e treinamento remotas;

e) promover a contínua contribuição de integrantes da comunidade de radiofarmácia para a ciência e para temas relativos aos cuidados com a saúde de todos.

Para atingir esses objetivos, um LV/CVE foi criado e colocado à disposição da comunidade de radiofarmácia, de modo a:

a) suprir as necessidades de fontes de informação para estudantes de radiofarmácia, por meio do fornecimento de materiais de ensino aderentes ao conteúdo programático estabelecido pela EANM;

b) estimular o desenvolvimento de capacidades e habilidades meta-cognitivas dos estudantes de radiofarmácia, juntamente com o estímulo ao desenvolvimento das habilidades de cada um de transferência de conhecimentos dentro do grupo e o incremento de sua capacidade de "aprender a aprender";

c) criar um ambiente de aprendizagem e uma comunidade com características tais que tende a maximizar a relação custo-efetividade de aprendizagem estabelecida como meta pelo Expert User Group.

Os aspectos tecnológicos orientadores na idealização e implantação do ambiente virtual do Projeto VirRAD, foram TIC, CMC e RV, e os aspectos-chave pedagógicos envolvidos consideraram a teoria Mindful Learning, de Langer.

\subsubsection{FUNDAMENTOS DO PROJETO VIRRAD}

Paralelamente à expansão da internet e da web, ocorrida nos anos 90, outras condições e recursos tecnológicos também evoluíram simultaneamente, como 
recursos (hardwares, softwares) da $\mathrm{RV}$, permitindo a criação e oferta de materiais de ensino e aprendizagem, em especial simuladores baseados em softwares, cada vez mais avançados e realistas.

A evolução dos recursos tecnológicos, por si só, no entanto, não basta para criar ambientes de ensino e aprendizagem eficazes, porque, para que isso se concretize, os recursos tecnológicos precisam estar a serviço de metodologias de ensino e abordagens cognitivas aderentes às características de ensino colaborativo.

No início do uso do computador e das TIC em processos de ensino/ aprendizagem, a partir da década de 50, o uso de tecnologia suportava uma aprendizagem baseada em recursos, ou $\mathrm{RBL}$, na qual o estudante seguia manuais pouco flexíveis que apresentavam os assuntos.

Expunha-se um tópico de forma esquemática, em seguida propunha-se uma série de perguntas, para serem respondidas por meio de testes de múltipla escolha, calculava-se o score obtido e permitia-se (ou não) ao aluno continuar para o próximo tópico, que seria estudado da mesma maneira. O foco de RBL estava na tecnologia (e não no aluno ou na aprendizagem) e que essa abordagem era aderente a uma visão behaviorista de ensino e aprendizagem.

Posteriormente, o enfoque RBL deu lugar a propostas focalizadas no aluno e na aprendizagem em grupo, denominados processos colaborativos, que passaram a valer-se de CVEs, onde o aprendiz pode interagir com outros dentro de um ambiente 3D virtual, onde ele pode incorporar um avatar.

É como se o aprendiz estivesse presente dentro do laboratório 3D, junto com os outros pesquisadores. Mas é importante salientar que o que se realiza dentro do LV 3D do CVE VirRAD é o treinamento de operações e procedimentos padronizados já existentes em laboratórios reais de radiofarmácia, e não atividades de pesquisa e de criação de novos procedimentos, o que poderá ocorrer no futuro.

Um projeto anterior ao VirRAD, com esforços direcionados a objetivos semelhantes, foi o C-Visions, que criou um CVE para suportar aprendizagem colaborativa interativa baseada em redes e usando simulações virtuais, desenvolvido por Chee \& Hooi, cujo design foi baseado em aprendizagem ativa e experimental, 
cuja meta era permitir condições para os alunos terem uma aprendizagem na primeira pessoa. De acordo com os trabalhos de CHEE e HOI (2002):

Nós explanamos o poder potencial da aprendizagem baseada em RV, especialmente com relação à mudança da perspectiva do aprendiz, de uma perspectiva de educação na terceira pessoa, impessoal, para uma perspectiva incorporada, usando a tecnologia para reificar conceitos a serem aprendidos, e provendo sustentação para auxiliar estudantes em sua transição de aprendizagem baseada em experimentos para modos mais simbólicos e abstratos de aprendizagem.

BOURAS et al. (2000) apontaram que o desenvolvimento do sistema VirRAD o dividiu em quatro áreas principais:

1) Public website: parte do site aberta a todos e que apresenta o projeto;

2) Community: parte do website que provê meios para que a comunidade comunique-se e troque informações;

3) Instructional component: parte que facilita a interação entre aprendizes, autores, mentores, e que engloba o LV do projeto;

4) Project internal site: recurso que permite a comunicação interna entre os administradores do sistema.

A plataforma do VirRAD é dividida em três partes, independentes mas complementares e disponíveis dentro do website VirRAD, que caracteriza-se por ser aberta à participação de qualquer interessado (basta o usuário cadastrar-se online). Essas partes são:

a) a comunidade virtual de aprendizagem e de relacionamento: com recursos de comunicação interligando todos a todos (multicast). Os fóruns de discussão são o foco do processo de comunicação, que também inclui painel de avisos, links para outras páginas úteis, documentos eletrônicos para download e um glossário de termos técnicos especializados em radiofarmácia. 
b) os recursos de aprendizagem multimídia: contidos dentro do material de curso, que abrangem vídeo, texto, diagramas e animações, com procedimentos técnicos em radiofarmácia.

c) o laboratório de radiofarmácia virtual 3D: um ambiente de RV que permite ao usuário executar os procedimentos de capacitação em radiofarmácia, por meio de simulações avançadas, podendo realizar, entre outros procedimentos: eluição de geradores, preparação de kits, dispensa de doses, execução de controle de qualidade.

Na TAB. 22 são apresentadas as partes do ambiente VirRAD:

TABELA 22. Partes do ambiente VirRAD

\begin{tabular}{|c|c|}
\hline Parte & Conteúdo \\
\hline $\begin{array}{l}\text { COMUNIDADE } \\
\text { VIRTUAL DE } \\
\text { APRENDIZAGEM }\end{array}$ & $\begin{array}{l}\text { - } \text { Recursos de comunicação multicast. } \\
\text { - } \text { Póruns de discussão. } \\
\text { - } \text { Processos de comunicação. } \\
\end{array}$ \\
\hline $\begin{array}{l}\text { RECURSOS DE } \\
\text { APRENDIZAGEM } \\
\text { MULTIMÍDIA }\end{array}$ & $\begin{array}{l}\text { : } \text { Vídeos. } \\
\text { - } \text { Textos. } \\
\text { - Animações. }\end{array}$ \\
\hline LV & $\begin{array}{l}\text { - Simulações 3D. } \\
\text { - Realização de procedimentos de radiofarmácia. }\end{array}$ \\
\hline
\end{tabular}

Fonte: (VIRRAD, 2006), adaptado pelo autor.

A representação do usuário, dentro do LV, por meio de um avatar, cumpre várias funções importantes, como:

a) a incorporação/integração do usuário ao CVE de forma dinâmica e interativa;

b) permite meios de interação dinâmica do usuário com o ambiente virtual e com outros avatares;

c) permite ao usuário "sentir" vários atributos do ambiente virtual onde ele se encontra e age. 
De acordo com os trabalhos de THALMANN (2004), o principal objetivo de um ambiente CVE, do ponto de vista de interação do usuário, é sintetizar o efeito desejado de movimento do usuário, por meio de uma mistura do movimento natural, sua percepção e imaginação.

\subsubsection{CARACTERÍSTICAS DO LV 3D VirRAD}

De acordo com o enunciado em VIRRAD (2006), o LV/CVE VirRAD foi criado com o objetivo de suportar uma comunidade virtual para facilitar a comunicação entre todos os membros da comunidade mundial de radiofarmácia e para auxiliá-los a:

a) compartilhar idéias e disseminar melhores práticas;

b) superar obstáculos práticos e solucionar dificuldades diárias;

c) desenvolver soluções inovadoras para problemas universais;

d) criar um recurso para aprendizagem remota;

e) promover a contribuição contínua para a especialidade da ciência e dos cuidados com a saúde.

As funcionalidades do sistema VirRAD são divididas em quatro grupos:

a) para administrar o sistema: funções para os trabalhos de administração dos usuários, de seus perfís e direitos, e dos serviços oferecidos pelo sistema.

b) para a comunidade VirRAD: as usadas para comunicação e troca de informações científicas e profissionais entre os membros da comunidade internacional de radiofarmácia representada.

c) de $R V 3 D$ do laboratório virtual VirRAD: facilidades de simulações baseadas em RV usadas para realizar procedimentos específicos de radiofarmácia dentro do laboratório virtual 3D. 
d) de acesso a conteúdos de curso VirRAD: são as utilizadas para acessar conteúdos convencionais (os implantados fora do ambiente de RV) tais como textos, figuras, diagramas; para efetuar upload de novos materiais de aprendizagem e para requisitar feedback a mentores de modo assíncrono.

Em seu aspecto de infra-estrutura, o 3D VR LAB é processado em pelo menos dois computadores, cada um com um ou mais processadores: o servidor, onde são processados os programas de controle de acesso de usuários remotos (serviços web e de multi-usuários) e de gerenciamento dos recursos do servidor, em especial seu banco de dados centralizado; e outro computador é o do usuário, onde é processado o web browser por meio do qual esse acessa os serviços do servidor, com o qual ele se comunica usando protocolos web (RMTP, HTTP). Na FIG. 3 é exibido o esquema da arquitetura física e lógica do 3D VR LAB. 


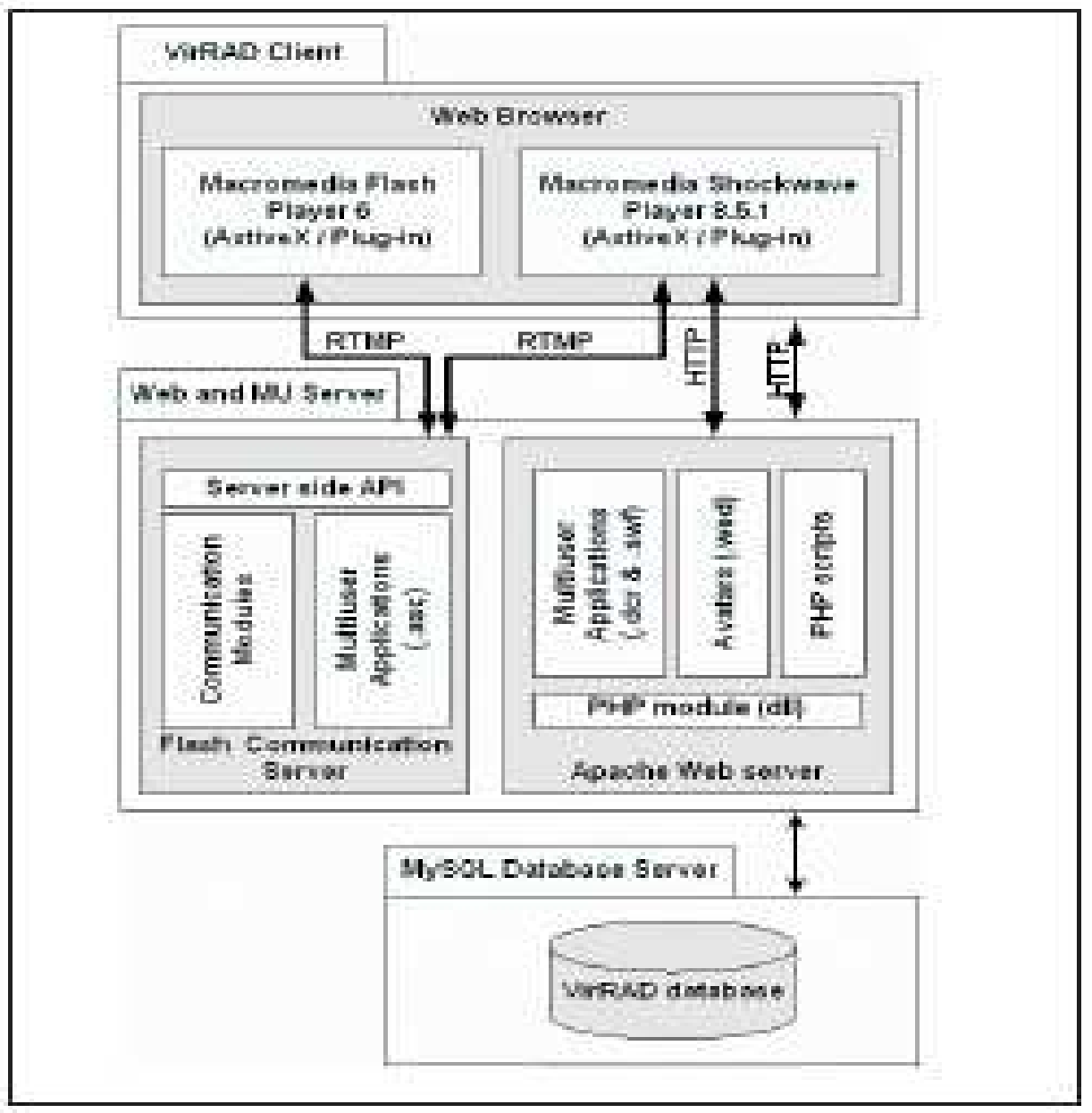

Figura 3. Arquitetura do LV VirRAD.

Fonte: (VIRRAD, 2006)

O 3D VR LAB suporta dois modos de interação:

a) o modo de estudos mono-usuário: no qual o avatar do usuário realiza suas tarefas sozinho, seguindo procedimentos que o guiam.

b) o modo multi-usuário: o avatar pode confrontar-se com outros aprendizes e interagir com eles por meio de gestos, textos ou áudio chats.

ALEXIOU et al. (2005) indicou que a interface colocada à disposição do aluno divide-se em quatro áreas ou funcionalidades: 
a) área 3D: um retângulo com a imagem digitalizada do laboratório 3D.

b) área de pontos de vista: um retângulo imediatamente abaixo e à esquerda da área 3D, contendo os modos de pontos de vista possíveis para serem selecionados pelo usuário.

c) área de descrição de objetos: um retângulo abaixo e à direita da área 3D, na qual o usuário pode ver o nome do objeto que seu mouse aponta.

d) área de feedback: um retângulo abaixo da área de descrição de objetos, na qual o sistema exibe textos variáveis informando ao usuário as conseqüências de suas ações dentro do 3D VR LAB.

Na FIG. 4 é exibida a tela do LV em modo de estudo mono-usuário, destacando-se também que podem ser visualizadas as mãos do avatar (o que representa uma visão default), e são fornecidos exemplos de objetos que podem ser visualizados.

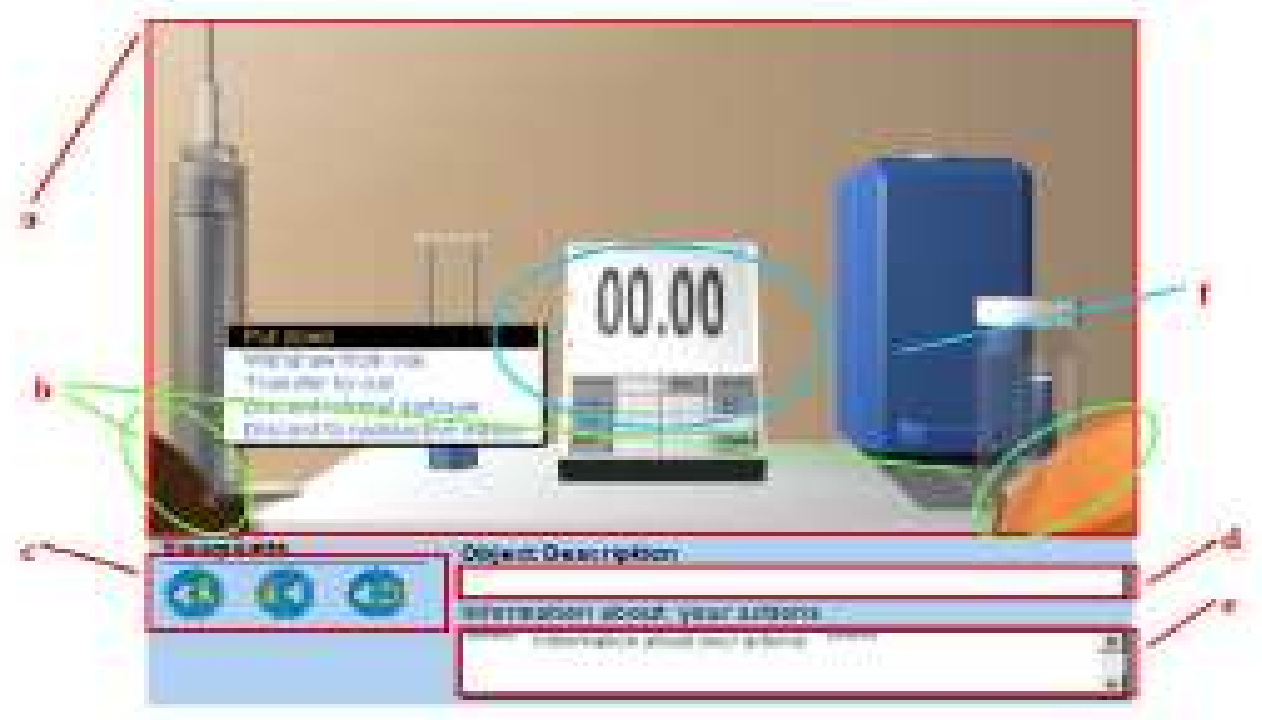

FIGURA 4. LV em modo de estudo mono-usuário

Fonte: (VIRRAD, 2006) 
No modo multi-usuário, o 3D VR LAB oferece funcionalidades semelhantes às do modo mono-usuário, porém com uma diferença fundamental: o usuário pode encontrar avatares que representam outros usuários ou mentores, com os quais pode comunicar-se usando recursos de voz e/ou de texto (chat).

$\mathrm{Na}$ interação com outros avatares, o usuário pode pedir permissão para acompanhar o trabalho que está realizando, ou conceder permissão, o que potencializa as condições para aprendizagem colaborativa.

A interface colocada à disposição do aluno no modo mono-usuário divide-se em seis áreas ou funcionalidades:

a) área 3D: um retângulo com a imagem digitalizada do laboratório 3D, onde ele pode visualizar os avatares de outros alunos ou mentores presentes.

b) área de pontos de vista: com localização e funcionalidades semelhantes às do modo mono-usuário.

c) área de descrição de objetos: com localização e funcionalidades semelhantes às do modo mono-usuário.

d) área de feedback: com localização e funcionalidades semelhantes às do modo mono-usuário.

e) área de gestos: um retângulo imediatamente abaixo da área de pontos de vista, na qual o aluno pode selecionar o ícone referente ao gesto que ele quer fazer para outro avatar que esteja compartilhando com ele o 3D VR LAB.

f) áreas de usuários online, de texto para chat e de voz: são três áreas idênticas empilhadas, situadas à direita da área 3D. (ALEXIOU, 2005)

Na FIG. 5 é exibida a tela do LV em modo de estudo multi-usuário. Nela, as áreas disponíveis para o usuário são:

a) área 3D: que oferece funcionalidade similar à do LV em modo de estudos. 
b) de gestos: área de pontos de vista, na qual o aluno pode selecionar o ícone referente ao gesto que ele quer fazer para outro avatar que esteja compartilhando com ele o 3D VR LAB.

c) área de pontos de vista: que oferece funcionalidade semelhante ao seu equivalente no modo de estudo mono-usuário.

d) área de descrição de objetos: idem ao modo mono-usuário.

e) feedback do sistema: onde o sistema retorna ao usuário orientações sobre conseqüências de suas ações.

f) representação de objetos do laboratório: onde está representado parte do acervo do 3D VR Lab.

g) área de gestos: área onde o usuário pode selecionar gestos para usar por meio de seu avatar.

h) área de usuários online: relação dos usuários que estão online no sistema nesse momento.

i e j) área de textos e de voz para chat: onde ficam registrados os textos trocados entre os usuários do sistema no momento. 


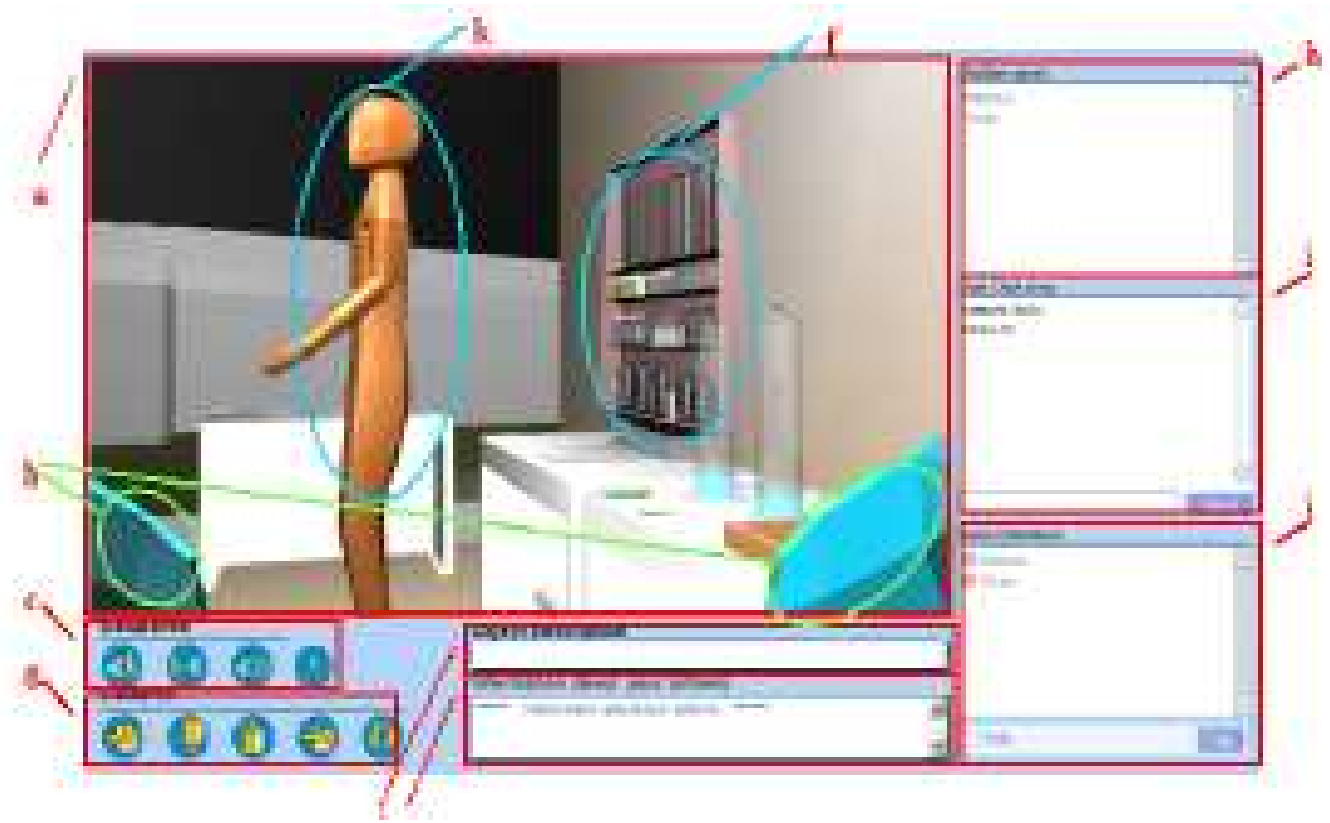

FIGURA 5. LV em modo de estudo multi-usuário Fonte: (VIRRAD, 2006)

\subsection{VANTAGENS DA UTILIZAÇÃO DO VIRRAD}

A utilização de um recurso de comunicação, ensino e aprendizagem com as características como as do VirRAD pela comunidade brasileira de radiofarmácia traz para seus membros as seguintes vantagens:

1. permitir o treinamento de técnicos e profissionais de radiofarmácia sem manipulação direta de material radioativo, evitando erros e seus efeitos sobre pessoas, equipamentos e meio ambiente, principalmente no que diz respeito a contaminações e doses de radiação recebidas pelos operadores.

2. acesso fácil, rápido e econômico a um espaço tecnológico-simbólico para simulações, colaboração e experimentação à distância, para pesquisas ou outras atividades criativas.

3. sua implantação representa significativa redução de investimentos, já que seu custo representa uma fração do custo de um laboratório real, e muitas das 
atividades de capacitação e treinamento de pessoal podem ser feitas no laboratório virtual ao invés de no laboratório real.

4. disponibilidade de um ambiente experimental virtual para analisar e demonstrar conceitos que não podem ser vistos e analisados, rápida e facilmente, por meio de laboratórios reais.

5. contato dos interessados com a modalidade da aprendizagem por experimentação, ou na primeira pessoa, estimulando as características de aprendizagem do tipo construção do conhecimento.

6. proporciona meios para o desenvolvimento do tipo de aprendizagem colaborativa, estimulando e fomentando a capacitação individual de pesquisa e a troca de experiências.

7. integra e aproxima a comunidade brasileira de radiofarmácia ao ambiente internacional VirRAD, cujo escopo é mundial, podendo, ao mesmo tempo, implementar módulos de escopo/interesses mais especificamente brasileiros.

8. permitem simulações de fenômenos difíceis de visualizar, seja por limitações devido à escala de tempo, a custos, a periculosidade, entre outros.

9. alta capacidade de absorção de erros em atividades de laboratórios, uma vez que problemas nos experimentos não danificam equipamentos, meio ambiente ou saúde dos envolvidos.

10. motiva estudantes e pesquisadores envolvidos a buscarem contato posterior com o laboratório real.

Ressalte-se também que utilização de um recurso como o VirRAD pela comunidade brasileira de radiofarmácia tem ainda os seguintes efeitos agregados:

1. um LV é uma alternativa tecnológica e metodológica para estudantes e pesquisadores de países e instituições que não dispõem de laboratórios reais. 
2. tem o seu potencial de utilidade e eficácia aumentado quando é implantado em conjunto com ambientes colaborativos virtuais (CVE).

3. LV/CVE podem representar um novo paradigma de comunicação, ensino e aprendizagem (a união de mundos virtuais com laboratórios reais), acelerar descobertas e beneficiar estudantes, instituições e pesquisadores. 


\section{METODOLOGIA}

Optou-se, neste trabalho, quanto à natureza da pesquisa, pela pesquisa exploratória (ao invés de se escolher a pesquisa descritiva), porque essa busca primeiramente aprimorar a familiaridade do pesquisador com o problema focalizado.

Quanto ao método de pesquisa, optou-se pelo estudo de caso (ao invés da opção por pesquisa documental ou pesquisa de campo), porque a mesma aborda casos reais, tratados em campo, diretamente onde ocorrem, mas utilizando uma amostragem reduzida.

Quanto ao tipo de pesquisa, optou-se pela pesquisa qualitativa, porque essa busca explicitar o conhecimento associado à expressão conceitual (e não numérica) dos fatos, ao invés de optar-se pela pesquisa quantitativa ou semi-quantitativa.

De acordo com RICHARDSON (1999), a escolha da natureza de pesquisa exploratória é normalmente realizada nos casos em que o fenômeno sob estudos é atual e ainda foi pouco examinado pela comunidade científica, e que visam descobrir as semelhanças entre fenômenos quando os pressupostos teóricos não estão claros, ou são difíceis de encontrar, realizando-se uma pesquisa exploratória não apenas para conhecer o tipo de relação existente, mas, sobretudo para determinar a existência da relação.

Segundo trabalhos de GIL (2002), a pesquisa de natureza exploratória cumpre três objetivos:

a) visa proporcionar maior familiaridade do pesquisador com o problema;

b) objetiva o aprimoramento de idéias ou a descoberta de intuições do pesquisador com relação ao problema estudado;

c) é flexível e possibilita a consideração dos mais variados aspectos relativos ao fenômeno estudado.

Optou-se pelo método de pesquisa do estudo de caso, um método amplamente utilizado nas ciências biomédicas e sociais, mais característico do tipo de pesquisas qualitativas (não-tradicionais) do que de pesquisas quantitativas 
(tradicionais), e considerado por diferentes autores como o mais adequado para investigar acontecimentos contemporâneos.

Para YIN (2001), o método de pesquisa estudo de caso representa uma investigação empírica e compreende uma abordagem abrangente, abarcando a lógica do planejamento, da coleta e da análise dos dados, e pode incluir tanto estudos de caso único quanto de casos múltiplos.

Esse autor também enfatiza a importância da correta aplicação do protocolo de pesquisa, que define a seqüência de atividades a serem desenvolvidas para se estudar o tema, de modo a aumentar a confiabilidade da pesquisa. O protocolo de pesquisa aplicado neste trabalho abrangeu as seguintes etapas:

1) destaque da relevância do tema (apresentada em 1.1);

2) revisão da literatura (apresentada em 3.);

3) detalhamento do tema (apresentada em 3.2 a 3.8);

4) critérios de seleção da amostra (apresentada em 4.);

5) a estratégia de condução do estudo (apresentada em 4.);

6) a análise dos dados (apresentada em 6.);

7) as conclusões do trabalho (apresentadas em 8.);

8) as sugestões para trabalhos futuros (apresentada em 8.1)

O ambiente LV/CVE VirRAD é utilizado por aproximadamente 1.500 (hum mil e quinhentos) usuários, originários de vários países (novas adesões ocorrem semanalmente), com predomínio da presença de usuários localizados em países europeus, todos ligados diretamente à especialidade de radiofarmácia. Ainda é pequena a participação de usuários brasileiros e sul-americanos,

É um ambiente on-line, real-time, interativo, dinâmico e conversacional, que apresenta como características tecnológicas os aspectos apresentados no tópico 1.3 deste trabalho. 
Para a coleta dos dados, foi elaborado um instrumento de pesquisa do tipo questionário de respostas fechadas (de múltipla escolha), contendo 59 (cinqüenta e nove) questões, sem identificação do respondente, que foi colocado à disposição, no período entre outubro a dezembro de 2008, em modo on-line no endereço eletrônico da web:

$$
\text { http://chvp-survey.net/index.php?sid=55651\&newtest }=Y
$$

Solicitou-se, por e-mail, a todos os usuários do ambiente, que acessassem o questionário em modo on-line e o respondessem, e foram coletadas respostas de 46 (quarenta e seis) usuários, sendo que o critério de escolha dos respondentes foi unicamente pertencerem ao universo de usuários ativos do LV/CVE VirRAD, independentemente de qualquer outra característica.

A estratégia utilizada para informar e sensibilizar os possíveis respondentes do questionário foi:

a) primeiramente, informar dois dos administradores do ambiente VirRAD (Dr. Steve Mather e Dra. Jane Sosabowski) sobre as características e propósito da pesquisa;

b) em seguida, foram contatados dezenas de usuários, por meio de e- mail, explicando resumidamente a pesquisa e solicitando suas respostas;

c) na sequência, 46 (quarenta e seis) dos usuários contatados responderam espontaneamente ao questionário, em momentos diferentes e independentemente uns dos outros;

d) as respostas foram automaticamente armazenadas pelo aplicativo Limesurvey, um software freeware disponível na web;

e) como última ação, o autor deste trabalho coletou, tabulou e reduziu os dados disponíveis no banco de dados do aplicativo, e cujos resultados são mostrados neste capítulo. 
O questionário foi dividido em quatro seções, a fim de agrupar questões afins, conforme mostrado na TAB. 23:

TABELA 23. Estrutura do questionário aplicado

\begin{tabular}{|c|c|c|c|c|}
\hline Seção & Objetivo & Descrição & $\begin{array}{l}\text { Ques } \\
\text { tões }\end{array}$ & $\begin{array}{l}\text { Nume- } \\
\text { ração }\end{array}$ \\
\hline 1 & $\begin{array}{l}\text { Identificação do } \\
\text { respondente }\end{array}$ & $\begin{array}{l}\text { Questões visando colher dados } \\
\text { pessoais dos respondentes: gênero, } \\
\text { idade, formação superior, ocupação, } \\
\text { tempo de carreira, visando utilizá-los } \\
\text { para caracterizar os respondentes. }\end{array}$ & 5 & \\
\hline 2 & $\begin{array}{l}\text { Coleta de dados } \\
\text { sobre perfil } \\
\text { cognitivo - parte } \\
1\end{array}$ & $\begin{array}{l}\text { Questões visando colher dados sobre } \\
\text { o perfil cognitivo dos usuários, com } \\
\text { base na teoria cognitiva das } \\
\text { Inteligências Múltiplas, de Howard } \\
\text { Gardner. }\end{array}$ & 24 & $\begin{array}{c}\text { MI01 } \\
\text { A } \\
\text { MI24 }\end{array}$ \\
\hline 3 & $\begin{array}{l}\text { Coleta de dados } \\
\text { sobre perfil } \\
\text { cognitivo - parte } \\
2\end{array}$ & $\begin{array}{l}\text { Questões visando colher dados sobre } \\
\text { o perfil cognitivo dos usuários, com } \\
\text { base na teoria cognitiva Mindful } \\
\text { learning, de Ellen Langer. }\end{array}$ & 17 & $\begin{array}{c}\text { ML01 } \\
\text { A } \\
\text { ML17 }\end{array}$ \\
\hline 4 & $\begin{array}{l}\text { Coleta de dados } \\
\text { sobre aspectos } \\
\text { tecnológicos do } \\
\text { LV/CVE VirRAD }\end{array}$ & $\begin{array}{l}\text { Questões visando colher dados sobre } \\
\text { a percepção dos aspectos } \\
\text { tecnológicos referentes a CMC e RV } \\
\text { envolvidos no LV/CVE VirRAD. }\end{array}$ & 13 & $\begin{array}{c}\text { VR01 } \\
A \\
\text { VR13 }\end{array}$ \\
\hline & & Total de questões & 59 & \\
\hline
\end{tabular}

Fonte: desenvolvido pelo autor

O questionário montado para a realização deste estudo de caso contem, no seu início, perguntas sobre cinco características visando descobrir/mostrar o perfil pessoal dos usuários do LV/CVE VirRAD, dados esses que podem ser cruzados com os demais dados obtidos, a fim de reforçar as características cognitivas observadas nesses usuários. As cinco características pessoais cujos dados foram levantados para estudo foram: gênero, idade, formação/curso superior, ocupação profissional e tempo de carreira profissional.

Em segundo lugar, foram levantados dados para analisar o perfil cognitivo do usuário, sob a perspectiva da teoria das inteligências múltiplas, de Howard Gardner (questões MI01 a MI24). 
Em terceiro lugar, levantaram-se dados para analisar o perfil cognitivo desses usuários, desta vez sob a perspectiva da teoria mindful learning, de Ellen Langer (questões ML01 a ML17).

Para finalizar, em quarto lugar, também se levantou dados sobre impressões/opiniões desses usuários sobre os aspectos tecnológicos contidos no ambiente LV/CVE VirRAD, referentes a TIC, CMC e RV (questões VR01 a VR14).

A análise dos dados coletados nos permitiu obter as conclusões apresentadas nesse trabalho, bem como incorporá-las ao protótipo de LV/CVE proposto. 


\section{RESULTADOS DO ESTUDO DE CASO}

Neste capítulo são apresentados os resultados obtidos por meio de uma pesquisa exploratória realizada junto aos usuários do LV/CVE VirRAD, a fim de conhecer seus perfis pessoais, suas características cognitivas e preferências tecnológicas, visando orientar a proposição de um ambiente LV/CVE que incorpore as características adequadas para satisfazer as necessidades detectadas.

\subsection{PERFIL PESSOAL DOS USUÁRIOS DO LV/CVE VirRAD}

Na FIG. 6 é exibida a distribuição de freqüência, que mostra que 52,2\%, dos usuários do LV/CVE VirRAD são do sexo masculino e 47,8\% são do sexo feminino.

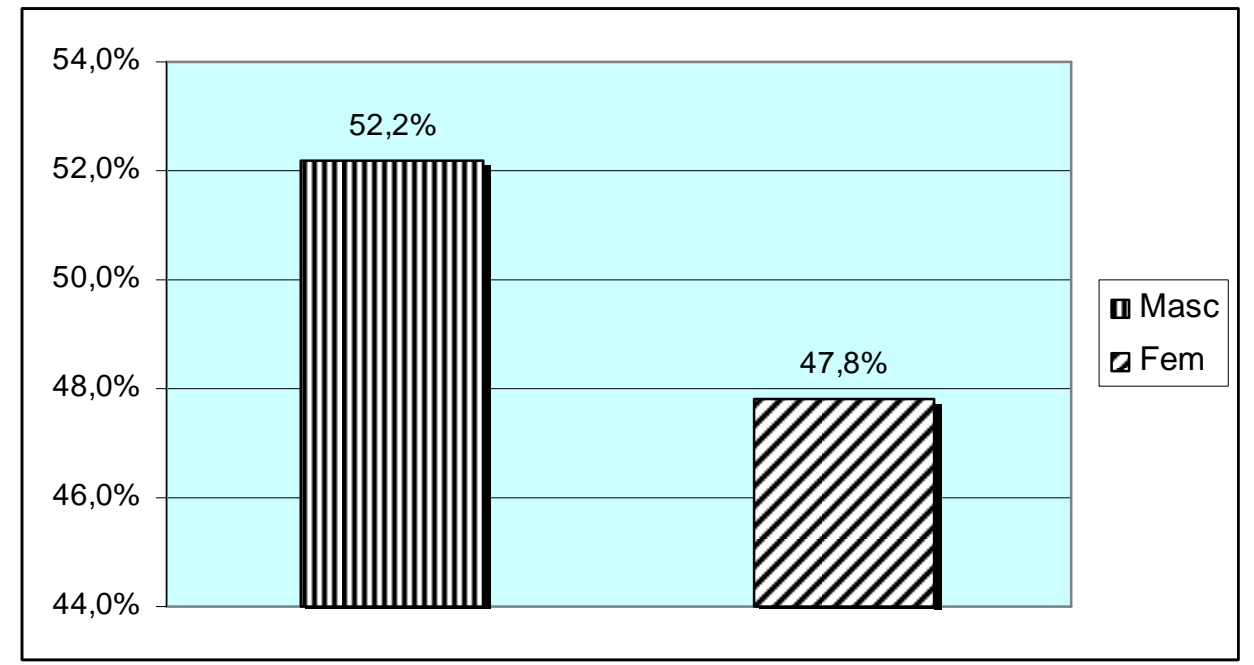

FIGURA 6. Gênero dos usuários do LV/CVE VirRAD

Quanto às suas idades (e faixas etárias), na FIG. 7 é mostrado que 2,2\% dos usuários são menores de 21 anos; 39,1\% têm idade entre 21 a 40 anos; 50,0\% têm entre 41 a 60 anos; e 8,7\% têm acima de 60 anos. 


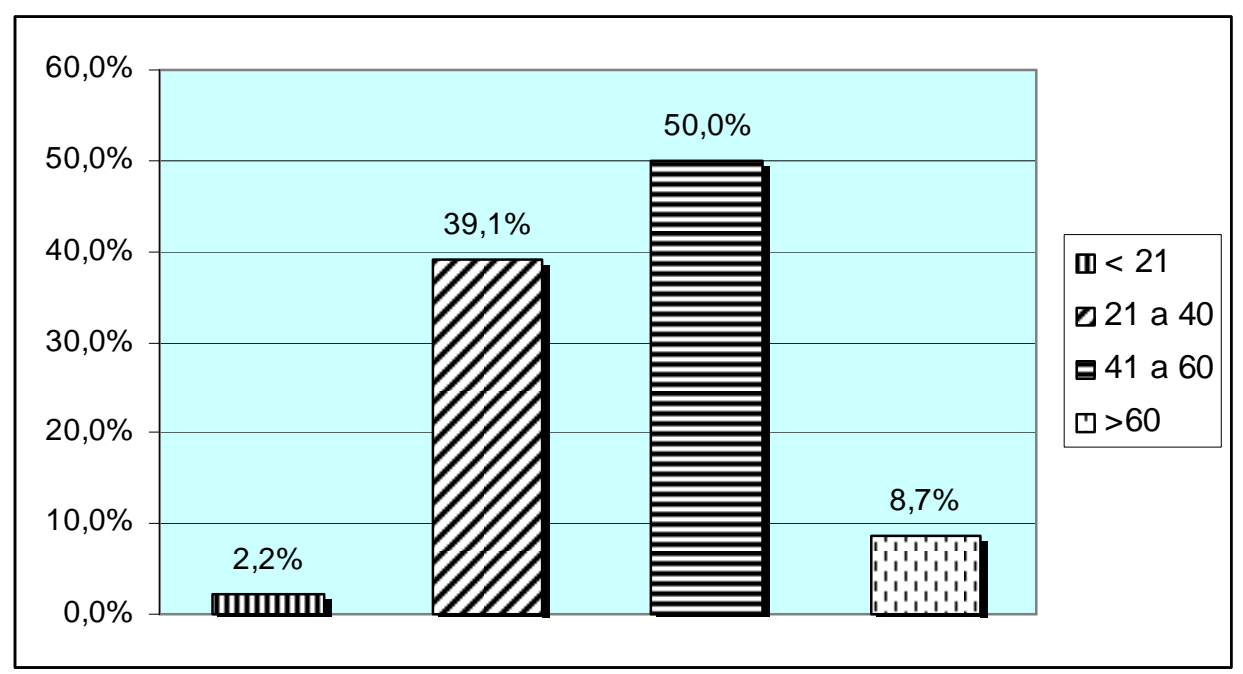

FIGURA 7. Faixas etárias dos usuários do LV/CVE VirRAD

Conforme mostrado na FIG. 8, quatro grupos concentram as principais formações acadêmicas: 30,4\% têm formação em engenharia ou radiologia; 26,1\% em química; $19,6 \%$ em radiofarmácia; $17,4 \%$ em medicina ou biologia. Outras ocupações de menor incidência não estão representadas.

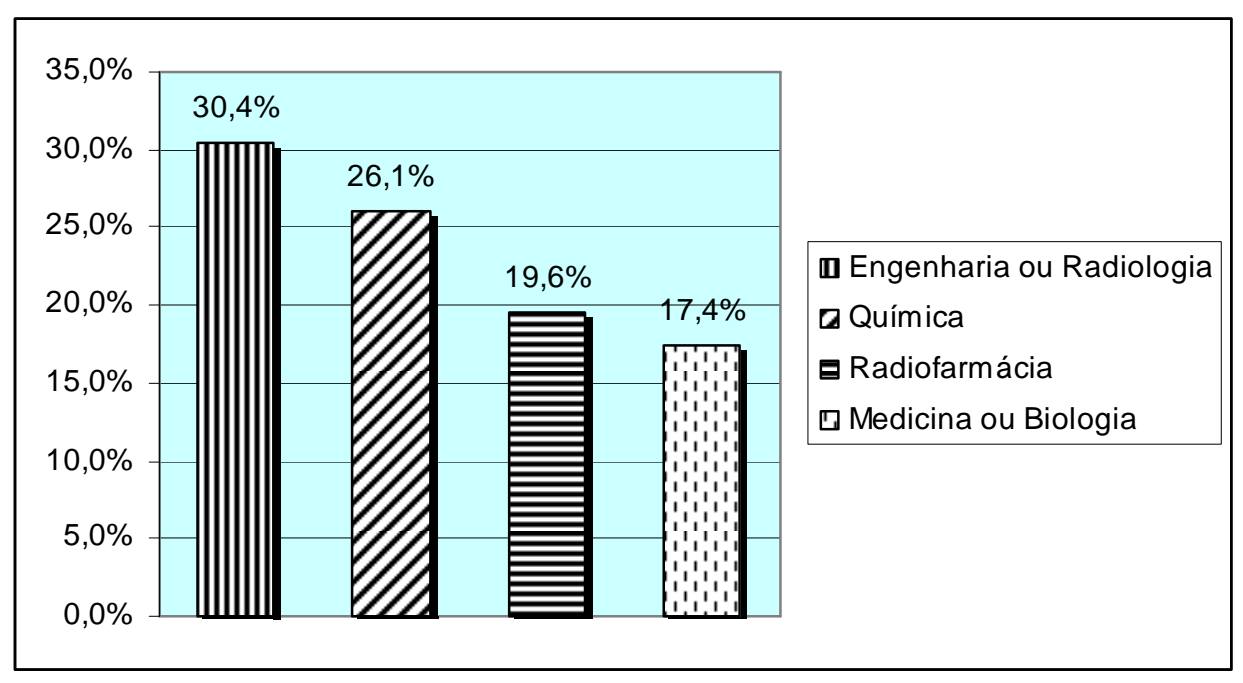

FIGURA 8. Formação acadêmica dos usuários do LV/CVE VirRAD 
A ocupação predominante entre os usuários, conforme mostrado na FIG. 9, é a de pesquisador, com $37,0 \%$; enquanto $23,9 \%$ são professores; $17,4 \%$ são radiofarmacêuticos; $13,0 \%$ são gerentes ou diretores; $8,7 \%$ são estudantes.

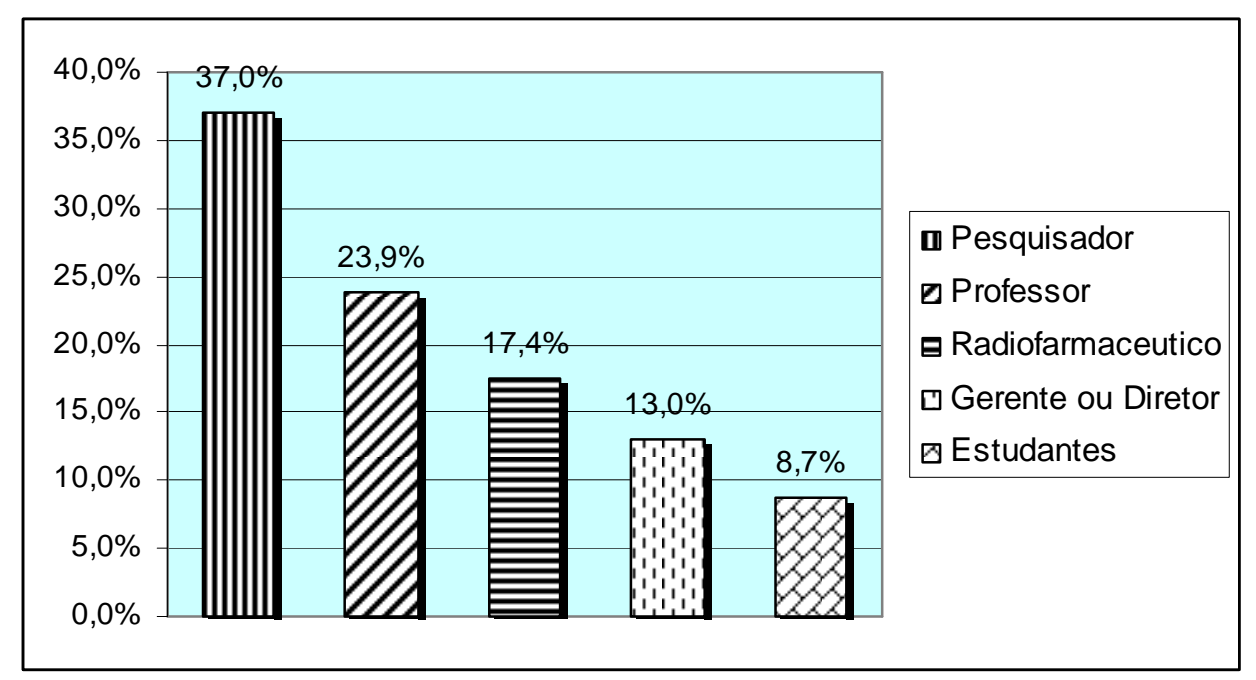

FIGURA 9. Ocupações dos usuários do LV/CVE VirRAD

O último item para caracterizar o perfil pessoal dos usuários é seu tempo de carreira, expresso em anos, conforme mostrado na FIG. 10, onde se constata que $8,7 \%$ têm menos de 5 anos; $19,6 \%$ têm entre 5 e 10 anos; $43,5 \%$ têm entre 11 e 20 anos; $28,3 \%$ têm mais de 20 anos.

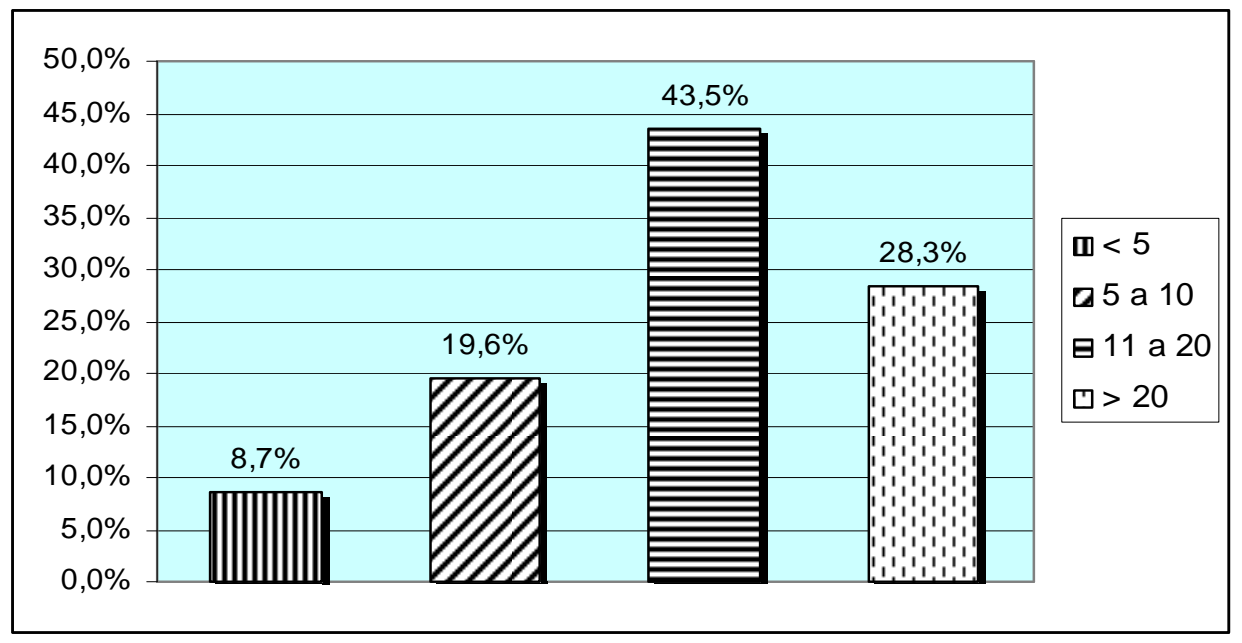

FIGURA 10. Anos de carreira dos usuários do LV/CVE VirRAD 


\subsection{PERFIL COGNITIVO DOS USUÁRIOS DO LV/CVE VirRAD}

O perfil cognitivo dos usuários do LV/CVE VirRAD é analisado neste trabalho sob a perspectiva de duas teorias cognitivas de repercussão mundial: inteligências múltiplas e mindful learning. A primeira busca comprovar que diferentes tipos de inteligências demandam (e são melhores atendidas por) diferentes abordagens e, consequentemente, por diferentes características dos LV/CVE.

A segunda defende que devem ser utilizados diferentes recursos de aprendizagem, visando causar formas variadas de aprendizagem e visando superar certos mitos equivocados sobre ensino e aprendizagem comumente encontrados tanto em atividades de ensino presenciais ou remotas on-line.

Para a teoria das inteligências múltiplas, existem oito tipos de inteligências, que ocorrem nas pessoas de modo simultâneo, manifestando-se em diferentes graus. Os oito tipos foram apresentados na TAB. 11.

$\mathrm{Na}$ tabela em referência foram destacados: 1) os pontos fortes que estimulam a capacidade cognitiva dos detentores de cada tipo de inteligência; 2) suas preferências quanto a atividades a desenvolver em seu cotidiano; 3) as formas/ações nas quais eles têm seu rendimento cognitivo aumentado; 4) suas necessidades de situações/materiais/ estratégias para melhorar seu aproveitamento cognitivo.

\subsubsection{SOB A PERSPECTIVA DE INTELIGÊNCIAS MÚLTIPLAS}

O perfil cognitivo dos usuários do LV/CVE VirRAD, de acordo com a teoria cognitiva inteligências múltiplas, revela que seus usuários possuem forte característica de inteligência verbal, já que 93,5\% deles afirmam dedicar-se a vários tipos de leituras diariamente, a fim de informarem-se e/ou adquirirem conhecimento, conforme mostrado na FIG. 11. 


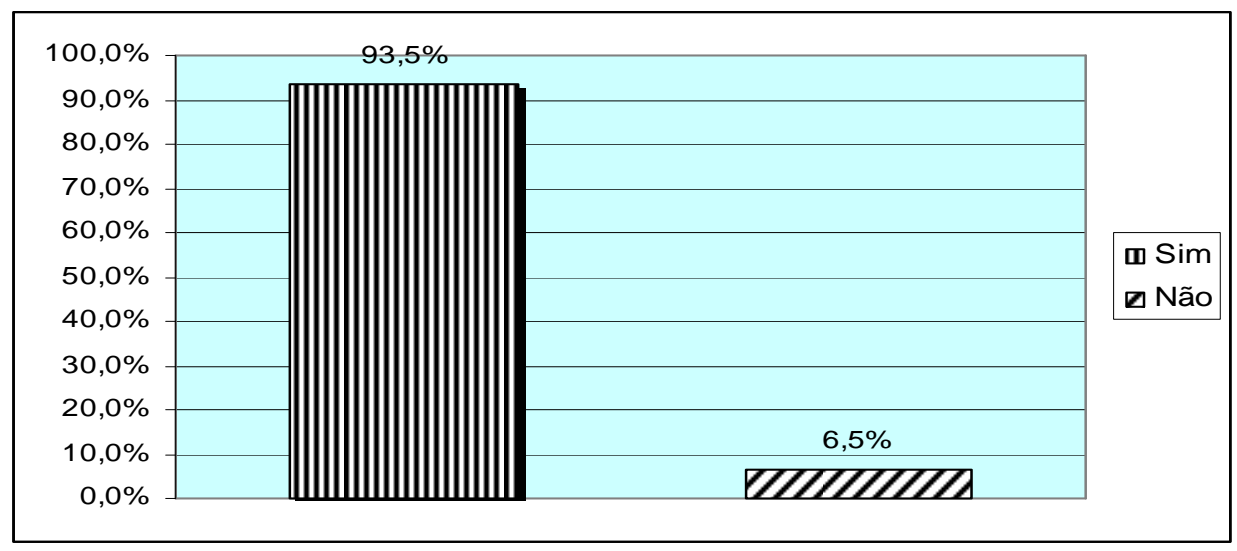

FIGURA 11. Inteligência verbal dos usuários do LV/CVE VirRAD

O segundo tipo de inteligência, a lógico-matemática, também está fortemente presente entre os membros da amostra, já que $76,1 \%$ afirmam que conseguem analisar números rapidamente, conforme mostrado na FIG. 12.

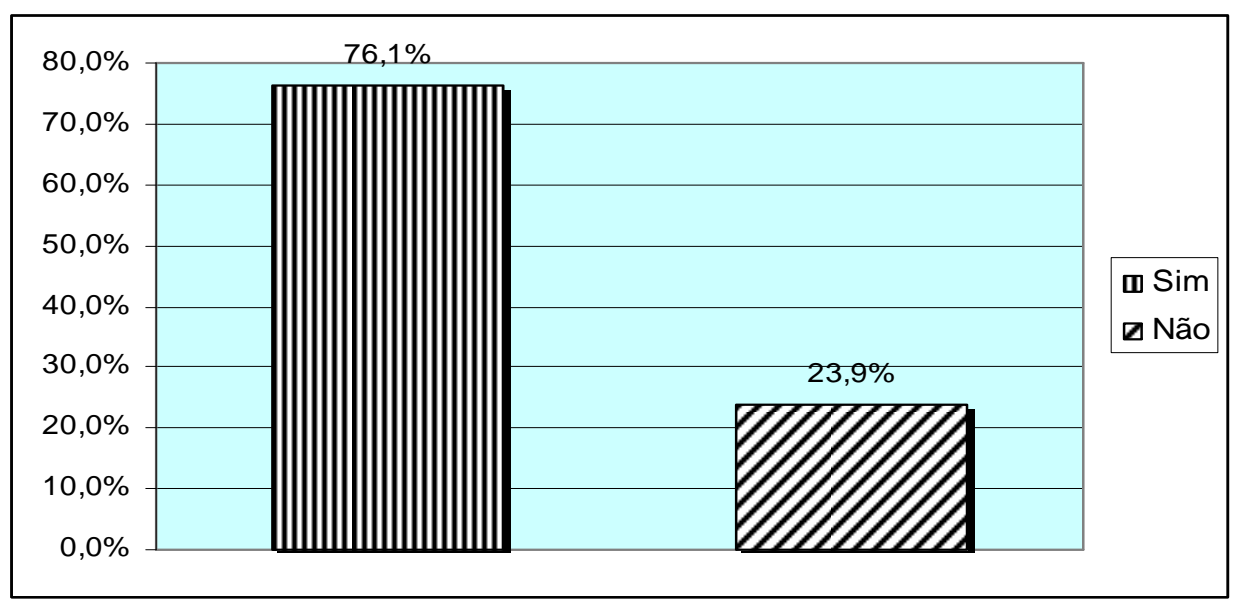

FIGURA 12. Inteligência lógico-matemática dos usuários do LV/CVE VirRAD

A inteligência visual-espacial é característica predominante em $89,1 \%$ dos usuários respondentes, que afirmam apreciar os aspectos visuais que fazem parte de seu ambiente; conforme mostrado na FIG. 13. 


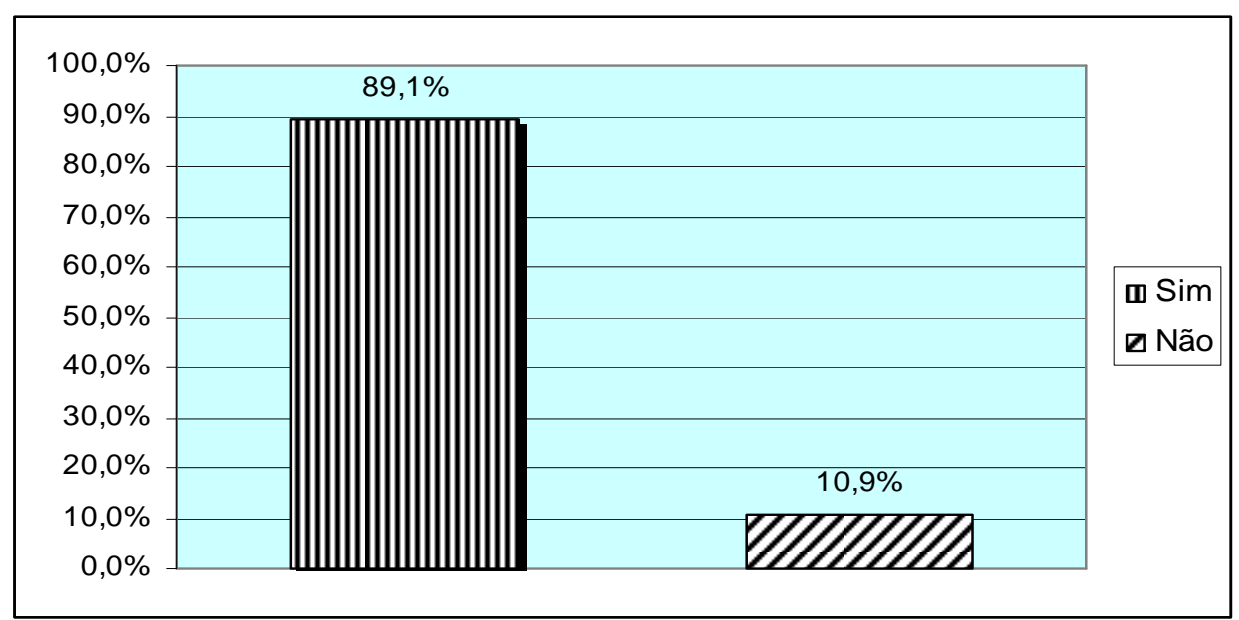

FIGURA 13. Inteligência visual-espacial dos usuários do LV/CVE VirRAD

Não é predominante no grupo estudado o tipo de inteligência corpóreacinestésica, uma vez que somente $45,6 \%$ dos respondentes afirmam que praticam regularmente corrida, skating, dança, artes marciais, aeróbica ou atividades semelhantes, conforme mostrado na FIG. 14.

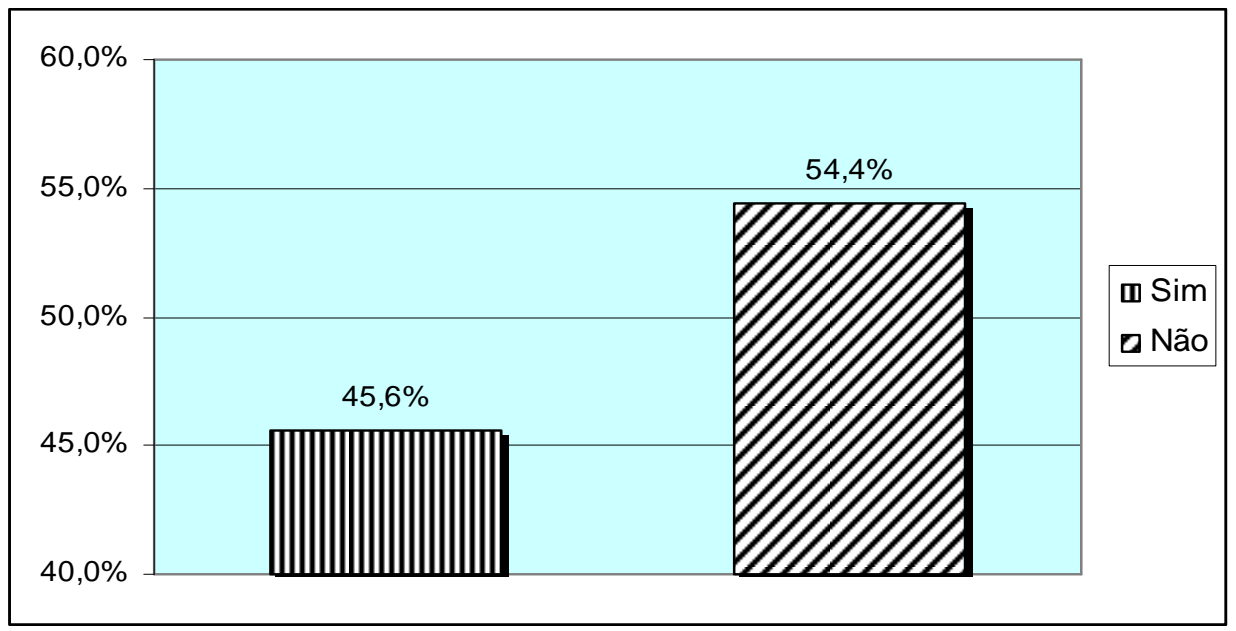

FIGURA 14. Inteligência corpórea-cinestésica dos usuários do LV/CVE VirRAD 
A inteligência naturalística é predominante no grupo estudado, já que caracteriza 58,7\% dos usuários respondentes, que afirmam ter interesse e habilidade em distinguir as diferentes espécies e tipos de plantas, animais ou minerais presentes em seu ambiente, conforme mostrado na FIG. 15.

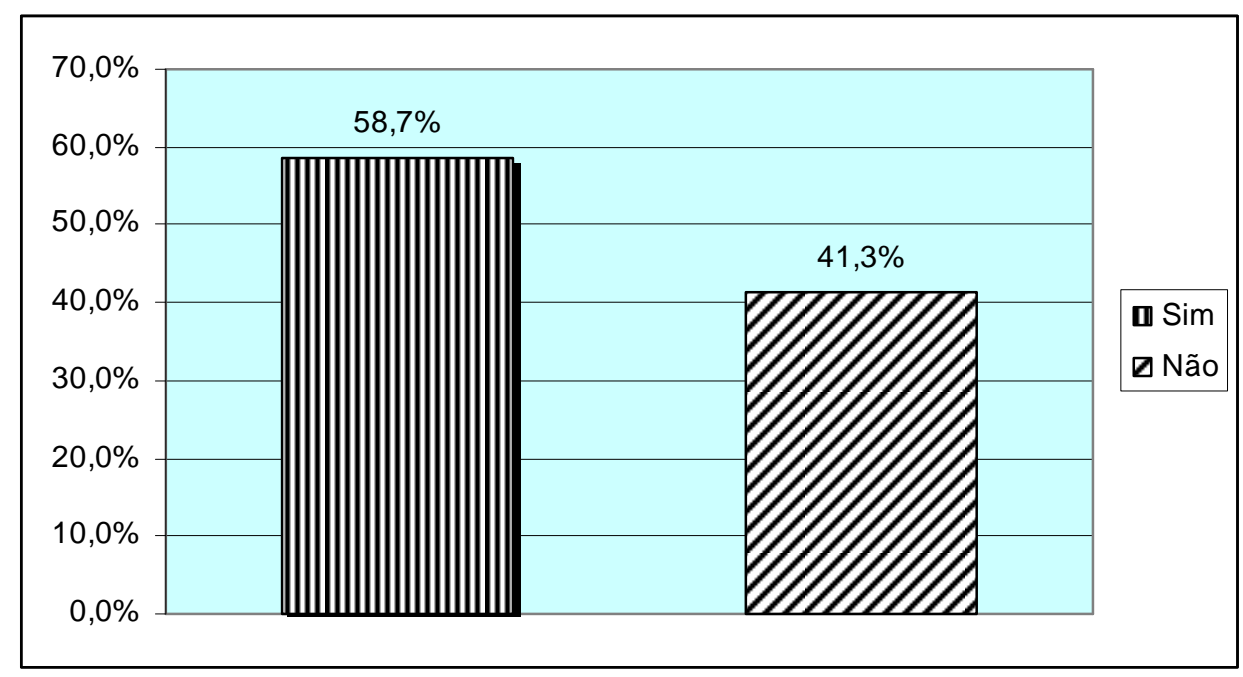

FIGURA 15. Inteligência naturalística dos usuários do LV/CVE VirRAD

O sexto tipo de inteligência, a musical, não é predominante entre os membros da amostra, já que apenas 32,6\% afirmam que gostam de acompanhar ritmos, cantar, ir a concertos ou tocar algum instrumento, conforme mostrado na FIG. 16.



FIGURA 16. Inteligência musical dos usuários do LV/CVE VirRAD 
Não é característica predominante no grupo estudado o tipo de inteligência intrapessoal: somente $34,8 \%$ dos respondentes afirmam que se dedicam a passar algum tempo sozinhos, unicamente pensando, ou que mantém um diário para registro de suas reflexões, conforme mostrado na FIG. 17.

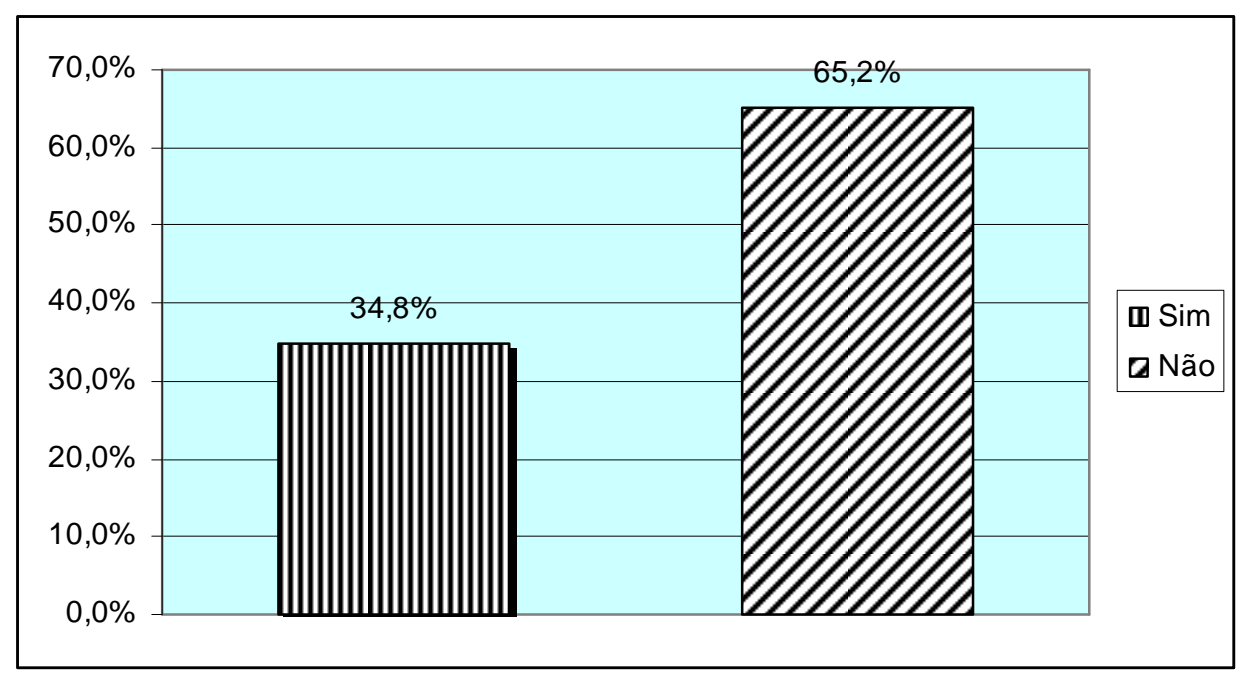

FIGURA 17. Inteligência intrapessoal dos usuários do LV/CVE VirRAD

A inteligência interpessoal é fortemente detectada entre os respondentes, na medida em que $82,6 \%$ deles afirmam estar interessados em fazer amigos e que ficam confortáveis próximos a novos conhecidos, conforme mostrado na FIG. 18.

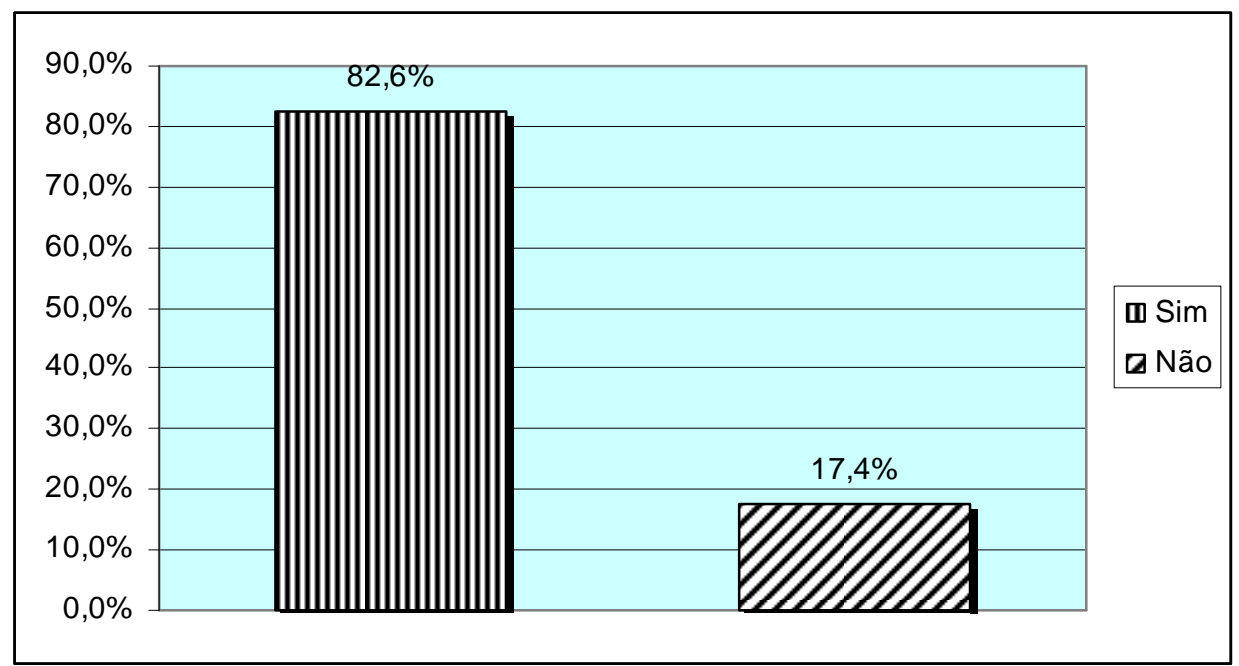

FIGURA 18. Inteligência interpessoal dos usuários do LV/CVE VirRAD 


\subsubsection{SOB A PERSPECTIVA DE MINDFUL LEARNING}

O perfil cognitivo dos usuários do LV/CVE VirRAD, analisado por meio das perspectivas da teoria mindful learning, revela que seus usuários têm uma visão que confirma o mito 1 (O básico deve ser aprendido tão bem a ponto de tornar-se uma segunda natureza da pessoa): 78,3\% dos respondentes acreditam que precisam estudar um novo assunto em detalhes e inúmeras vezes antes de iniciá-lo, conforme mostrado na FIG. 19.

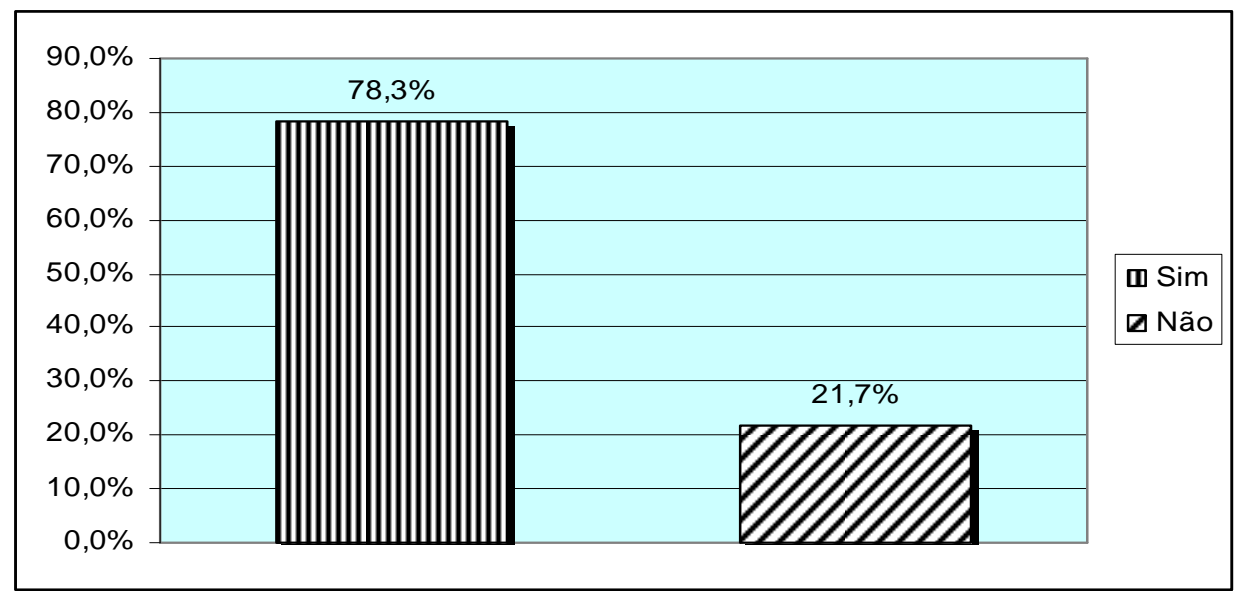

FIGURA 19. Usuários do LV/CVE VirRAD que confirmam o mito 1

Também confirma-se o mito 2 (Prestar atenção é estar focado em um assunto de cada vez): $58,8 \%$ das pessoas precisam isolar-se dos outros a fim de concentrarem-se em um novo assunto, conforme mostrado na FIG. 20.

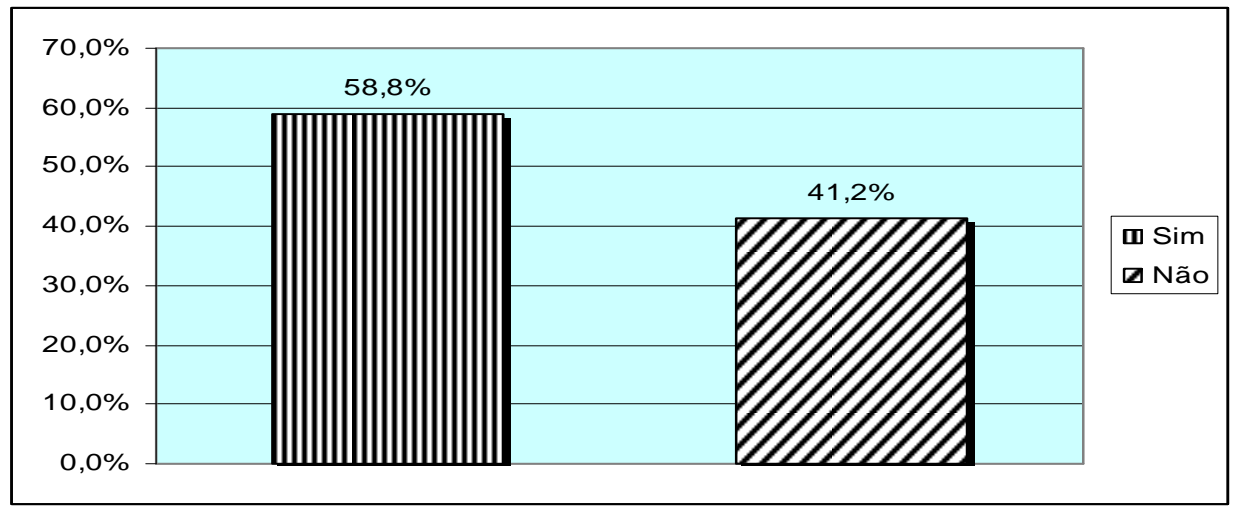

FIGURA 20. Usuários do LV/CVE VirRAD que confirmam o mito 2 
O mito 3 (É importante retardar gratificações no processo de ensino e aprendizagem) é confirmado por apenas $45,6 \%$ dos respondentes. Para $54,4 \%$ deles é necessário obter imediatamente os créditos quando atingem um objetivo que consideram importante. Na FIG. 21 são exibidos os resultados.

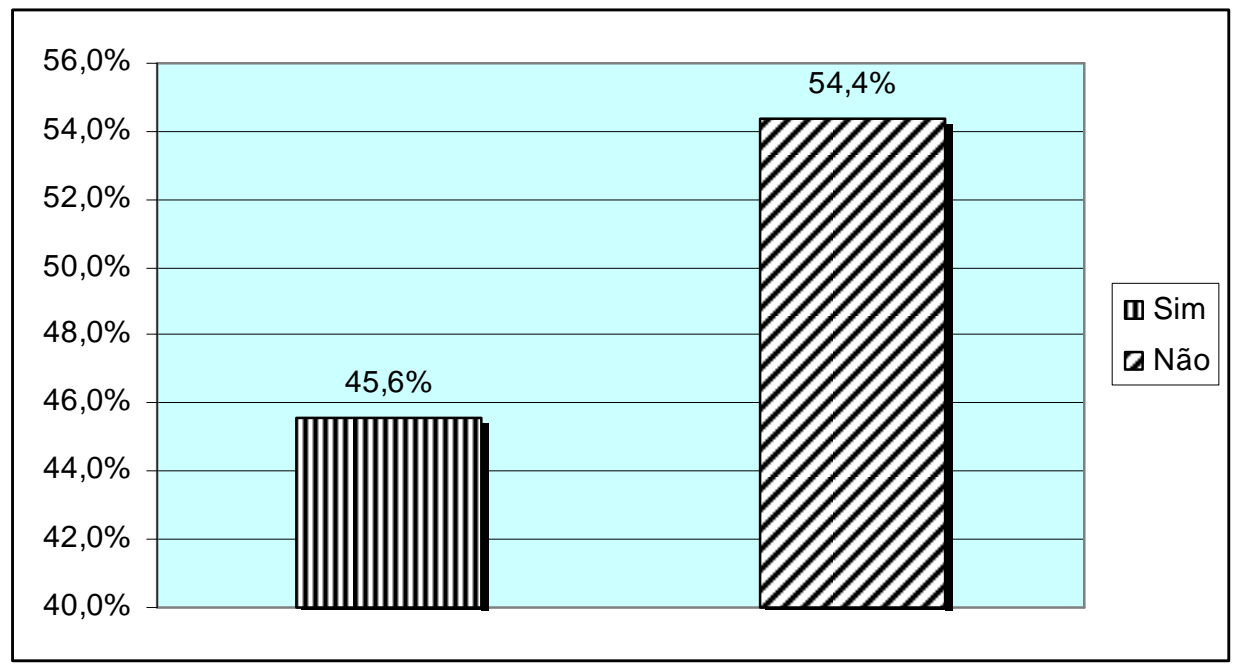

FIGURA 21. Usuários do LV/CVE VirRAD que confirmam o mito 3

Já o mito 4 (Memorização é um fator essencial no processo de ensino e aprendizagem), tem o apoio de apenas $39,1 \%$ dos respondentes, enquanto é negado por $60,9 \%$ dos respondentes, conforme mostrado na FIG. 22.

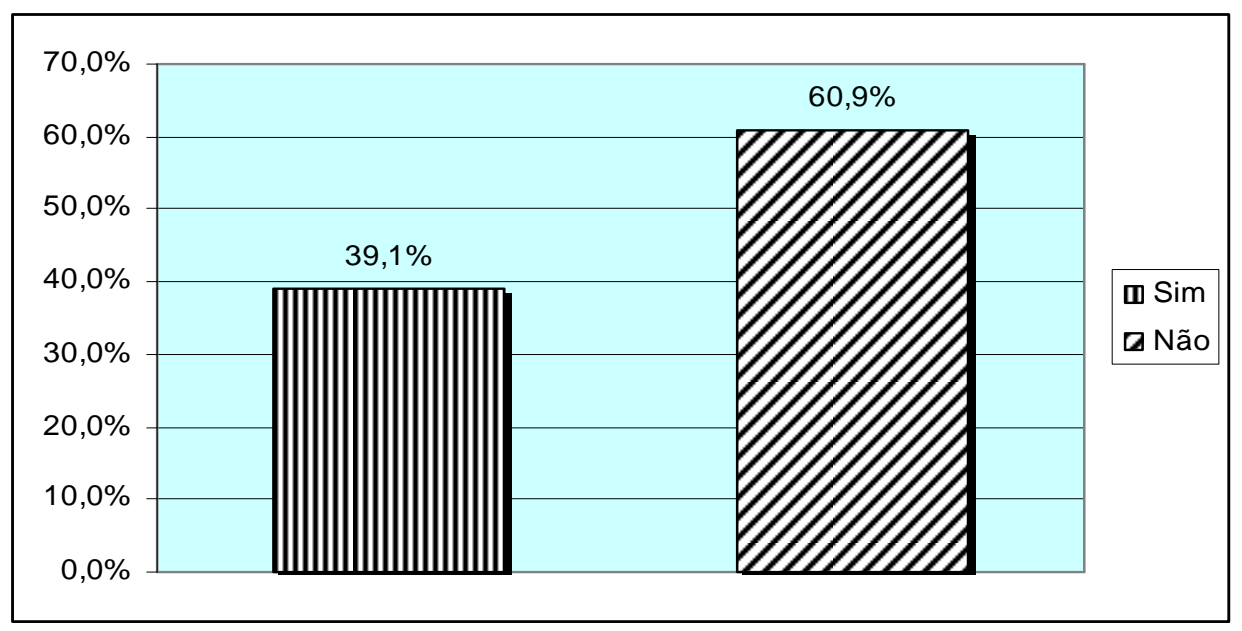

FIGURA 22. Usuários do LV/CVE VirRAD que cofirmam o mito 4 
Quanto ao mito 5 (Inteligência é conhecer as coisas "exatamente como elas são"), é confirmado por $50 \%$ dos respondentes. Na opinião de $50,0 \%$ deles, no entanto, é necessário realizar alguma modificação de perspectiva imediatamente ao se conhecer qualquer assunto, conforme mostrado na FIG. 23.

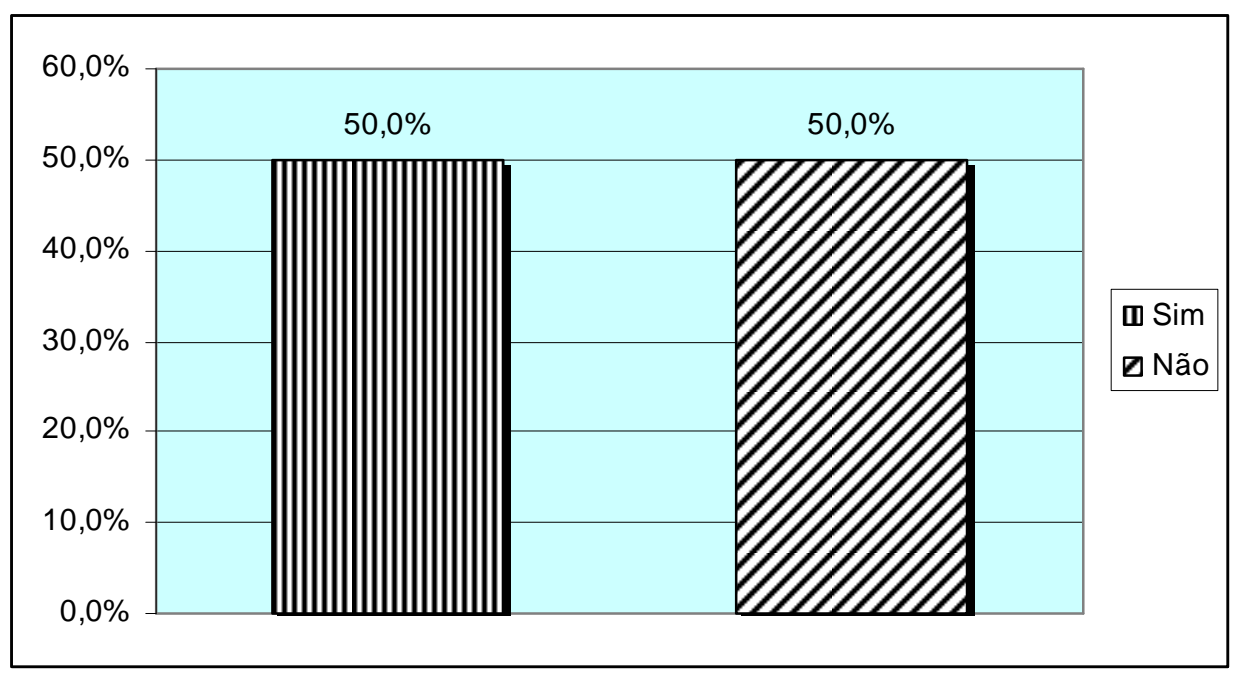

FIGURA 23. Usuários do LV/CVE VirRAD que confirmam o mito 5

Conforme mostrado na FIG. 24, sobre o mito 6 (Há somente respostas certas ou respostas erradas), o mesmo é verdadeiro para $43,5 \%$, enquanto que para $56,5 \%$ deles a realidade é diversa, sendo difícil dizer o que é certo e o que é errado.

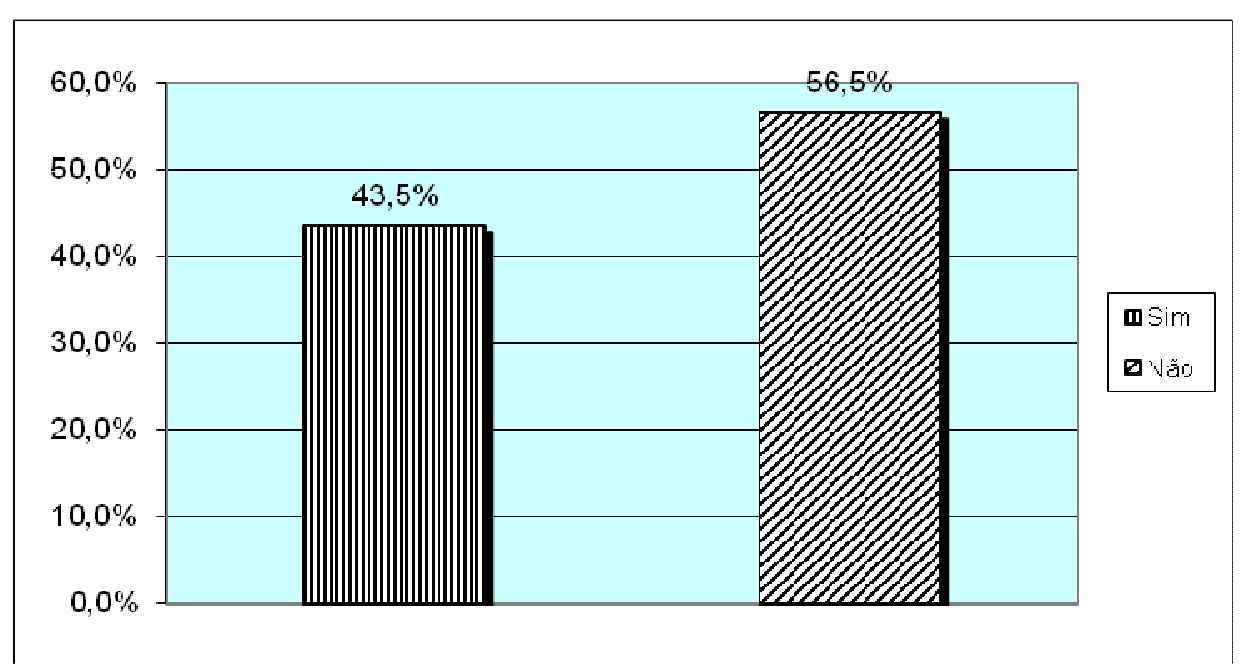

FIGURA 24. Usuários do LV/CVE VirRAD que confirmam o mito 6 
Por último, o mito 7 (Esquecer é um problema) é confirmado por apenas $26,5 \%$ dos usuários; para $63,5 \%$ não há problema em ter que consultar suas anotações quando se esquecem de algum assunto, conforme mostrado na FIG. 25.

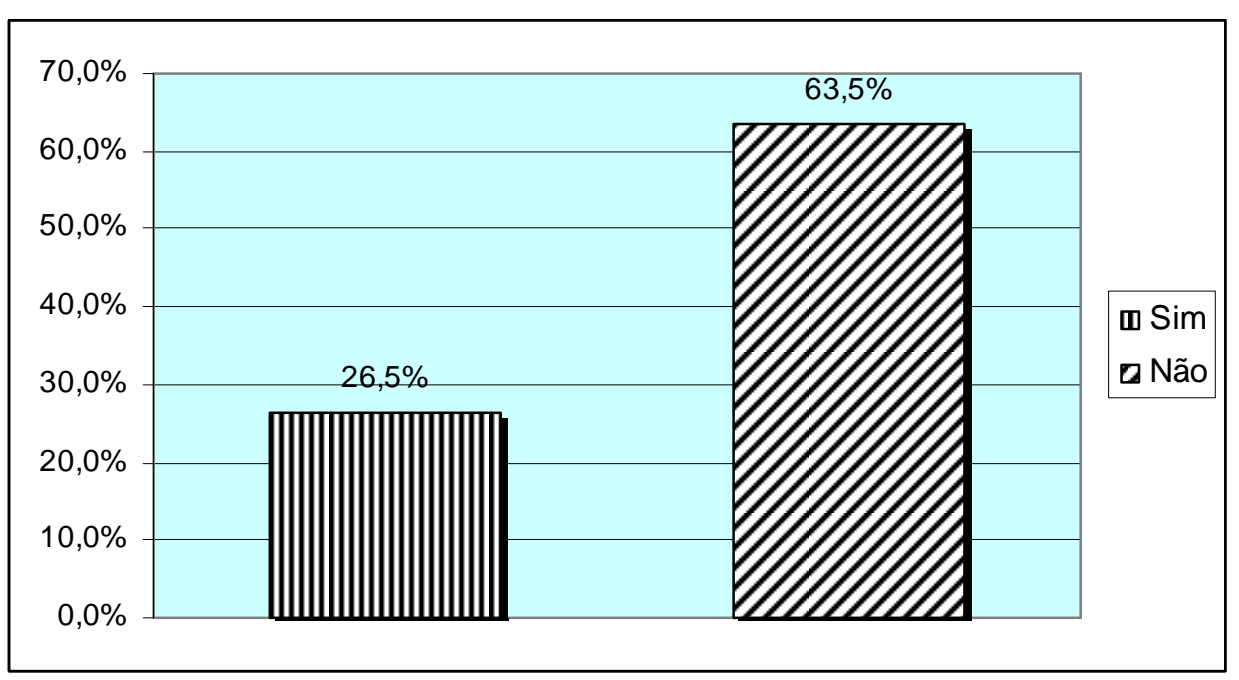

FIGURA 25. Usuários do LV/CVE VirRAD que confirmam o mito 7

Na FIG. 26 está mostrado o percentual de usuários que criam continuamente novas categorias de conhecimentos quando confrontados com novos assuntos. Para $80,4 \%$ dos usuários, a criação de novas categorias ocorre, enquanto que para 19,5\% dos usuários isso não ocorre.



FIGURA 26. Usuários que criam novas categorias de conhecimentos 
Na FIG. 27 está mostrado o percentual de usuários que declaram estar abertos continuamente a novas informações. Isso ocorre para $91,3 \%$ dos usuários, enquanto que para $8,7 \%$ dos usuários isso não ocorre.

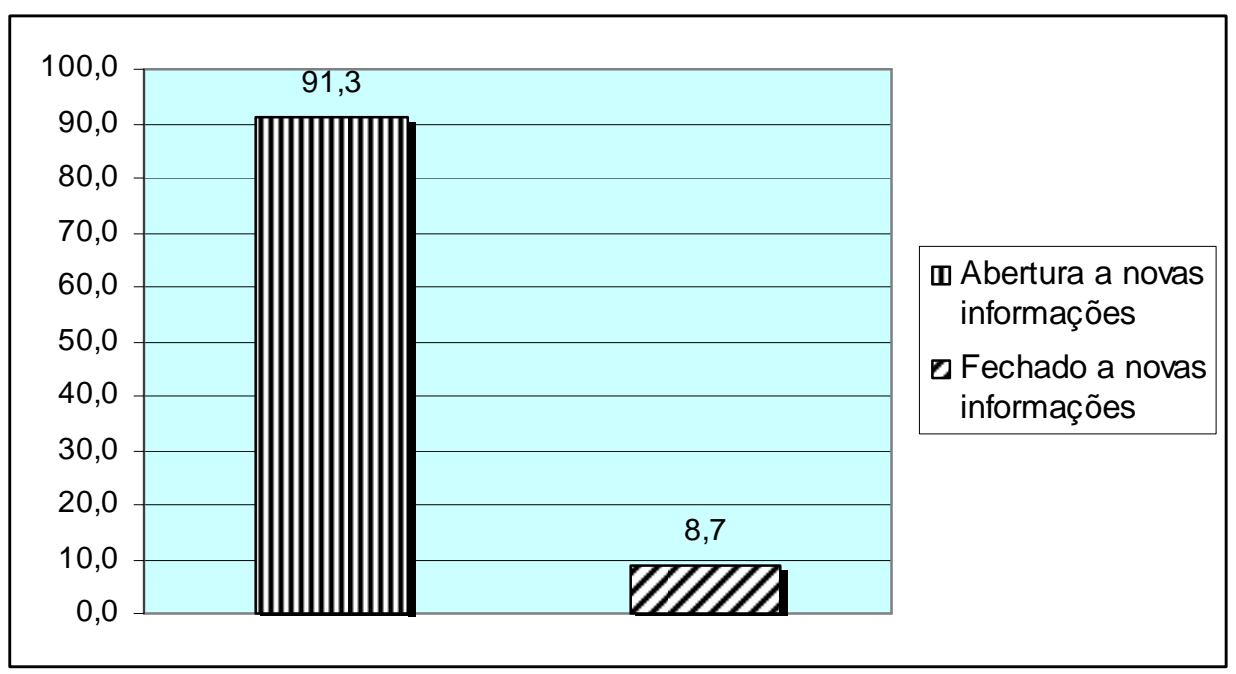

FIGURA 27. Usuários abertos a novas categorias de conhecimentos

Na FIG. 28 está mostrado o percentual de usuários que declaram estar atentos simultaneamente a mais de uma perspectiva sobre qualquer assunto. Isso ocorre para $67,4 \%$ dos usuários, enquanto que para $32,6 \%$ dos usuários isso não ocorre.

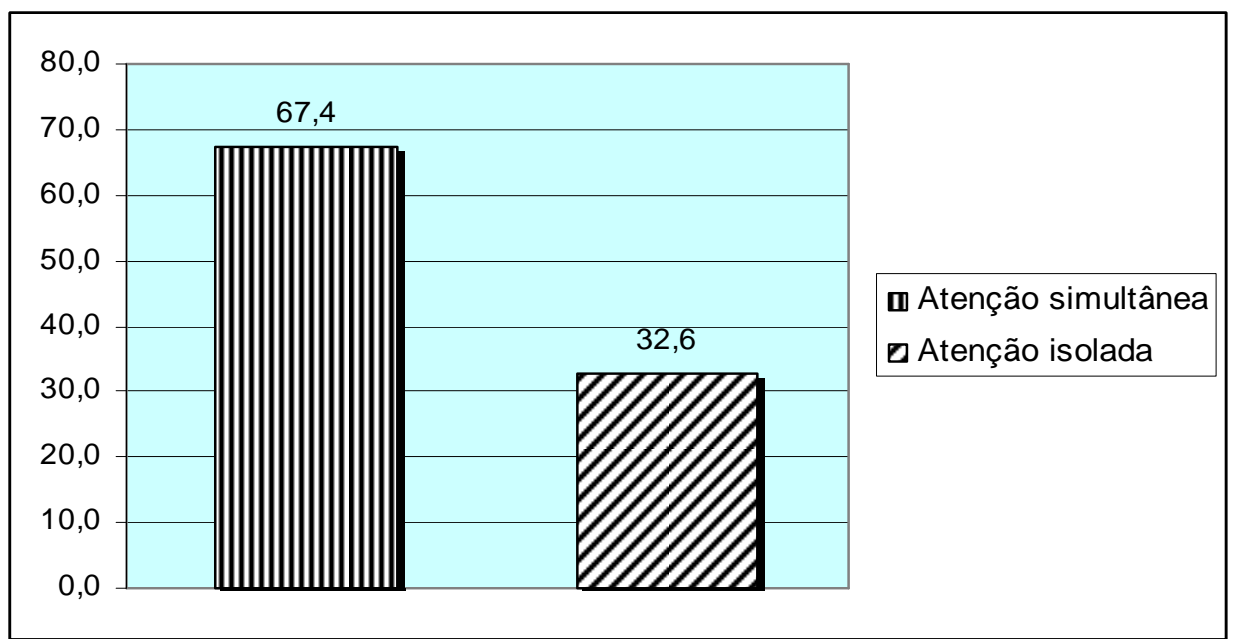

FIGURA 28. Usuários atentos a múltiplas perspectivas 


\subsection{ASPECTOS DA UTILIZAÇÃO DO LV/CVE VirRAD}

O perfil de utilização quantitativa do LV/CVE VirRAD é observado neste trabalho levando-se em consideração a quantidade e características dos seus acessos ao ambiente estudado, conforme demonstrado a seguir.

Quanto à quantidade de acessos, $41,1 \%$ dos respondentes o fazem pelo menos duas vezes por mês, enquanto $26,1 \%$ o fazem quatro vezes, e $8,8 \%$ o fazem oito vezes, conforme mostrado na FIG. 29. 4,4\% acessam diariamente e 19,6\% acessam raramente.

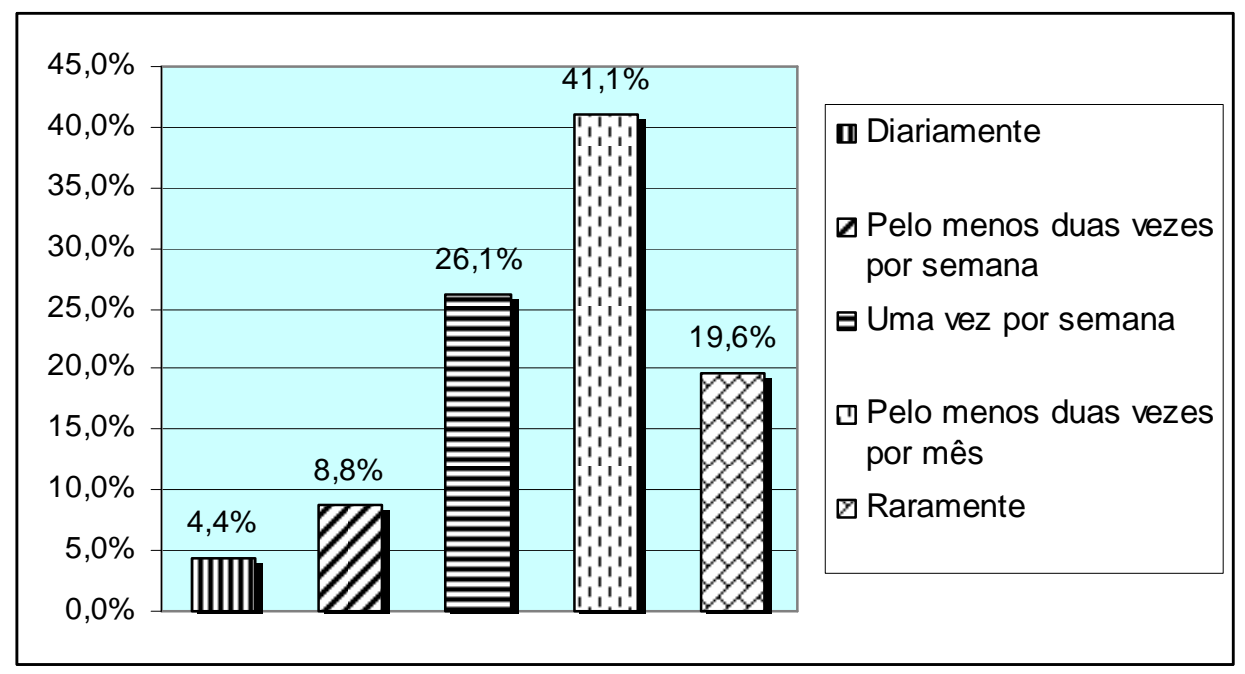

FIGURA 29. Freqüência de acesso dos usuários ao LV/CVE VirRAD 
Quanto às funções mais acessadas do VirRAD, 78,3\% priorizam a seção News/events, enquanto $41,3 \%$ focalizam a seção Fóruns e $39,1 \%$ a seção Biblioteca, conforme mostrado na FIG. 30.

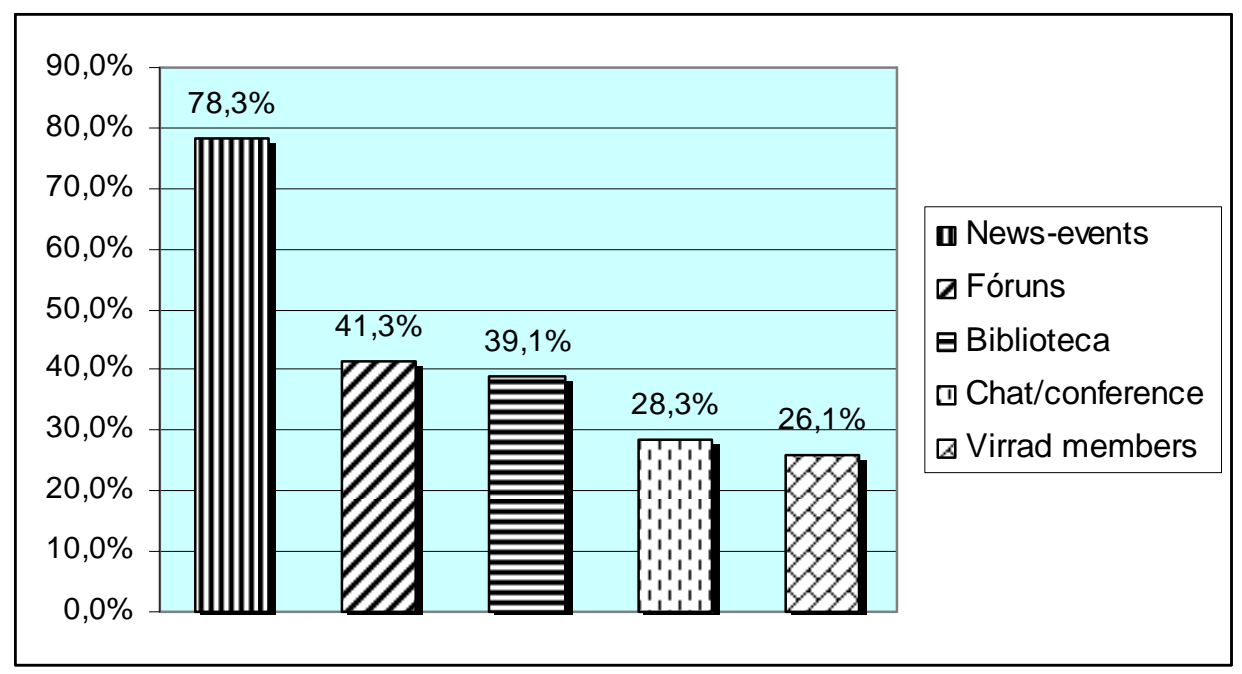

FIGURA 30. Funções mais acessadas pelos usuários do LV/CVE VirRAD

Quanto ao papel desempenhado pelos usuários dentro do $\operatorname{VirRAD}, 82,6 \%$ acessam o ambiente para ler notícias, enquanto 43,5\% acessam para desempenhar papel de aprendiz, e 4,4\% para desempenhar papel de mentores, conforme mostrado na FIG. 31.

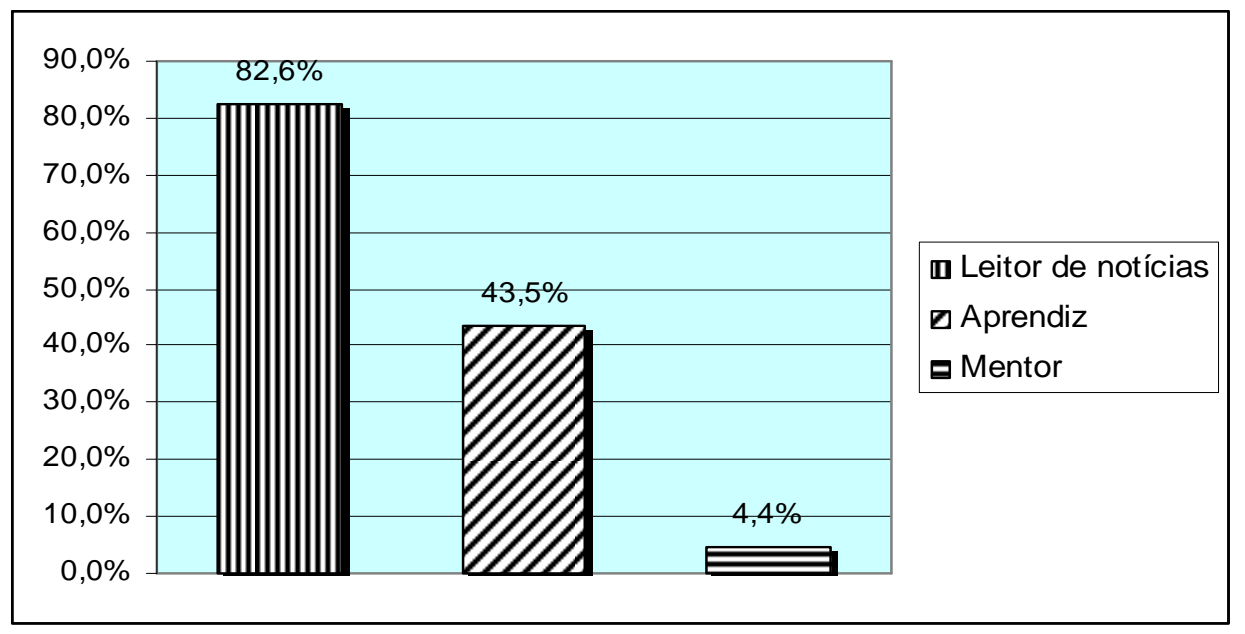

FIGURA 31. Papel desempenhado pelos usuários do LV/CVE VirRAD 
Quanto ao modo como os usuários acessam o 3D VR Lab VirRAD, 60,9\% o fazem de modo assistido (With Learner Modelling Assistance), enquanto os demais 39,1\% preferem acessá-lo sem assistência de software (Without Learner Modelling Assistance). O resultado é mostrado na FIG. 32.



FIGURA 32. Modo como os usuários acessam o 3D VR Lab do LV/CVE VirRAD,

Os três procedimentos de radiofarmácia mais executados no 3D VR Lab do LV/CVE VirRAD são: Preparação do kit ${ }^{99 \mathrm{~m}} \mathrm{Tc}$, com $19,6 \%$, Execução de Controle de Qualidade, com 15,2\%, Preparar LFC, com 13,0\%, conforme mostrado na FIG. 33.

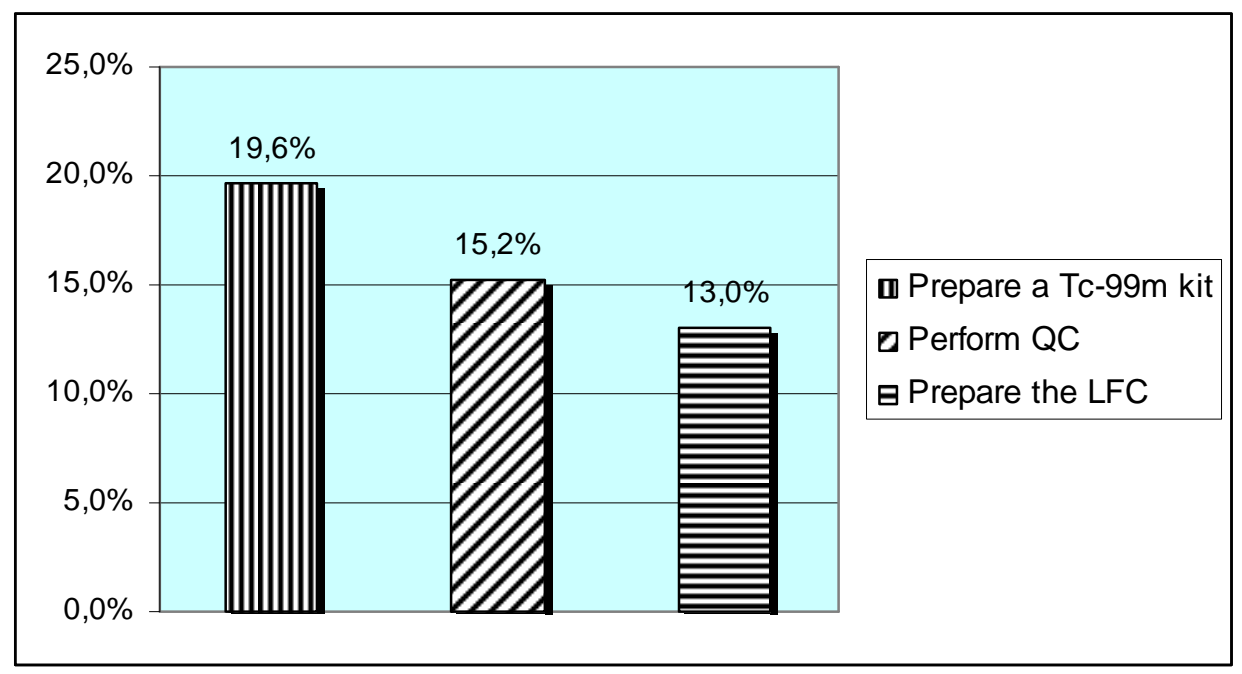

FIGURA 33. Procedimentos mais executados no 3D VR LAB do LV/CVE VirRAD 
Quanto à importância que os usuários atribuem ao uso de avatares para representá-los no 3D VR LAB do LV/CVE VirRAD, como um fator favorável/decisivo ao seu aprendizado, $32,6 \%$ os consideram essenciais, $58,7 \%$ os consideram importantes, e 8,7\% os consideram irrelevantes, conforme mostrado na FIG. 34.

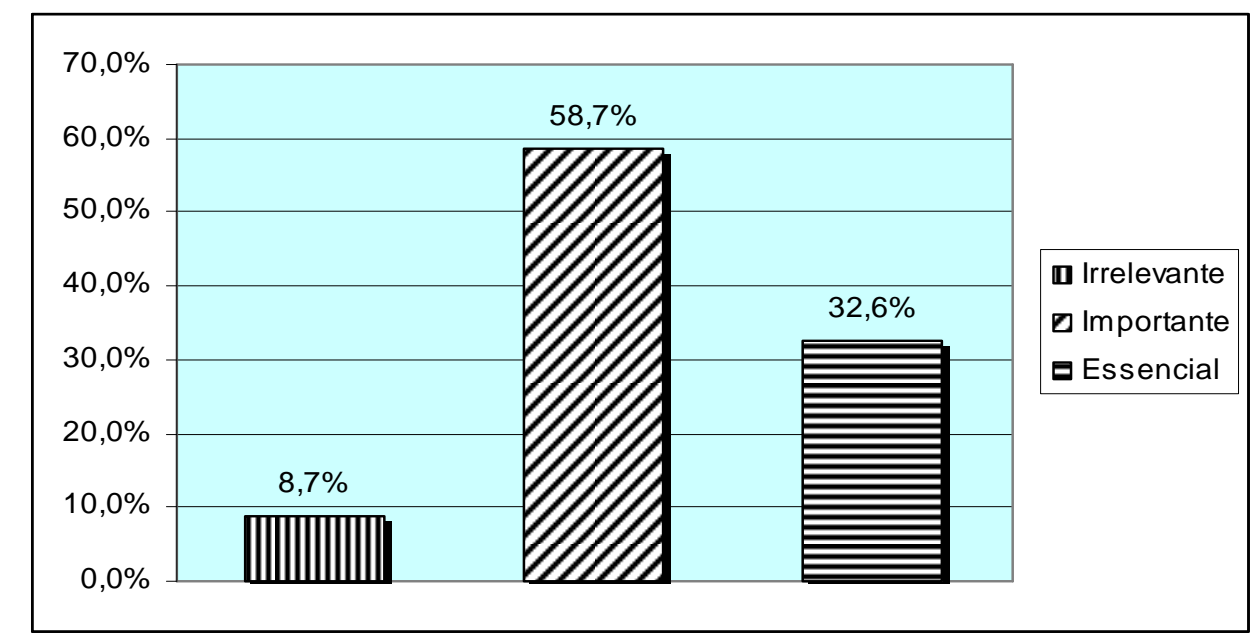

FIGURA 34. Importância do uso de avatares no 3D VR LAB do LV/CVE VirRAD

Sobre o grau de correção dos procedimentos do 3D VR Lab do ambiente VirRAD, em comparação com seus equivalentes reais, $10,9 \%$ dos usuáriois os consideram piores, $84,8 \%$ os vêem como equivalentes e $4,4 \%$ como melhores que os reais. O resultado é mostrado na FIG. 35.

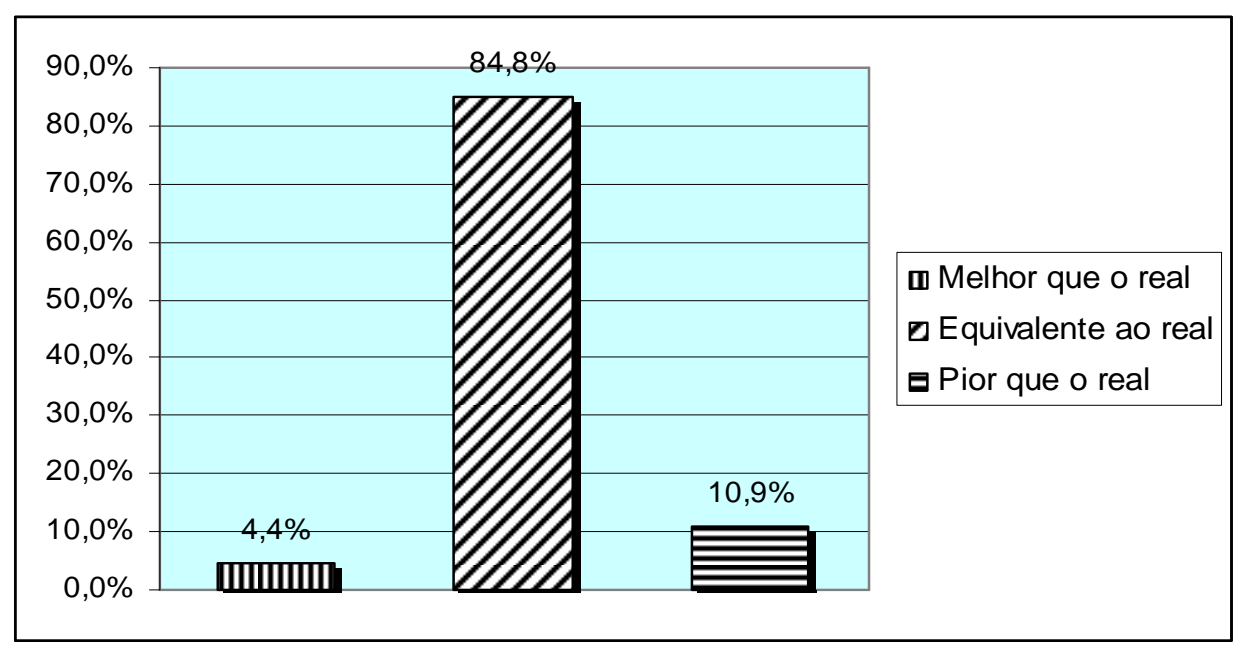

FIGURA 35. Correção dos procedimentos do 3D VR LAB do LV/CVE VirRAD, 
Quanto aos usuários considerarem mais ou menos completos os procedimentos do 3D VR LAB do ambiente VirRAD, em comparação com seus equivalentes reais, $17,4 \%$ os consideram piores, $71,7 \%$ os vêem como equivalentes e $10,8 \%$ os consideram melhores que os reais, conforme mostrado na FIG. 36.

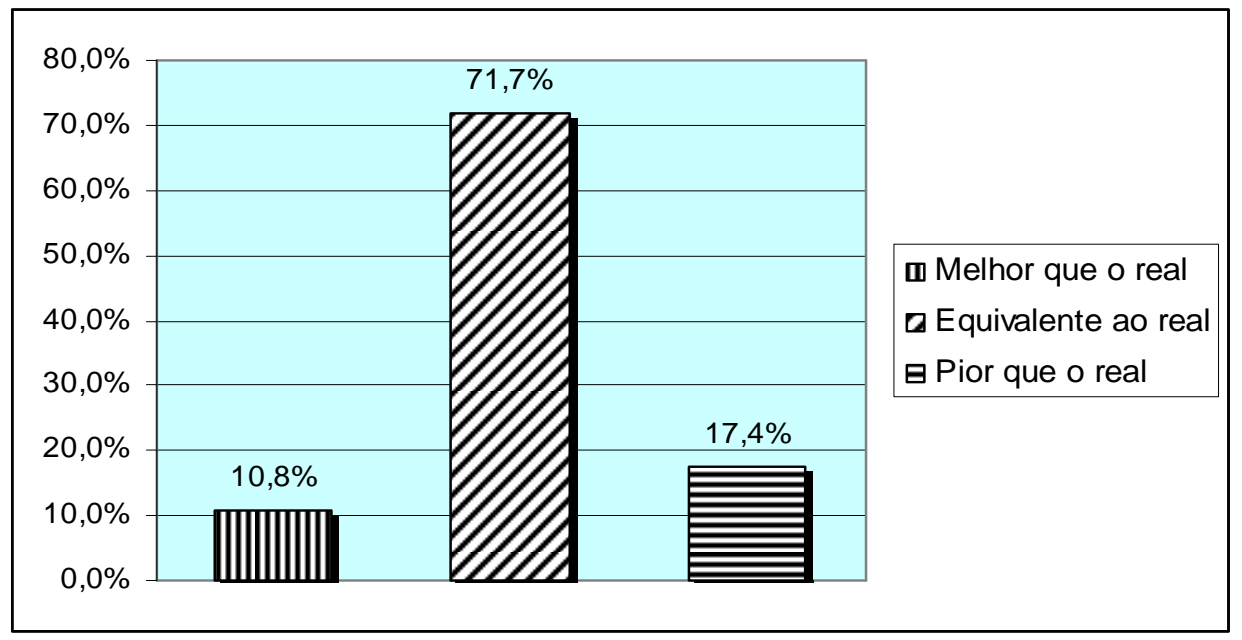

FIGURA 36. Completeza dos procedimentos do 3D VR LAB do LV/CVE VirRAD

Quanto à usabilidade dos procedimentos do 3D VR LAB do LV/CVE VirRAD, em comparação à usabilidade de um laboratório real, 21,7\% dos usuários a consideram inferior; para $60,9 \%$ é equivalente, e para $17,4 \%$, melhor. O resultado é mostrado na FIG. 37.

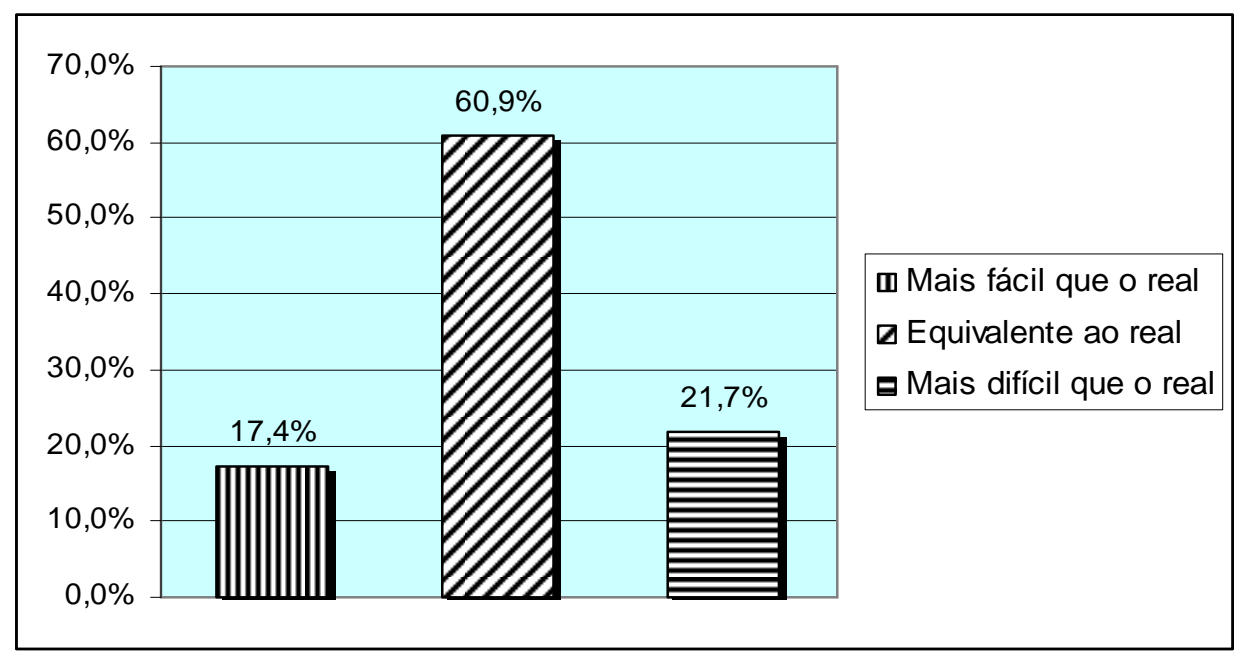

FIGURA 37. Usabilidade dos procedimentos do 3D VR LAB do LV/CVE VirRAD, 
Com referência às durações dos procedimentos no $3 D$ VR LAB te VirRAD, em comparação com a dos procedimentos realizados em um laboratório real, 10,9\% os consideram abaixo dos reais, $30,4 \%$ como iguais e $58,7 \%$ como acima (mais lentos) dos reais, conforme mostrado na FIG. 38.

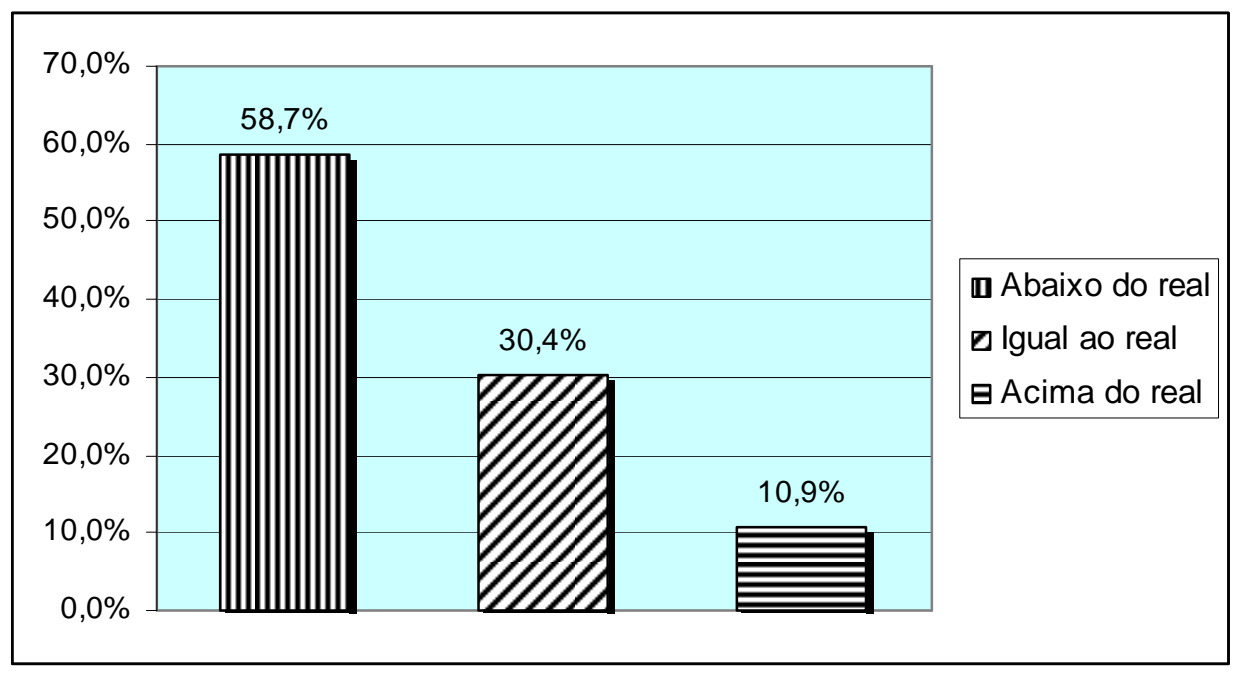

FIGURA 38. Tempo de execução procedimentos do 3D VR LAB do LV/CVE VirRAD

Sobre a diversidade de procedimentos disponíveis no 3D VR LAB VirRAD, $41,3 \%$ os consideram uma amostra fraca dos procedimentos reais, $58,7 \%$ os vêem como uma amostra boa. O resultado é mostrado na FIG. 39.

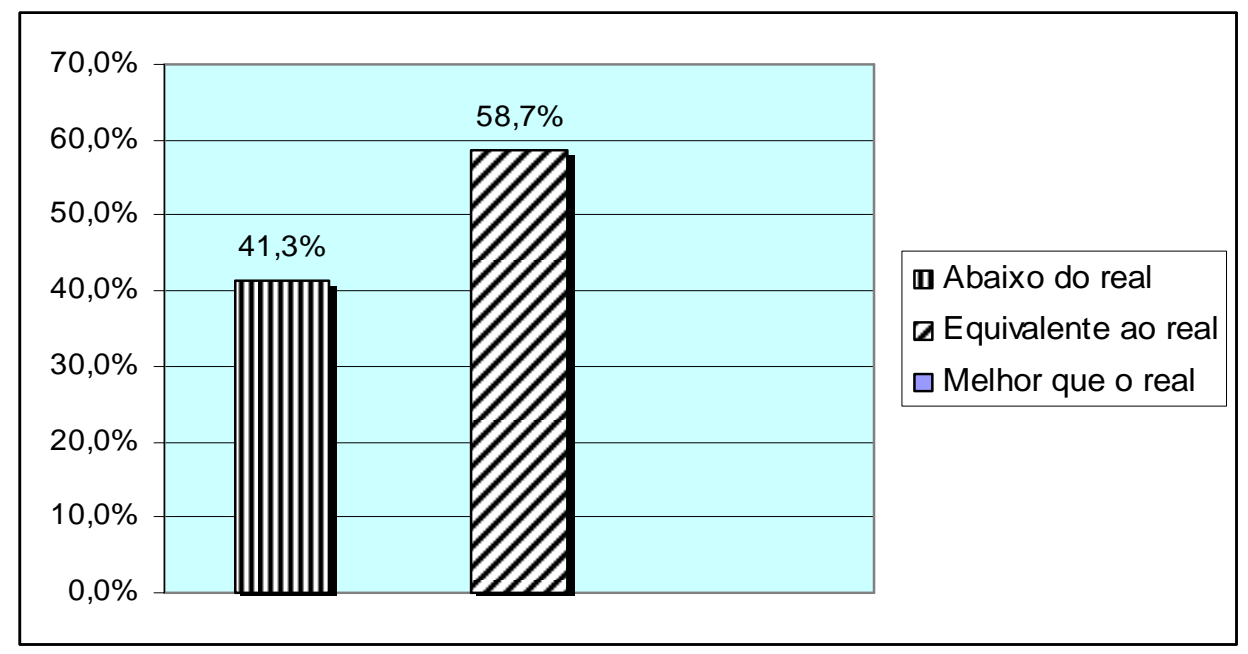

FIGURA 39. Variedade de procedimentos no 3D VR LAB do LV/CVE VirRAD 
Quanto aos recursos disponíveis no ambiente VirRAD como um todo, 60,9\% consideram que são muito úteis como ferramenta de comunicação; $52,2 \%$ têm a mesma percepção sobre o VirRAD, mas como ferramenta de ensino e aprendizagem, e outros $52,2 \%$ o vêem do mesmo modo, mas como recurso para atividades de pesquisa, conforme mostrado na FIG. 40.

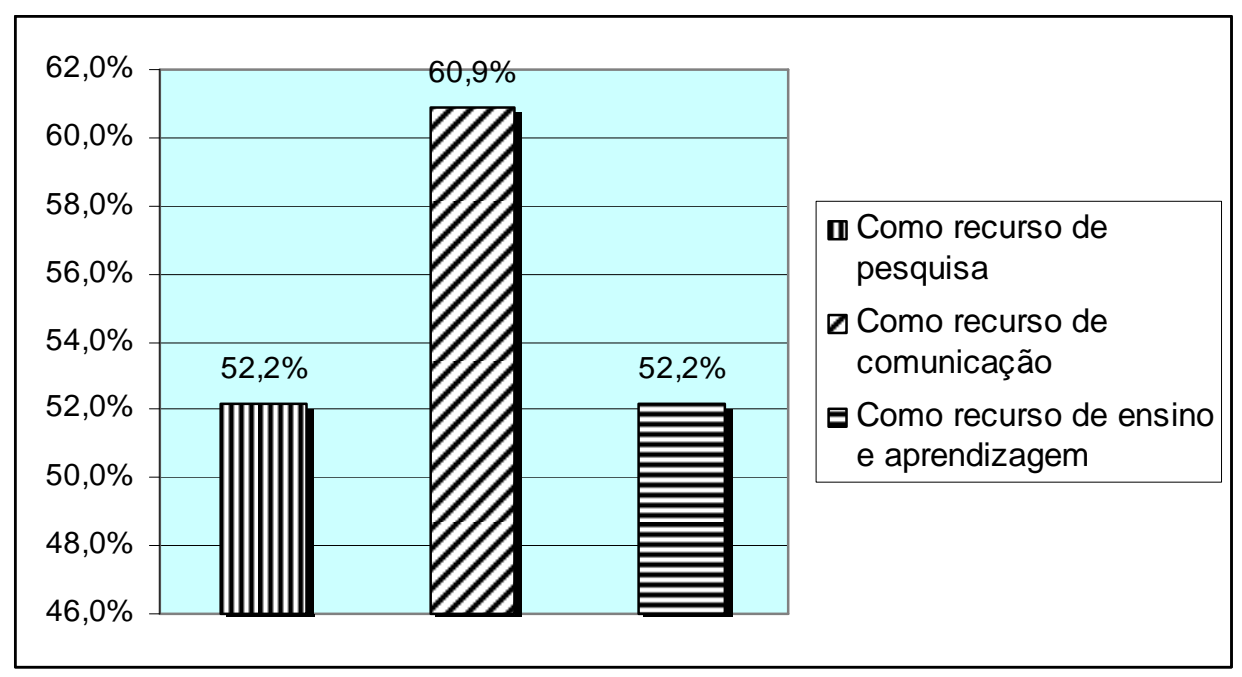

FIGURA 40. Utilidade do ambiente VirRAD como um todo 


\section{ANÁLISE E DISCUSSÃO DOS RESULTADOS}

O estudo de caso revela que são predominantes nos usuários do LV/CVE VirRAD cinco tipos das inteligências definidas por Gardner, enquanto três delas ocorrem de modo minoritário, na visão dos próprios usuários.

Predominam os tipos: inteligência verbal, lógico-matemática, visual-espacial, naturalística e Interpessoal na maioria dos respondentes.

E são minoritários os tipos: inteligências corpórea-cinestésica, musical e Intrapessoal na maioria dos respondentes.

As respostas obtidas estão relacionadas na TAB. 24.

TABELA 24. Presença das oito inteligências nos usuários

\begin{tabular}{|c|c|c|}
\hline Tipo & Inteligência & $\begin{array}{c}\text { \% de } \\
\text { Presença }\end{array}$ \\
\hline 1 & VERBAL & $\mathbf{9 3 . 5}$ \\
\hline 2 & LÓGICO-MATEMÁTICA & $\mathbf{7 6 . 1}$ \\
\hline 3 & VISUAL-ESPACIAL & $\mathbf{8 9 . 1}$ \\
\hline 4 & CORPÓREA-CINESTÉSICA & 45.6 \\
\hline 5 & NATURALISTICA & $\mathbf{5 8 . 7}$ \\
\hline 6 & MUSICAL & 32.6 \\
\hline 7 & INTRAPESSOAL & 34.8 \\
\hline 8 & INTERPESSOAL & $\mathbf{8 2 . 6}$ \\
\hline
\end{tabular}

Fonte: Estudo de caso, criada pelo autor.

Quanto à confirmação ou negação da influência/repercussão dos mitos sobre ensino e aprendizagem previstos na teoria mindful learning sobre o perfil cognitivo e nas atividades cognitivas dos respondentes, a partir de pontos de vista dos próprios respondentes, obteve-se: 
a) A confirmação dos respondentes quanto a acreditarem e praticarem ações aderentes aos mitos 1 e 2 ;

b) A negação dos respondentes quanto a acreditarem e praticarem ações aderente aos mitos $3,4,5,6$ e 7 .

As respostas obtidas estão relacionadas na TAB. 25.

TABELA 25. Visão dos usuários sobre mitos educacionais

\begin{tabular}{|c|c|c|}
\hline Mito & Descrição & $\begin{array}{c}\% \text { de } \\
\text { confirmação }\end{array}$ \\
\hline 1 & $\begin{array}{c}\text { Os fundamentos devem ser aprendidos tão } \\
\text { profundamente a ponto de tornarem-se uma segunda } \\
\text { natureza da pessoa }\end{array}$ & 78.3 \\
\hline 2 & $\begin{array}{c}\text { Prestar atenção significa estar focado em uma coisa } \\
\text { de cada vez }\end{array}$ & 58.8 \\
\hline 3 & É importante retardar gratificações & 45.6 \\
\hline 4 & $\begin{array}{c}\text { Memorização é um fator essencial no processo de } \\
\text { ensino e aprendizagem }\end{array}$ & 39.1 \\
\hline 5 & $\begin{array}{c}\text { Inteligência é conhecer as coisas } \\
\text { "exatamente como elas são" }\end{array}$ & 50.0 \\
\hline 6 & Existem somente respostas certas ou erradas & 43.5 \\
\hline 7 & Esquecer é um problema & 26.5 \\
\hline
\end{tabular}

Fonte: Estudo de caso, criada pelo autor.

Quanto às ações que necessitam ser praticadas para evitar o predomínio de uma abordagem mindless e favorecer uma abordagem mindful, a partir da percepção dos próprios respondentes, obteve-se os percentuais mostrados na TAB. 26.

TABELA 26. Visão dos usuários sobre abordagem mindful

\begin{tabular}{|c|c|c|}
\hline Abordagem & Descrição & $\begin{array}{c}\% \text { de } \\
\text { confirmação }\end{array}$ \\
\hline 1 & Criação contínua de novas categorias de conhecimentos & 80.4 \\
\hline 2 & Abertura contínua a novas informações & 91.3 \\
\hline 3 & Atenção implícita e simultânea a mais de uma perspectiva & 67.4 \\
\hline
\end{tabular}

Fonte: Estudo de caso, criada pelo autor. 
Quanto às características tecnológicas que precisam estar presentes no ambiente LV/CVE, referentes a TIC, CMC e RV, para adequar o LV/CVE proposto às demandas originadas por seus usuários, de acordo com o estudo de caso realizado, obteve-se os percentuais mostrados na TAB. 27:

TABELA 27. Visão dos usuários sobre aspectos tecnológicos

\begin{tabular}{|c|c|c|}
\hline & Característica desejável & \% de confirmação \\
\hline 1 & Uso de avatar & 91.3 \\
\hline 2 & Maior exatidão & 89.3 \\
\hline 3 & Maior completeza & 82.5 \\
\hline 4 & Maior usabilidade & 78.3 \\
\hline 5 & Maior fidedignidade & $89.3^{*}$ \\
\hline 6 & Adequação de escala de tempo & 89.1 \\
\hline 7 & Maior variedade de cenários & 58.7 \\
\hline
\end{tabular}

* considerado em conjunto com o item 2

Fonte: Estudo de caso, criada pelo autor. 


\section{PROPOSTA DE UM LV/CVE APERFEIÇOADO}

Neste capítulo são analisadas as características relevantes desejáveis que estejam presentes em um LV/CVE, a fim de maximizar os benefícios de sua utilização, com base nos estudos realizados por meio de análises bibliográficas e do estudo de caso.

As características levantadas são comparadas às características do LV/CVE VirRAD, propondo-se, como resultado dessa comparação, um LV/CVE que reúna as características e funcionalidades consideradas importantes para otimizar seu uso e resultados para a comunidade a que se destina.

A análise das características desejadas para o LV/CVE proposto levou em conta os três grupos de fatores abordados na pesquisa exploratória realizada, que foram:

1) aspectos do perfil cognitivo do usuário, com base na teoria cognitiva das inteligências múltiplas, de Howard Gardner,

2) aspectos do perfil cognitivo do usuário, com base na teoria cognitiva mindful learning, de Ellen Langer,

3) aspectos tecnológicos envolvidos na utilização do LV/CVE, com base nas características atualmente disponíveis no LV/CVE VirRAD.

Para cada grupo de fatores abordados, foram feitas sugestões de aperfeiçoamento com base na análise das respostas que obtivemos no estudo de caso realizado. 


\subsection{CARACTERÍSTICAS DO LV/CVE PROPOSTO}

Em primeiro lugar, para adequar o LV/CVE proposto às demandas originadas pelos tipos de inteligências existentes entre os usuários do ambiente, de acordo com a teoria Inteligências Múltiplas, de Gardner, o LV/CVE proposto deverá reunir as funcionalidades ("recursos necessários para satisfazê-la"), conforme mostrado na TAB. 28. 
TABELA 28. Recursos necessários por tipo de inteligência

\begin{tabular}{|c|c|c|c|}
\hline & $\begin{array}{c}\text { Tipo de } \\
\text { Inteligência }\end{array}$ & Recursos necessários para satisfazê-la & Aspecto \\
\hline 1 & VERBAL & $\begin{array}{ll}\checkmark & \text { Textos explicativos } \\
\checkmark & \text { Jogos (palavras cruzadas, quiz, charadas, etc.) } \\
\checkmark & \text { Notícias, artigos, curiosidades, etc. } \\
\checkmark & \text { Estímulo para o usuário produzir textos próprios } \\
\checkmark & \text { Recursos de voz e texto: chat, e-mail, vídeo- } \\
& \text { conferência } \\
\checkmark & \text { Banco de dados dos recursos acima }\end{array}$ & Ml1 \\
\hline 2 & $\begin{array}{l}\text { LÓGICO- } \\
\text { MATEMÁTICA }\end{array}$ & $\begin{array}{l}\checkmark \text { Proposição de problemas envolvendo quebra- } \\
\text { cabeças, adivinhações, questões: para comple- } \\
\text { tar, múltipla-escolha, envolvendo estatística, } \\
\text { lógicas) } \\
\checkmark \text { Banco de dados de problemas propostos e } \\
\text { resolvidos }\end{array}$ & MI2 \\
\hline 3 & $\begin{array}{l}\text { VISUAL- } \\
\text { ESPACIAL }\end{array}$ & $\begin{array}{ll}\checkmark & \text { Imagens, ícones, figuras, gráficos, esquemas e } \\
& \text { animações } \\
\checkmark & \text { Uso abundante de cores } \\
\checkmark & \text { Simulações utilizando avatares (envolvendo } \\
& \text { percursos) } \\
\checkmark & \text { Jogos bi e tri-dimensionais } \\
\checkmark & \text { Banco de dados dos recursos acima }\end{array}$ & MI3 \\
\hline 4 & $\begin{array}{l}\text { CORPÓREO- } \\
\text { CINESTÉSICO }\end{array}$ & $\begin{array}{ll}\checkmark & \text { Dispositivos hápticos } \\
\checkmark & \text { Sons } \\
\checkmark & \text { Ambientes de RV, tais como: CAVE, capacete, } \\
& \text { luvas, atuadores diversos }\end{array}$ & MI4 \\
\hline 5 & $\begin{array}{l}\text { NATURA- } \\
\text { LIISTICA }\end{array}$ & $\begin{array}{l}\checkmark \quad \text { Uso de recursos visuais com temática sobre } \\
\text { fauna e flora } \\
\checkmark \quad \text { Simulações de ambientes, paisagens e } \\
\text { animações referentes a fenômenos da natureza } \\
\checkmark \quad \text { Banco de dados dos recursos acima }\end{array}$ & MI5 \\
\hline 6 & MUSICAL & $\begin{array}{ll}\checkmark & \text { Uso de sons, músicas, vinhetas } \\
\checkmark & \text { Uso de melodias e seqüências sonoras } \\
\checkmark & \text { Banco de dados dos recursos acima }\end{array}$ & MI6 \\
\hline 7 & $\begin{array}{l}\text { INTRA- } \\
\text { PESSOAL }\end{array}$ & $\begin{array}{l}\checkmark \text { Uso de avatar, em modo single-user } \\
\checkmark \text { Solicitar pontos de vista do usuário sobre sua } \\
\text { própria atuação } \\
\checkmark \quad \text { Banco de dados dos pontos de vista acima }\end{array}$ & MI7 \\
\hline 8 & $\begin{array}{l}\text { INTER- } \\
\text { PESSOAL }\end{array}$ & $\begin{array}{ll}\checkmark & \text { Uso de avatar, em modo multi-user } \\
\checkmark & \text { Solicitar pontos de vista do usuário sobre suas } \\
& \text { observações dos outros usuários } \\
\checkmark & \text { Banco de dados dos pontos de vista acima }\end{array}$ & MI8 \\
\hline
\end{tabular}

Fonte: Estudo de caso, criada pelo autor. 
Em segundo lugar, para adequar o LV/CVE proposto às demandas originadas por aspectos da teoria mindful learning, de Langer, buscando-se evitar os sete mitos negativos, o LV/CVE proposto deverá reunir as funcionalidades ("ações para evitálos") conforme mostradas na TAB. 29:

TABELA 29. Ações para evitar os sete mitos negativos

\begin{tabular}{|c|c|c|c|}
\hline & MITO & Ações para evitá-los & Aspecto \\
\hline 1 & $\begin{array}{l}\text { O básico deve ser aprendido tão } \\
\text { bem a ponto de tornar-se uma } \\
\text { segunda natureza da pessoa }\end{array}$ & $\begin{array}{l}\text { Apresentar o assunto selecionado } \\
\text { (escolhido) sob diferentes } \\
\text { abordagens, a fim de reforçar os } \\
\text { conceitos básicos. }\end{array}$ & ML1 \\
\hline 2 & $\begin{array}{l}\text { Prestar atenção é estar focado } \\
\text { em um assunto de cada vez }\end{array}$ & $\begin{array}{l}\text { Montar menus dinâmicos, de } \\
\text { modo que outras opções, além da } \\
\text { selecionada pelo usuário, } \\
\text { apareçam com destaque nas } \\
\text { próximas telas. }\end{array}$ & ML2 \\
\hline 3 & $\begin{array}{l}\text { É importante retardar } \\
\text { gratificações }\end{array}$ & $\begin{array}{l}\text { Proporcionar recompensas } \\
\text { imediatas, na forma de: dicas, } \\
\text { links, mais informações, etc. }\end{array}$ & ML3 \\
\hline 4 & $\begin{array}{l}\text { Memorização é importante em } \\
\text { educação }\end{array}$ & $\begin{array}{l}\text { Montar recursos de "auxílios a } \\
\text { memória" em todas as telas }\end{array}$ & ML4 \\
\hline 5 & Esquecer é um problema & $\begin{array}{l}\text { Montar recursos de "auxílios a } \\
\text { memória" em todas as telas }\end{array}$ & ML5 \\
\hline 6 & $\begin{array}{l}\text { Inteligência é conhecer "as } \\
\text { coisas como elas são" }\end{array}$ & $\begin{array}{c}\text { Expor diferentes visões sobre um } \\
\text { mesmo assunto }\end{array}$ & ML6 \\
\hline 7 & Há respostas certas ou erradas & $\begin{array}{c}\text { Expor diferentes visões sobre um } \\
\text { mesmo assunto }\end{array}$ & ML7 \\
\hline
\end{tabular}

Fonte: Estudo de caso, criada pelo autor.

E buscando-se evitar a abordagem mindless e favorecer a abordagem mindful, ainda conforme aspectos da teoria mindful learning, de Langer, o LV/CVE proposto deverá reunir as funcionalidades ("ações para reforçá-las") mostradas nas TAB. 30: 
TABELA 30. Ações para evitar abordagem mindless e favorecer abordagem mindful

\begin{tabular}{|c|c|c|c|c|}
\hline & $\begin{array}{c}\text { Abordagem } \\
\text { mindless }\end{array}$ & Abordagem mindful & Ações para reforça-las & Aspecto \\
\hline 1 & $\begin{array}{c}\text { Classificação de } \\
\text { novos assuntos em } \\
\text { categorias antigas }\end{array}$ & $\begin{array}{c}\text { A contínua criação } \\
\text { de novas } \\
\text { categorias. }\end{array}$ & $\begin{array}{c}\text { Propor que novos assuntos } \\
\text { devem ser analisados como } \\
\text { pertencentes a novas } \\
\text { categorias, se possível, antes } \\
\text { de enquadrá-los nas } \\
\text { categorias anteriores. }\end{array}$ & ML8 \\
\hline 2 & $\begin{array}{c}\text { Comportamento } \\
\text { automático que } \\
\text { exclui atender a } \\
\text { novos sinais }\end{array}$ & $\begin{array}{c}\text { A contínua abertura } \\
\text { a novas } \\
\text { informações. }\end{array}$ & $\begin{array}{c}\text { Apresentar links dinâmicos a } \\
\text { assuntos afins, criados } \\
\text { semanalmente a partir de } \\
\text { pesquisa no Google. }\end{array}$ & ML9 \\
\hline 3 & $\begin{array}{c}\text { Adoção de ações } \\
\text { que operam sob } \\
\text { uma perspectiva } \\
\text { única }\end{array}$ & $\begin{array}{c}\text { Uma atenção implí- } \\
\text { cita a mais de uma } \\
\text { perspectiva simul- } \\
\text { tâneamente }\end{array}$ & $\begin{array}{c}\text { Apresentar diferentes } \\
\text { perspectivas simultânea- } \\
\text { mente. }\end{array}$ & ML10 \\
\hline
\end{tabular}

Fonte: Estudo de caso, criada pelo autor.

Em terceiro lugar, para adequar o LV/CVE proposto às demandas originadas pelas características tecnológicas desejáveis (referentes a TIC, CMC e RV) levantadas junto aos seus usuários, de acordo com o estudo de caso realizado, o LV/CVE proposto deverá reunir as funcionalidades ("ações para reforçá-las") mostradas na TAB. 31: 
TABELA 31. Características tecnológicas desejáveis no LV/CVE Proposto

\begin{tabular}{|c|c|c|c|}
\hline & Característica desejável & Ações para reforçá-las & Aspecto \\
\hline 1 & Uso de avatar & $\begin{array}{c}\text { Usar avatares em todas as funções } \\
\text { de comunicação, ensino e } \\
\text { aprendizagem. }\end{array}$ & TC1 \\
\hline 2 & Maior exatidão & $\begin{array}{c}\text { Aumentar exatidão dos processos } \\
\text { reproduzidos virtualmente. }\end{array}$ & TC2 \\
\hline 3 & Maior completeza & $\begin{array}{c}\text { Aumentar detalhamento dos } \\
\text { processos reproduzidos virtualmente. }\end{array}$ & TC3 \\
\hline 4 & Maior usabilidade & $\begin{array}{c}\text { Aumentar facilidade de uso dos } \\
\text { processos reproduzidos virtualmente. }\end{array}$ & TC4 \\
\hline 5 & Maior fidedignidade & $\begin{array}{c}\text { Aumentar fidedignidade dos } \\
\text { processos reproduzidos virtualmente. }\end{array}$ & TC5 \\
\hline 6 & Adequação de escala de & $\begin{array}{c}\text { Aumentar correspondência à escala } \\
\text { de tempo dos processos } \\
\text { reproduzidos virtualmente. }\end{array}$ & TC6 \\
\hline 7 & Maior variedade de cenários & $\begin{array}{l}\text { Incluir processos ainda não } \\
\text { considerados no ambiente virtual. }\end{array}$ & TC7 \\
\hline
\end{tabular}

Fonte: Estudo de caso, criada pelo autor.

\subsection{FUNCIONALIDADE DO LV/CVE PROPOSTO}

Incorporando-se os recursos identificados no estudo de caso ao LV/CVE VirRAD, esse passa a ter as funcionalidades mostradas na TAB. 32, na qual as novas funções aparecem relacionadas em itálico e em negrito: 
TABELA 32. Funcionalidade completa do LV/CVE Proposto

\begin{tabular}{|c|c|c|}
\hline Tela/Menu & Função & Satisfaz aspectos \\
\hline Geral & $\begin{array}{l}\text { 1.FAQs/Documentação } \\
\text { 2.Projetos Relacionados } \\
\text { 3.Search-engine }\end{array}$ & $\begin{array}{l}\text { 2. ML6,ML8,TC7 } \\
\text { 3. Ml1 }\end{array}$ \\
\hline Pessoas & $\begin{array}{l}\text { 1.Administradores } \\
\text { 2.Cientistas radiofarmácia (links) } \\
\text { 3.Perfís } \\
\text { 4.Pesquisadores }\end{array}$ & 2. MI8,ML10 \\
\hline $\begin{array}{l}\text { Instruto- } \\
\text { res }\end{array}$ & $\begin{array}{l}\text { 1.Criação de simuladores } \\
\text { 2.Criação de tutoriais (templates) } \\
\text { 3.Curso formação de instrutores } \\
\text { 4.Foruns (grupos especiais) } \\
\text { 5.Pessoas/contatos }\end{array}$ & $\begin{array}{l}\text { 1. MI3,ML1,TC1 } \\
\text { 2. Ml1,TC1 } \\
\text { 3. MI8,ML9,TC1 } \\
\text { 4. Ml8,ML2,TC1 } \\
\text { 5. Ml8,ML10,TC1 }\end{array}$ \\
\hline $\begin{array}{c}\text { 3D VR } \\
\text { Lab }\end{array}$ & 1.Laboratório virtual (com avatar) & Ver Tabela 33 \\
\hline $\begin{array}{l}\text { Estu- } \\
\text { dantes }\end{array}$ & $\begin{array}{l}\text { 1.Atividades } \\
\text { 2.Cenários de radiofarmácia } \\
\text { 3.Foruns (iniciantes) } \\
\text { 4.Introdução } \\
\text { 5.Simuladores } \\
\text { 6.Testes/avaliações } \\
\text { 7.Tutoriais }\end{array}$ & $\begin{array}{l}\text { 3. MI8,ML9,TC1 } \\
\text { 5. MI3,7,8,ML6,9,TC1,5,7 } \\
\text { 6. Ml2,ML4,ML7,ML8,TC1,TC3,TC4 }\end{array}$ \\
\hline $\begin{array}{l}\text { Recur- } \\
\text { sos }\end{array}$ & $\begin{array}{l}\text { 1.Acesso a Web } \\
\text { 2.Cursos on-line } \\
\text { 3.Formação de grupos } \\
\text { 4.Glossário } \\
\text { 5.Hospitais } \\
\text { 6.Links com outros vlabs } \\
\text { 7.Mercado de radiofarmácia } \\
\text { 8.Notícias } \\
\text { 9.Papers } \\
\text { 10.Reações adversas } \\
\text { 11.Search-engine } \\
\text { 12. Vídeo-conferência } \\
\text { 13.Vídeos }\end{array}$ & $\begin{array}{l}\text { 1. Ml4,8,ML2,3,6,7,9,TC1,7 } \\
\text { 2. Ml8,ML1,2,3,6,10,TC1 } \\
\text { 3. Ml8,ML9,TC1 } \\
\text { 5. Ml1,8,ML1-10,TC1,7 } \\
\text { 6. Ml1,8,ML1-10,TC1,7 } \\
\text { 7. Ml1,8,ML1-10,TC1,7 }\end{array}$ \\
\hline
\end{tabular}

Em negrito: novas funções propostas (não existentes no VirRAD).

Fonte: Estudo de caso, criado pelo autor. 
A relação total de funções desejadas (atuais e novas) especificamente dentro do 3D VR Lab do LV/CVE Proposto, está mostrada na TAB. 33:

TABELA 33. Funcionalidade completa do LV/CVE Proposto - Menu 3D VR Lab

\begin{tabular}{|c|c|c|}
\hline Tela/Menu & Função & Satisfaz aspectos \\
\hline $\begin{array}{c}3 \mathrm{D} \\
\text { VR Lab }\end{array}$ & $\begin{array}{l}\text { 1.Acesso Web } \\
\text { 2.Animações } \\
\text { 3.Avaliações/check-points } \\
\text { 4.Avatar multi-user } \\
\text { 5.Avatar single-user } \\
\text { 6.Biblioteca } \\
\text { 7.Chat } \\
\text { 8. Comparações com outros assuntos } \\
\text { 9. Cores } \\
\text { 10.Dicionário/tradutor simultâneo } \\
\text { 11.Dispositivos hápticos } \\
\text { 12. Histórico da utilização anterior } \\
\text { 13.Imagens } \\
\text { 14.Integração com outros VR Labs } \\
\text { 15.Modo de estudo / modo de trabalho } \\
\text { 16. Níveis de dificuldades diferentes } \\
\text { 17.Permitir formação de equipes c/ líder } \\
\text { 18.Propostas de novas categorias } \\
\text { 19.Reconhecimento de voz } \\
\text { 20.Recursos multimídia } \\
\text { 21.Simulações baseadas na natureza } \\
\text { 22.Simulações usando avatares } \\
\text { 23. Sons, músicas, vinhetas } \\
\text { 24. Vídeo-conferência } \\
\text { 25.Vídeos de experimentos }\end{array}$ & 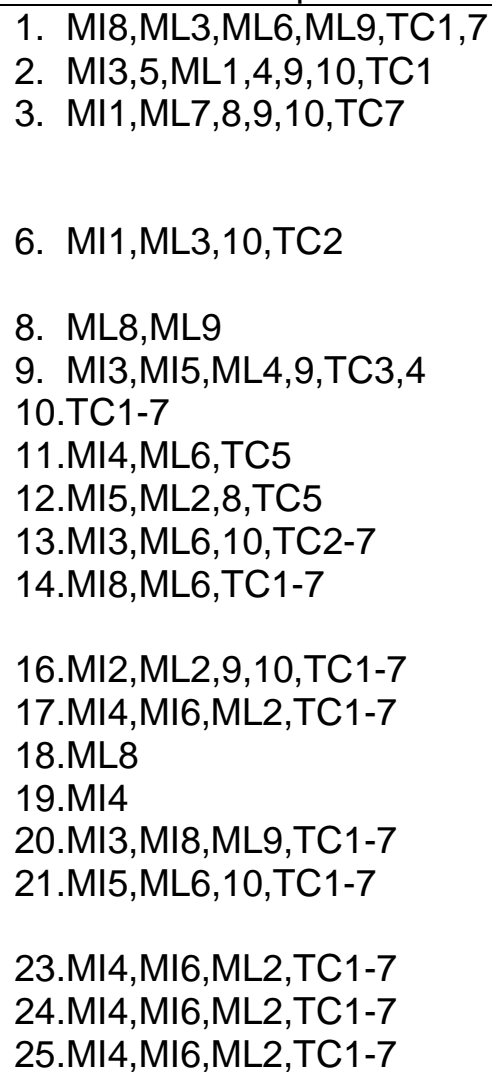 \\
\hline
\end{tabular}

Em negrito: novas funções propostas (não existentes no Menu 3D VR Lab VirRAD).

Fonte: Estudo de caso, criado pelo autor.

As novas funções agregadas ao LV/CVE Proposto têm as finalidades mostradas na TAB. 34 . 
TABELA 34. Finalidades das funções acrescentadas ao LV/CVE Proposto

\begin{tabular}{|c|c|c|}
\hline Menu & Função & Finalidade \\
\hline \multirow[t]{2}{*}{ GERAL } & 2.Projetos Relacionados & $\begin{array}{l}\text { Relacionar dados dos projetos de } \\
\text { radiofarmácia existentes fora do VirRAD. }\end{array}$ \\
\hline & 3.Search-engine & $\begin{array}{l}\text { Prover mecanismo de busca na internet, } \\
\text { dentro desse menu. }\end{array}$ \\
\hline PESSOAS & $\begin{array}{l}\text { 2.Cientistas de } \\
\text { radiofarmácia }\end{array}$ & $\begin{array}{l}\text { Relacionar pesquisadores mundiais de } \\
\text { radiofarmácia e suas contribuições. }\end{array}$ \\
\hline \multirow[t]{5}{*}{ INSTRUTORES } & 1.Criação de simuladores & $\begin{array}{l}\text { Prover ferramenta de software para os } \\
\text { instrutores criarem simulações. }\end{array}$ \\
\hline & 2.Criação de tutoriais & $\begin{array}{l}\text { Prover ferramenta de software para os } \\
\text { instrutores criarem tutoriais. }\end{array}$ \\
\hline & $\begin{array}{l}\text { 3.Curso de formação de } \\
\text { instrutores }\end{array}$ & $\begin{array}{l}\text { Criar curso para formar novos instrutores } \\
\text { sobre recursos/facilidades do VirRAD. }\end{array}$ \\
\hline & 4.Fóruns (grupos especiais) & $\begin{array}{lll}\text { Promover fóruns específicos } & \text { entre } \\
\text { instrutores, para aperfeiçoamento. }\end{array}$ \\
\hline & 5.Pessoas (contatos) & Disponibilizar dados de instrutores. \\
\hline \multirow[t]{3}{*}{ ESTUDANTES } & 3.Fóruns (iniciantes) & $\begin{array}{l}\text { Promover fóruns assistidos } \\
\text { participação de iniciantes. }\end{array}$ \\
\hline & 5.Simuladores & $\begin{array}{l}\text { Disponibilizar simuladores para permitir } \\
\text { navegações de estudantes. }\end{array}$ \\
\hline & 6.Testes / avaliações & $\begin{array}{l}\text { Disponibilizar recursos de testes e e } \\
\text { avaliações para estudantes, com correções } \\
\text { automáticas. }\end{array}$ \\
\hline \multirow[t]{9}{*}{ RECURSOS } & 1.Acesso a web & $\begin{array}{l}\text { Prover mecanismo de busca na internet, } \\
\text { dentro desse menu. }\end{array}$ \\
\hline & 2.Cursos on-line & $\begin{array}{l}\text { Disponibilizar acesso via web para cursos } \\
\text { afins. }\end{array}$ \\
\hline & 3.Formação de grupos & $\begin{array}{l}\text { Prover facilidade para formação de grupos } \\
\text { e gestão de conhecimento. }\end{array}$ \\
\hline & 5. Hospitais & $\begin{array}{lll}\text { Prover relação/formas de contato } & \text { com } \\
\text { hospitais ligados a radiofarmácia. } & \\
\end{array}$ \\
\hline & 6.Links com outros vlabs & $\begin{array}{l}\text { Prover hiperlinks para acesso a outros } \\
\text { vlabs. }\end{array}$ \\
\hline & 7.Mercado de radiofarmácia & $\begin{array}{l}\text { Prover informações comerciais sobre } \\
\text { mercado de radiofarmácia. }\end{array}$ \\
\hline & 11.Search-engine & $\begin{array}{l}\text { Prover mecanismo de busca dentro da } \\
\text { internet. }\end{array}$ \\
\hline & 12. Vídeo-conferência & $\begin{array}{l}\text { Prover facilidades para a realização de } \\
\text { vídeo-conferências. }\end{array}$ \\
\hline & 13. Vídeos & Disponibilizar (links a) vídeos de interesse. \\
\hline
\end{tabular}

Fonte: Estudo de caso, criado pelo autor. 
TABELA 34. Finalidade das funções acrescentadas ao LV/CVE Proposto (cont.)

\begin{tabular}{|c|c|c|}
\hline Menu & Função & Finalidade \\
\hline \multirow[t]{20}{*}{ 3D VR LAB } & 1.Acesso a web & $\begin{array}{l}\text { Prover mecanismo de busca na internet, } \\
\text { dentro desse menu. }\end{array}$ \\
\hline & 2.Animações & $\begin{array}{l}\text { Disponibilizar animações ilustrativas de } \\
\text { procedimentos. }\end{array}$ \\
\hline & 3.Avaliações/check-points & $\begin{array}{l}\text { Disponibilizar recursos para avaliação de } \\
\text { aprendizagem. }\end{array}$ \\
\hline & 6.Biblioteca & $\begin{array}{l}\text { Disponibilizar acesso on-line a acervo } \\
\text { bibliográfico. }\end{array}$ \\
\hline & $\begin{array}{l}\text { 8.Comparações com outros } \\
\text { assuntos }\end{array}$ & $\begin{array}{l}\text { Disponibilizar referências cruzadas com } \\
\text { assuntos afins. }\end{array}$ \\
\hline & 9. Cores & $\begin{array}{l}\text { Disponibilizar painel de cores associadas } \\
\text { a assuntos/tópicos. }\end{array}$ \\
\hline & $\begin{array}{l}\text { 10.Dicionário/tradutor } \\
\text { simultâneo }\end{array}$ & $\begin{array}{l}\text { Prover recurso on-line para tradução de } \\
\text { palavras e textos. }\end{array}$ \\
\hline & 11.Dispositivos hápticos & $\begin{array}{l}\text { Prover dispositivos hápticos para usuário } \\
\text { interagir com o ambiente. }\end{array}$ \\
\hline & 12. Histórico da utilização & $\begin{array}{l}\text { Disponibilizar histórico das navegações } \\
\text { realizadas pelo usuário. }\end{array}$ \\
\hline & 13.Imagens & $\begin{array}{l}\text { Disponibilizar figuras e imagens dos } \\
\text { processos e procedimentos. }\end{array}$ \\
\hline & $\begin{array}{l}\text { 14.Integração com outros VR } \\
\text { Labs }\end{array}$ & $\begin{array}{l}\text { Disponibilizar hiperlink para outros VR } \\
\text { Labs afins. }\end{array}$ \\
\hline & $\begin{array}{l}\text { 16. Niveis de dificuldades } \\
\text { diferentes }\end{array}$ & $\begin{array}{l}\text { Disponibilizar cenários de radiofarmácia } \\
\text { (processos e procedimentos) pré-classi- } \\
\text { ficados por nível de dificuldade. }\end{array}$ \\
\hline & $\begin{array}{l}\text { 17.Permitir formação de equipes } \\
\text { com líder }\end{array}$ & $\begin{array}{l}\text { Prover recursos para formação de } \\
\text { equipes, com distinção de funções. }\end{array}$ \\
\hline & $\begin{array}{l}\text { 18.Propostas de novas catego- } \\
\text { rias }\end{array}$ & $\begin{array}{l}\text { Prover recurso para permitir criação de } \\
\text { diferentes taxonomias. }\end{array}$ \\
\hline & 19. Reconhecimento de voz & $\begin{array}{l}\text { Prover recurso para captar comandos por } \\
\text { meio de voz. }\end{array}$ \\
\hline & 20 Recursos multimídia & $\begin{array}{l}\text { Prover recursos multimídia ilustrativos de } \\
\text { procedimentos. }\end{array}$ \\
\hline & $\begin{array}{l}\text { 21.Simulações baseadas na } \\
\text { natureza }\end{array}$ & $\begin{array}{l}\text { Disponibilizar simulações com base em } \\
\text { fenômenos da natureza. }\end{array}$ \\
\hline & 23.Sons, músicas, vinhetas & $\begin{array}{l}\text { Disponibilizar recursos } \\
\text { associados a procedimentos. }\end{array}$ \\
\hline & 24. Vídeo-conferência & $\begin{array}{l}\text { Disponibilizar recursos para realização de } \\
\text { videoconferências. }\end{array}$ \\
\hline & 25. Vídeos de experimentos & $\begin{array}{l}\text { Disponibilizar vídeos (ou hiperlinks) de } \\
\text { experimentos. }\end{array}$ \\
\hline
\end{tabular}

Fonte: Estudo de caso, criado pelo autor. 


\section{CONCLUSÕES}

Como apontado na Introdução deste trabalho, para um ambiente LV/CVE ter sua eficácia maximizada como uma solução e interface tecnológica de comunicação, ensino e aprendizagem, para usuários de qualquer área científica (e em especial para a área de radiofarmácia), propõe-se que sua concepção e utilização deve basear-se na aplicação integrada tanto de pressupostos cognitivos quanto de pressupostos tecnológicos, o que não é encontrado de modo plenamente realizado no ambiente LV/CVE VirRAD, embora o mesmo apresente alto nível de qualidade quanto à sua concepção e realização.

Os pressupostos cognitivos considerados necessários no ambiente virtual de ensino e aprendizagem LV/CVE são os que atendem aos tipos de inteligências apontados pela teoria Inteligências Múltiplas e às recomendações sobre ensino e aprendizagem feitas pela teoria mindful learning.

Os pressupostos tecnológicos considerados necessários são os apontados pelos requisitos de TIC, CMC e de RV.

Quanto à presença dos tipos de inteligências referentes à teoria inteligências múltiplas observadas nos usuários do LV/CVE VirRAD, conclui-se que:

a) A maioria dos usuários possui os tipos de inteligência verbal, lógicomatemática, visual-espacial, naturalística e inter-pessoal bem desenvolvidas, e esse é um fator positivo, já que esses tipos de inteligências proporcionam a seus possuidores melhores perspectivas de aprendizagem, portanto conclui-se que é recomendável incrementar recursos e facilidades ao LV/CVE VirRAD que reforcem e estimulem a manutenção desses tipos de inteligência;

b) A maioria dos usuários não possui os tipos de inteligência corpóreacinestésica, musical e intrapessoal bem desenvolvidas, e esse é um fator negativo, já que esses tipos de inteligência proporcionariam aos seus possuidores melhores possibilidades de aprendizagem, portanto conclui-se que é recomendável prover 
recursos e facilidades ao LV/CVE VirRAD que estimulem o incremento desse tipo de inteligência.

Quanto às recomendações da teoria mindful learning para que se evite incorrer nos sete mitos educacionais prejudiciais às atividades de ensino e aprendizagem no ambiente LV/CVE VirRAD, conclui-se que:

a) A maioria dos usuários acredita e tem ações aderentes a confirmar a prevalência dos mitos 1 e 2, e esse é um fator negativo, já que essa postura representa dificuldades e limitações de resultados nos processos cognitivos, portanto conclui-se que é recomendável prover e incrementar recursos e facilidades para desestimular as condições geradoras desses mitos;

b) A maioria dos usuários acredita e tem ações aderentes a confirmar os efeitos negativos da prevalência dos mitos 3, 4, 5, 6 e 7, e esse é um fator positivo, já que as posturas apontadas neles, quando adotadas, causam dificuldades e limitações nos resultados de processos cognitivos, portanto conclui-se que é recomendável prover e incrementar recursos e facilidades para estimular as condições que mantenham esses mitos distantes do LV/CVE VirRAD.

Quanto às recomendações da teoria mindful learning para que se estimule a adoção e desenvolvimento de uma abordagem mindful e se evite uma abordagem mindless em atividades de ensino e aprendizagem, conclui-se que a maioria dos usuários:

1) está aberta à criação de novas categorias para conter novos conhecimentos, quando de sua aquisição;

2) está receptiva continuamente a novas informações;

3) tem sua atenção voltada a múltiplas perspectivas simultaneamente;

e que esses são três aspectos positivos, já que as posturas apontadas neles facilitam e otimizam resultados em processos cognitivos, portanto conclui-se que é 
recomendável prover, incrementar e manter recursos e facilidades para estimular essas abordagens no LV/CVE VirRAD.

Quanto aos fatores tecnológicos observados no LV/CVE VirRAD, referentes a TIC, CMC e RV, conclui-se que a maioria dos usuários têm uma visão positiva sobre sua presença dentro do ambiente LV/CVE VirRAD, bem como esperam utilizá-lo mais intensamente como ferramenta de ensino, aprendizagem e comunicação, na medida em que ele passe a apresentar evoluções em seus pressupostos tecnológicos e cognitivos, tais como as apresentadas neste trabalho. Seus usuários, atualmente:

a) Geram alta quantidade de acessos ao ambiente;

b) Têm como principal objetivo de sua utilização o acesso a notícias de radiofarmácia;

c) Consideram o uso de avatares entre importante e essencial;

d) Confiam no grau de correção, fidedignidade, completeza dos dados e usabilidade dos recursos.

\subsection{SUGESTÕES PARA TRABALHOS FUTUROS}

Vislumbram-se oportunidades para trabalhos futuros relacionados à análise de ambientes LV/CVE, que incorporem visões que confrontem as características e necessidades dos LV/CVE perante:

a) outros aspectos tecnológicos relacionados a soluções ou interfaces desse tipo, não abordados aqui, tal como: interface homem-computador (IHC);

b) outras teorias cognitivas além das apresentadas aqui, como a teoria denominada aprendizagem significativa, de David Ausubel e seus colaboradores;

c) outros aspectos teórico-práticos relacionados a ensino e aprendizagem, como é o caso dos temas gestão do conhecimento (GC), comunidades de prática e elearning. 
d) outros aspectos de RV ou Inteligência Artificial, não abordados aqui ou abordados de forma periférica, mas que poderiam sê-lo de forma nuclear em outros estudos.

Há grande potencial para estudos interdisciplinares envolvendo TIC, LV/CVE e teorias cognitivas, que sejam destinados a criar ambientes interativos para ensino e aprendizagem de conceitos de ciências exatas, como radiofarmácia, biologia, medicina, física, química, informática ou matemática, entre outras. E esses estudos poderão ser realizados por equipes de pesquisadores dessas áreas, e para os quais poderão colaborar os cientistas com formações, interesses e expertises relacionadas a essas e a outras áreas de estudos. 
09. ANEXOS

\section{QUESTIONÁRIO \\ VIRRAD USER'S QUESTIONNAIRE}

Part 1: WHO I AM

\section{GENDER:}

$\square$ man $\square$ woman

AGE:

$\square$ less than 30 years

$\square$ between 31 and 40 years

$\square$ between 41 and 50 years

$\square$ between 51 and 60 years

$\square$ more than 60 years

\section{SUPERIOR EDUCATION:}

$\square$ engineering/radiology/medical technology

$\square$ medicine or biology

$\square$ physics

$\square$ chemistry

$\square$ information technology

$\square$ other:

\section{GRADUATION YEAR:}

$\square 1980$ or less

$\square$ between 1981 and 1990

$\square$ between 1991 and 2000

$\square$ after 2000

\section{MAIN OCCUPATION:}

$\square$ researcher

$\square$ manager or director

$\square$ student

$\square$ teacher or professor

$\square$ other: 
CAREER TIME:
$\square 5$ years or less
$\square$ between 6 and 10 years
$\square$ between 11 and 20 years
$\checkmark$ more than 20 years 


\subsection{QUESTIONÁRIO MINDFUL LEARNING}

\section{Part 2: WHAT BEST DESCRIBES ME}

\section{Choose only one alternative for each question:}

ML01: Before starting a new task, I study it:

1. in details, many times,

2. in details, but once,

3. in its general sense, a few times,

4. superficially, but once, later I study it better when necessary

5. learn the times it is true but also when it may not be

ML02: At school (high school or college), in order to prepare me for examinations, presentations or exams, I used to study:

1. the same subject in details, many times,

2. the same subject in details, but once,

3. a subject in its general sense, a few times,

4. a subject superficially, but once, then I get back to study it before the test

ML03: In order to learn a new subject/task at my work place, I:

1. isolate myself and focus exclusively at the subject

2. totally concentrate on the subject, better if isolated

3. priority concentrate on the subject, anywhere, but manages to do other things at the same time

4. don't need to concentrate a lot; normally do many things at the same time

5. think about it in many different ways

ML04: When I achieve something that I find good or important, I:

1. want to get the credits immediately

2. don't want to get the credits immediately, but in the future

3. don't want to get the credits immediately or in the future

4. am indifferent if I get the credits, immediately or in the future

5. enjoy getting the credit but don't take it very seriously 


\section{ML05: In my opinion:}

1. It's very important to remember clearly about a subject

2. I don't try to learn it by heart; when I need information about something, I know where to find it

3. To remember the basic is enough for me

4. I don't know almost anything by heart; that's why I keep my notes

5. My privileged memory is one of my greatest qualities

6. Remember is not important. It's more important to ratiocinate about the present

ML06: Every time I forget something, I:

1. Check my notes, without any problem

2. Search on the web, at the books, on my files (my registers) without any problem

3. Get nervous and check my notes, my files (my registers) or on the web

4. Usually I wait until remember it after a little period

ML07: I think that:

1. There are just correct or incorrect answers. There can't be a maybe.

2. Reality is diverse. It's hard to say what's correct or incorrect.

3. I try to keep the tradition about what's correct and incorrect

4. I try to find new answers to old and new questions

ML08: I read papers, magazines and news in the WEB/TV:

1. Every day and accurately

2. Every day and accurately, and also attend to courses/congresses every semester or year

3. Accurately, twice or three days a week

4. Accurately, twice or three days a week, and also attend to courses/congresses every year or each two years

5. At a glance, one day a week or less, and also have attended to a course/congress since 2005

6. At a glance, one day a week or less

MLO9: What kind of WEB user I am:

1. Don't use to access WEB neither blogs, communities of practice or similar

2. I use to access WEB everyday, looking for news, access blogs, news, etc.

3. I'm enrolled in communities of practice, for business and/or cultural purposes

4. I'm a community of practice leader, for business and/or cultural purposes 
ML10: Last time I wrote a technical paper or article, for an academic magazine, was:

1. Alone, during 2007

2. With partner(s), during 2007

3. Alone, between 2005 and 2007

4. With partner(s), between 2005 and 2007

5. Alone, since 2000

6. With partner(s), since 2000

7. Alone, before 2000

8. With partner(s), before 2000

9. I have never produced one

ML11: Last time I had to face any organizational changes in my job (working methods, hierarchical, etc.):

1. I refused them; I quit the job

2. I didn't accept them at the beginning; I took a long time to accept them

3. I didn't accept them yet

4. I have adopted them since the beginning, carefully

5. I have adopted them since the beginning, enthusiastically

ML12: When I achieve a new knowledge, I:

1. Try to compare it with my previous knowledge and classify then in this context

2. At first, I try to create a new category to classify it, even tough I would check the category again

3. Try to classify it on my knowledge base and taxonomy. If I can't, I give it away

4. Don't think if it's from the same type from the others knowledges

ML13: Looking at myself through the last 10 years, I recognize:

1. My knowledge basis and categories are essential the same

2. My knowledge basis and categories are different in some ways

3. My knowledge basis and categories are profoundly different

4. I can't identify if there is any changes in my knowledge basis and categories

ML14: The latest new knowledge that I got was:

1. More than 5 years ago

2. More than 1 year ago

3. More than 1 month ago

4. More than 1 week ago

5. Less than 1 week ago 
ML15: I used to look for new information (congress, publications, new fellows, new places, google, etc.):

1. Every day

2. Every week

3. Every month

4. Only when I'm requested by someone

ML16: When I learn something, I:

1. Get it exactly as I it was teached

2. Get it with some little adaptations into my perspectives, that I do immediately

3. Create immediately my own scheme, normally different from what was teached

4. Create my own scheme after I have internalized it

ML17: When I am in a public place, among unknown people, I:

1. Always I'm focused in others conversations, when I'm alone

2. Always I'm focused in others conversations, even when I'm not alone

3. Don't stay focused in others conversations, even when I'm alone

4. Don't stay focused in others conversations, even when I'm not alone 


\subsection{QUESTIONÁRIO INTELIGÊNCIAS MÚLTIPLAS}

\section{Just choose yes or no for each one:}

MI01:

$\square$ yes $\square$ no I like to read and I use to read everyday: newspapers, books, magazines, web sites.

MI02:

$\square$ yes $\square$ no I like to solve word games, puns and rhymes

MI03:

$\square$ yes $\square$ no I am accustomed to writing, speaking and/or teaching on a regular basis

MI04:

$\square$ yes $\square$ no I can analyze numbers quickly

MI05:

$\square$ yes $\quad \square$ no I use statistical data and/or higher math routinely

MI06:

$\square$ yes $\square$ no I am a accomplished logistician or mathematician

MI07:

$\square$ yes $\square$ no I appreciate the visual world

MI08:

$\square$ yes $\square$ no I am interested in colors and patterns

MI09:

$\square$ yes $\square$ no I enjoy tinkering with things

MI10:

$\square$ yes $\square$ no l enjoy taking long walks

MI11:

$\square$ yes $\square$ no I like to exercise moderately

MI12:

$\square$ yes $\quad \square$ no $\quad$ I am an amateur in a particular sports or activity such as running,skating, dancing or aerobics 
MI13:

$\square$ yes $\square$ no I enjoy being close to nature such as the beach and the field

MI14:

$\square$ yes $\quad \square$ no I am interested in differentiating the different species/types of plants, animals or minerals around

MI15:

$\square$ yes $\quad \square$ no People always look to me when they have queries regarding flora and fauna

MI16:

$\square$ yes $\quad \square$ no I like to tap out rhythms when I am listening to music and/or singing in the shower

MI17:

$\square$ yes $\square$ no l love to go to concerts

MI18:

$\square$ yes $\square$ no I play an instrument and/or I am a vocalist

MI19:

$\square$ yes $\quad \square$ no I am very interested in personal instrospection

MI20:

$\square$ yes $\quad \square$ no I like to spend time alone thinking

MI21:

$\square$ yes $\square$ no I keep a journal that includes my inner thoughts

MI22

$\square$ yes $\square$ no $\quad$ I am interested in making friends and I am comfortable around new people

MI23

$\square$ yes $\square$ no People come to me for advice

MI24

$\square$ yes $\quad \square$ no I am seen as a leader by many and I am involved in teaching or managing others in my daily life 


\title{
9.3 QUESTIONÁRIO ASPECTOS DA UTILIZAÇÃO DO LV/CVE VirRAD
}

\author{
Part 3: MY OPINION ABOUT VIRRAD ENVIRONMENT
}

Choose only one alternative for each question (except when indicated):

VR01: SCORE FROM 1 TO 3 (GREATER) TO EACH FEATURE OF VIRRAD MAIN AREA, ACCORDING ITS IMPORTANCE TO YOU:

Community (tools for the communication, collaboration and information exchange)

$\square$ 3D VR Laboratory (lab simulation environment, in order to carry out specific radiopharmacy scenarios)

$\square$ Courseware (VirRAD non-VR materials)

VR02: I USE TO LOGIN AT VIRRAD ENVIRONMENT:

$\square$ Everyday

$\square$ At least twice a week

$\square$ Once a week

At least twice a month

$\square$ Rarely

VR03: USUALLY MY MAIN INTEREST AMONG VIRRAD MAIN FUNCTIONS IS ORIENTED TO THE SECTION (non exclusive):

News - events

Forums

Chat - conference

$\square$ Library

$\square$ Adverse reactions

$\square$ Glossary of terms

$\square$ Links

$\square$ Search

$\square$ VirRAD Members

VirRAD Team 
VR04: USUALLY MY ROLE AT VIRRAD ENVIRONMENT IS (non-exclusive):

$\square$ Mentor

Author

Learner

$\square$ News reader

$\square$ Administrator / content manager

VR05: USUALLY, WHEN USING 3D VR LAB, I DO IT:

$\square$ with Learner Modelling Assistance

$\square$ without Learner Modelling Assistance

VR06: THE THREE 3D VR LAB SCENARIOS I HAD PERFORMED MORE TIMES UNTIL NOW WAS:

Prepare the LFC

Elute the generator

$\square$ Measure Mo-99 breakthrough

$\square$ Replace the generator element

Install generator

$\square$ Prepare a Tc-99m kit

$\square$ Perform QC

$\square$ Prepare Mag-3

$\square \mathrm{QC}$ of $99 \mathrm{~m}-\mathrm{Tc}-\mathrm{Mag}-3$

VR07: I THINK THE AVATAR FEATURE INSIDE 3D VR LAB IS:

Irrelevant to my learning process

$\square$ Important to my learning process

$\square$ Essential to my learning process 
VR08: THINKING ON THE CORRECTNESS OF SCENARIO ACTIVITIES I USE TO PERFORM AT 3D VR LAB:

$\square$ it's better than the real one (is more accurate)

$\square$ it's equivalent to the real one (has the same accuracy)

$\square$ it's worse than the real one (is less accurate)

VR09: THINKING ON THE COMPLETENESS OF SCENARIO ACTIVITIES I USE TO PERFORM AT 3D VR LAB:

$\square$ it's better than the real one (has more steps)

$\square$ it's equivalent to the real one (has the same steps)

$\square$ it's worse than the real one (has less steps)

VR10: THINKING ON THE USABILITY OF SCENARIO ACTIVITIES I USE TO PERFORM $A T$ 3D VR LAB:

$\square$ it's easier than the real one (it flows better)

$\square$ it's equivalent to the real one (it flows like)

$\square$ it's harder than the real one (it flows harder)

VR11: THINKING ON THE FIDEDIGNITY OF SCENARIO ACTIVITIES I USE TO PERFORM AT 3D VR LAB:

$\square$ it's better than the real one (has more details)

$\square$ it's equal to the real one (has the same details)

$\square$ it's worse than the real one (has less details)

VR12: THINKING ON THE TIME SCALE OF SCENARIO ACTIVITIES I USE TO PERFORM $A T$ 3D VR LAB:

they use to be faster than the real ones

$\square$ they use to last the same time of the real ones

$\square$ they use to be slower than the real ones 
VR13: THINKING ON THE VARIETY OF SCENARIOS AVAILABLE AT 3D VR LAB, I THINK:

$\square$ they represent a poor sample of radiopharmacy procedures/scenarios

$\square$ they represent a good sample of radiopharmacy procedures/scenarios

$\square$ they represent an excellent sample of radiopharmacy procedures/scenarios

VR14: THINKING ON THE 3D VR LAB AS A WHOLE, I CAN SAY (non-exclusive):

$\square$ I can't see how they could be useful to me

$\square$ they are not useful to me but I recognize they can be useful for beginners in radiopharmacy

$\square$ they can be useful to me as a research tool as far as they can be improved

$\square$ they can be useful to me as a communication tool as far as they can be improved

$\square$ they can be useful to me as a teaching and learning tool as far as they can be improved

$\square$ they are already very useful to me as a research tool

$\square$ they are already very useful to me as a communication tool

$\square$ they can already very useful to me as a teaching tool 


\subsection{TELAS DO LV/CVE PROPOSTO}

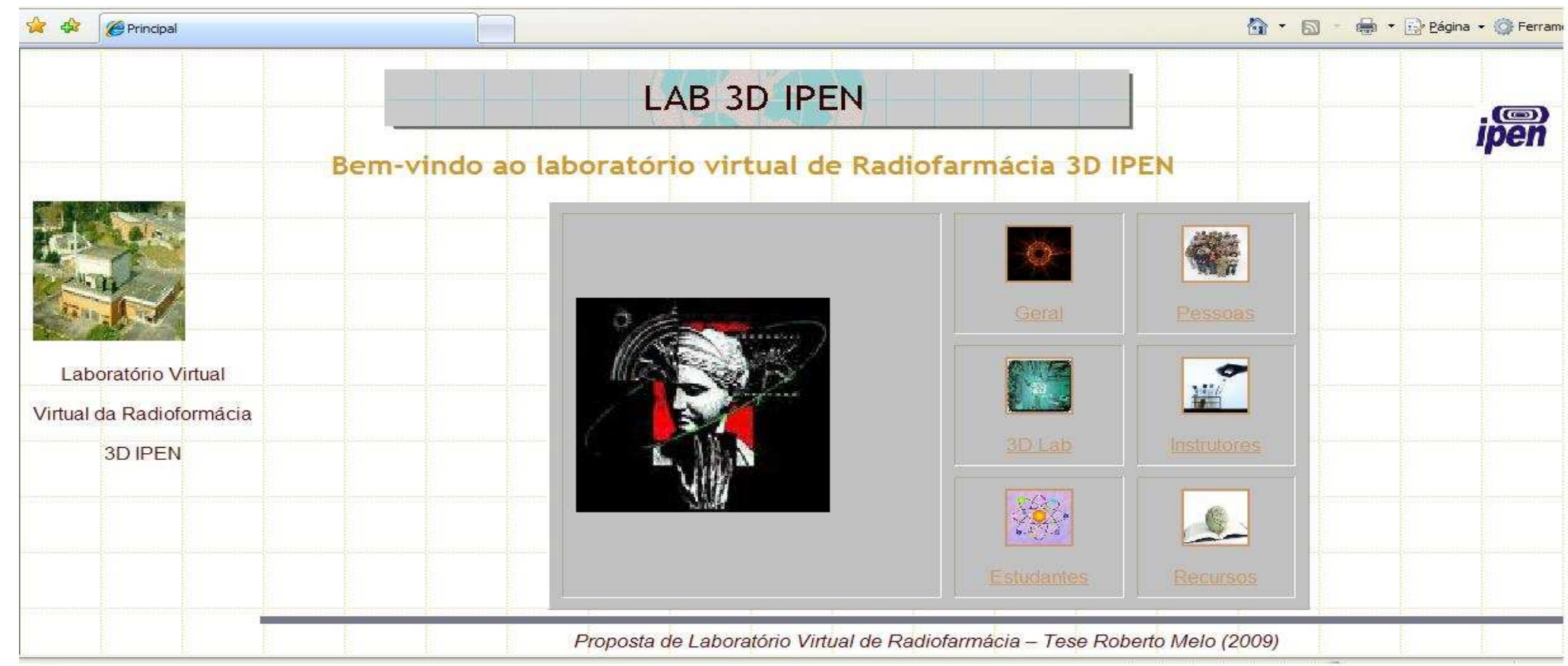




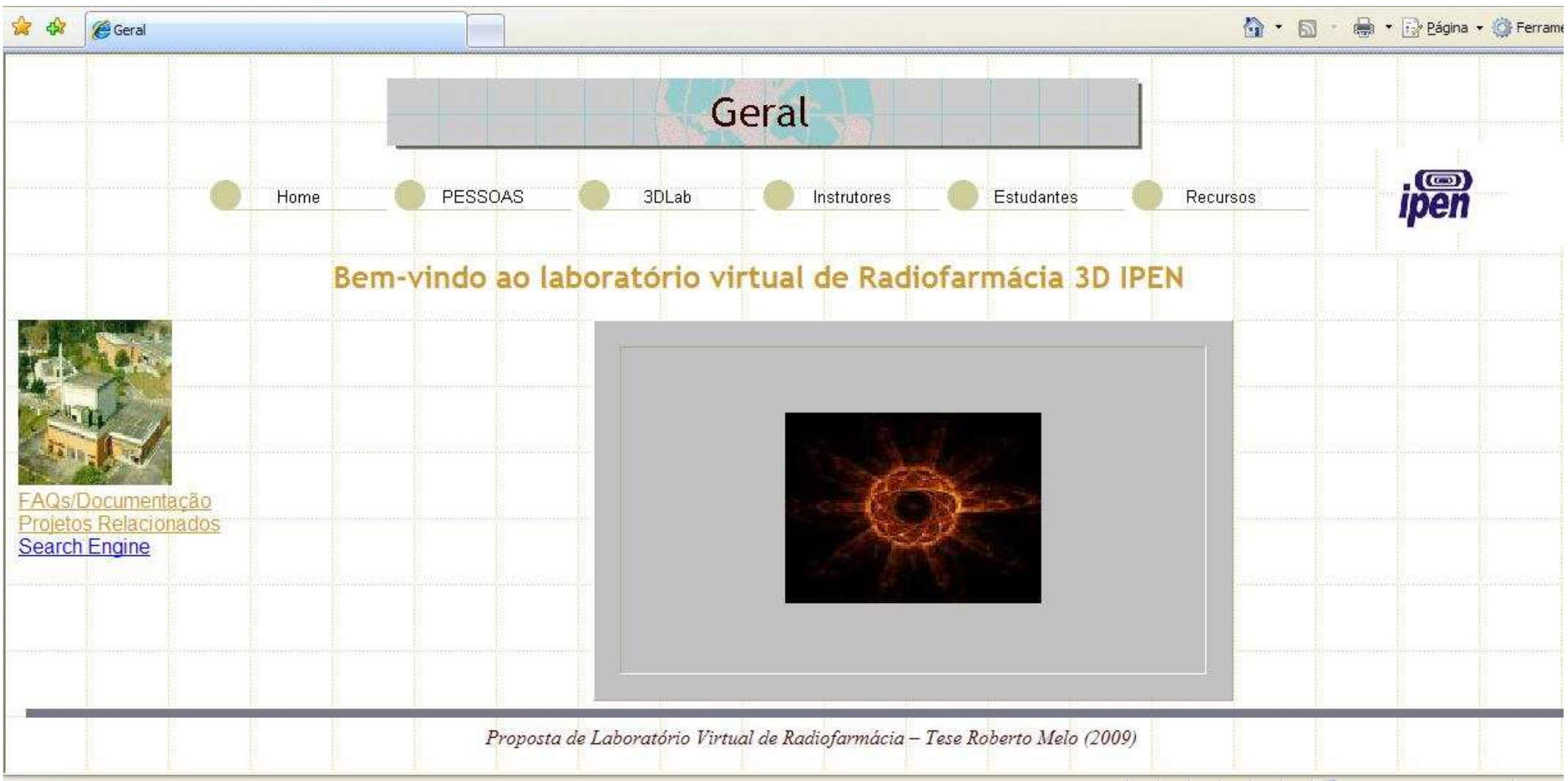




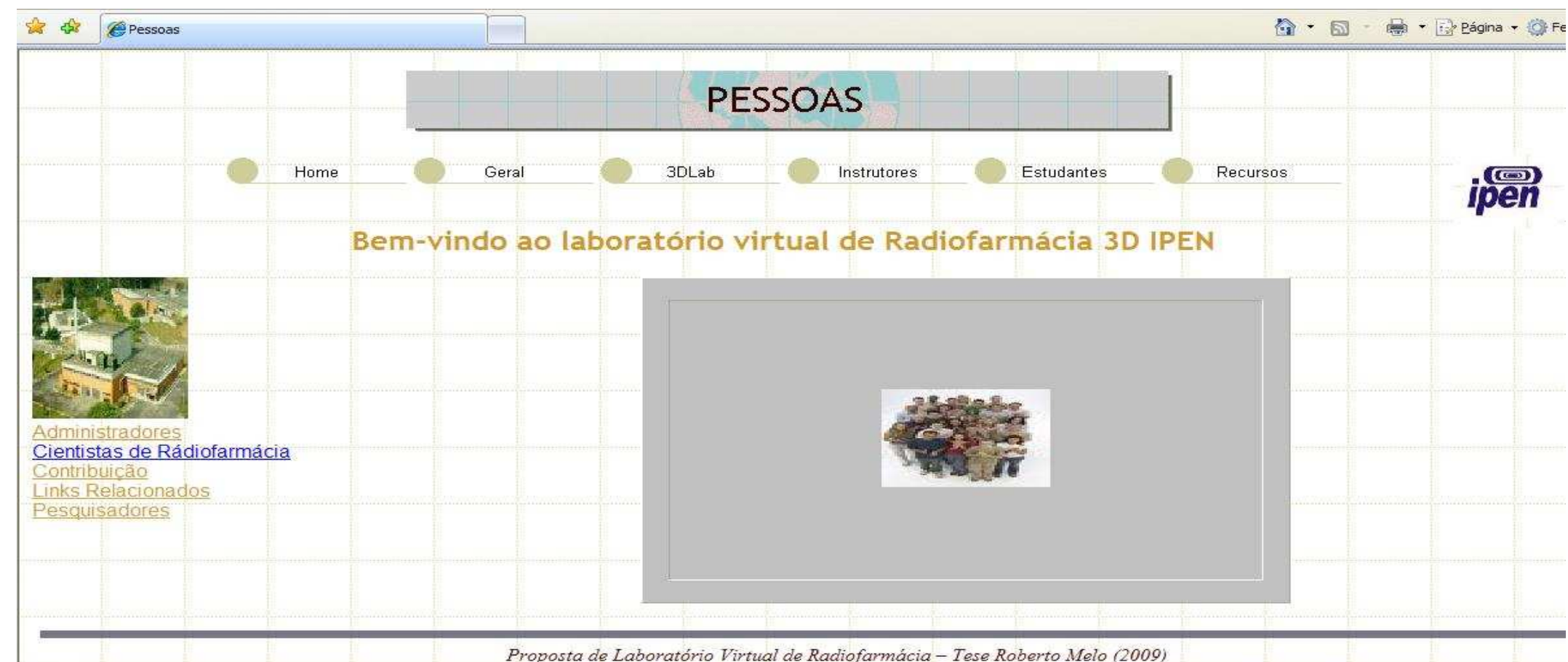

Proposta de Laboratório Virtual de Radiofarmácia - Tese Roberto Melo (2009) 


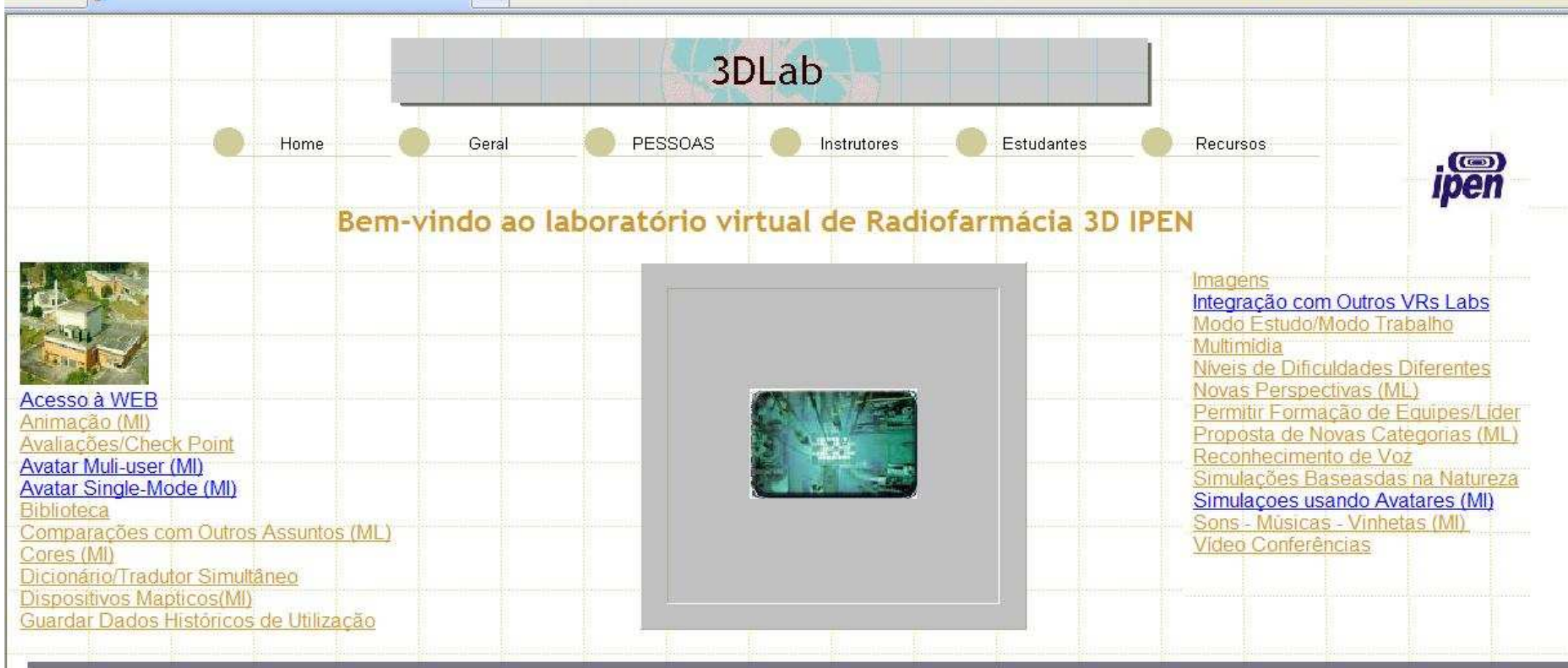

Proposta de Laboratório Virtual de Radiofarmácia - Tese Roberto Melo (2009) 


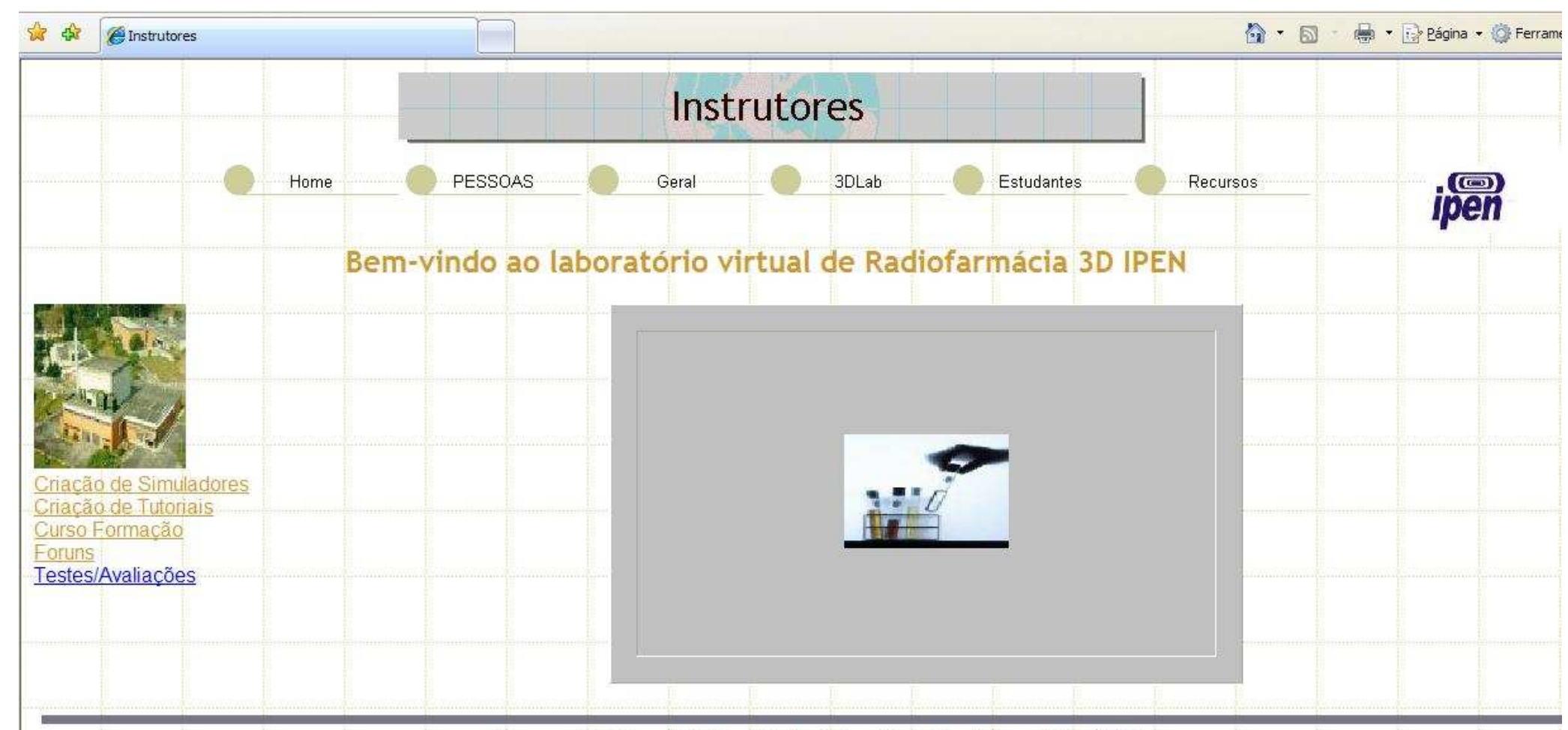

Proposta de Laboratório Virtual de Radiofarmácia - Tese Roberto Melo (2009) 


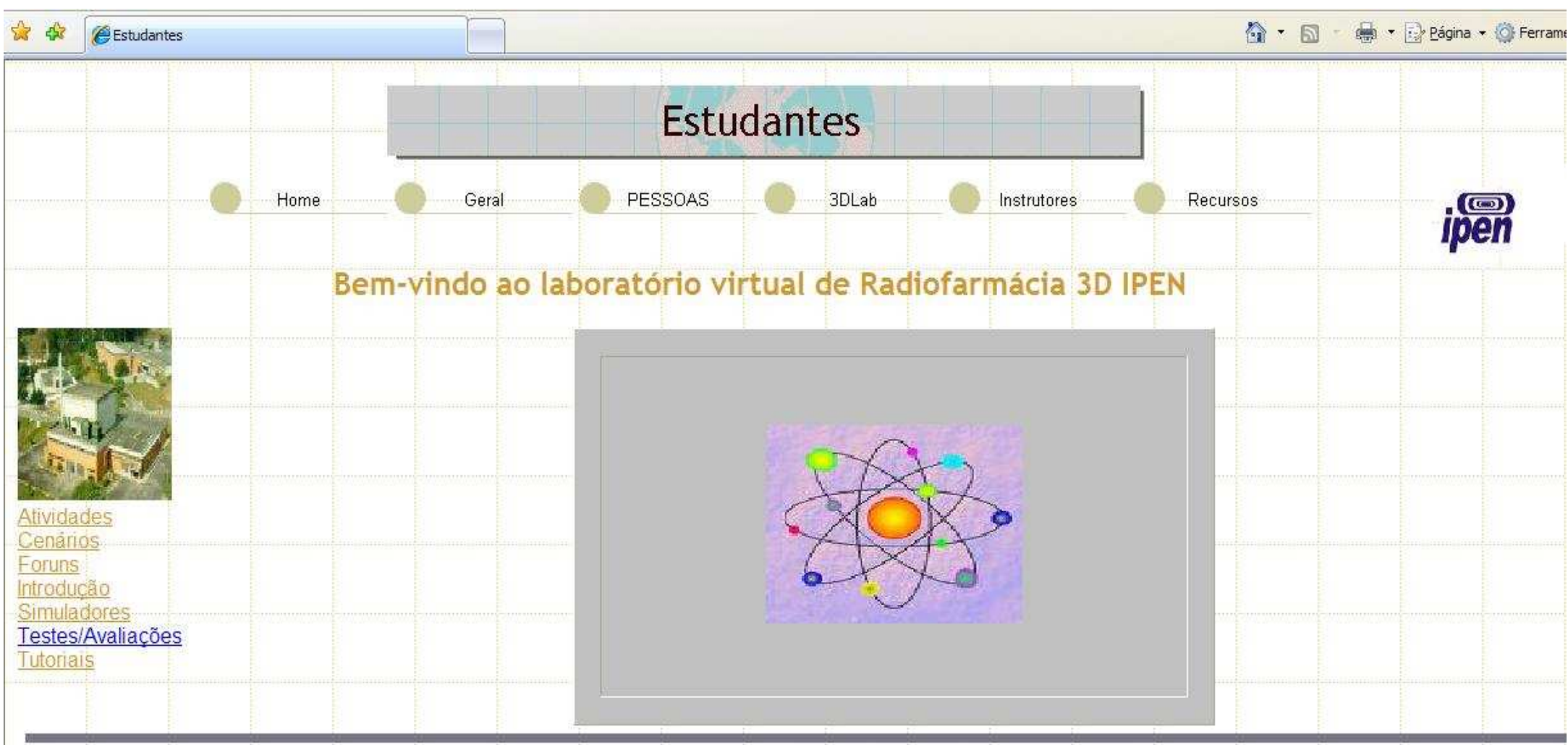

Proposta de Laboratório Virtual de Radiofarmácia - Tese Roberto Melo (2009) 


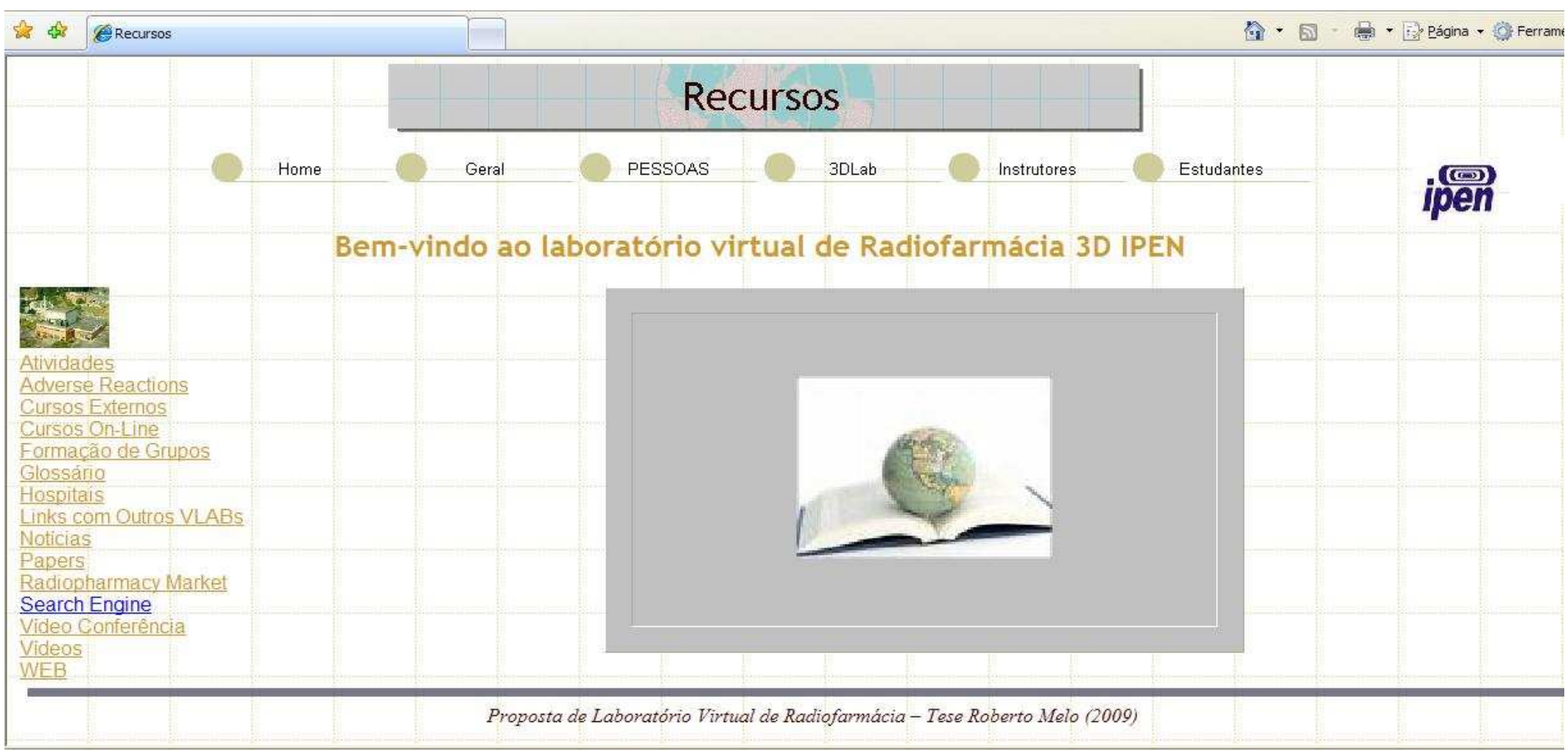




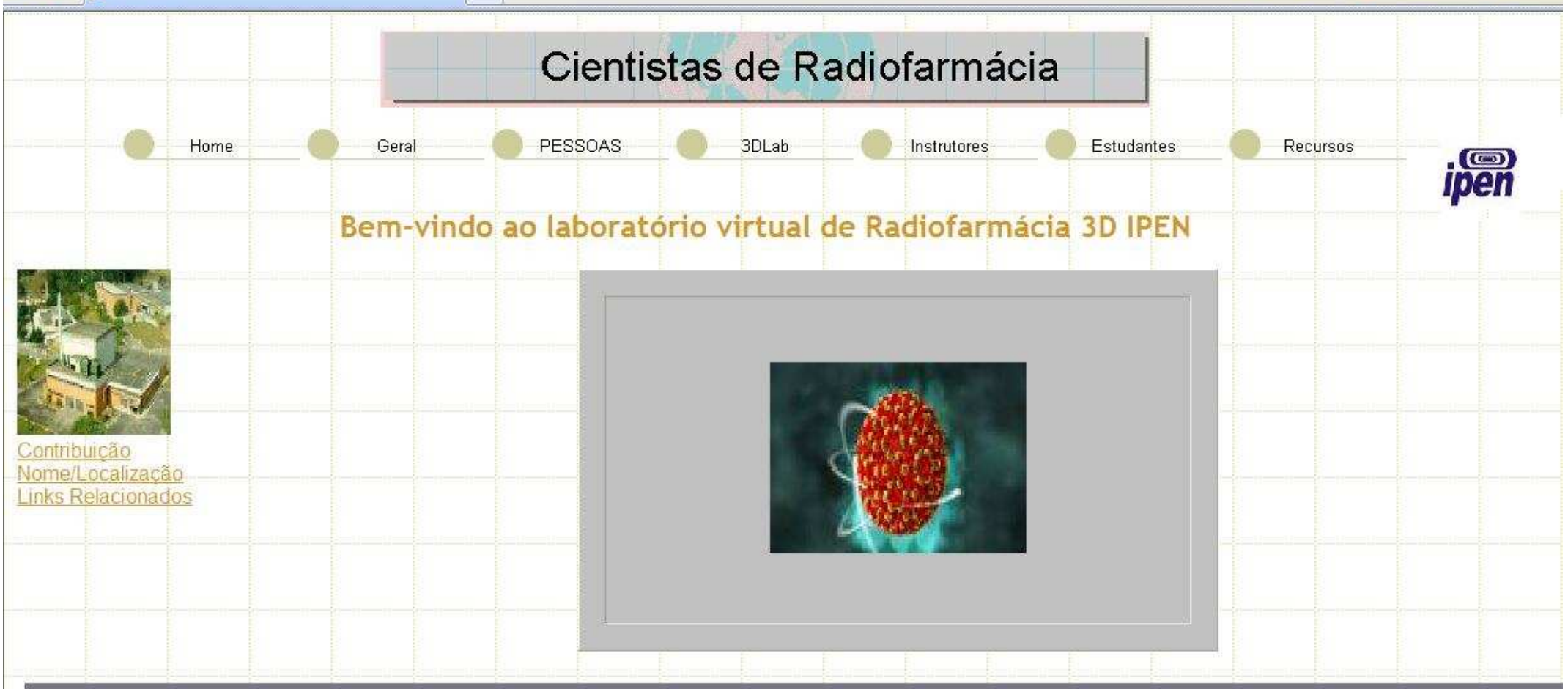




\section{REFERÊNCIAS BIBLIOGRÁFICAS}

1. ALEXIOU, A.; BOURAS, C.; GIANNAKA, E.; KAPOULAS, V.; NANI, M.; TSIATSOS, TH.; The Virtual Radiopharmacy Laboratory: a 3D Simulation for Distance Learning. Disponível em: http://ru6.cti.gr/Publications/1019.pdf Acesso: 20/ago/2005.

2. ALEXIOU, A.; BOURAS, C.; GIANNAKA, E. Virtual Laboratories in Education: a cheap way for schools to obtain laboratories for all courses, by using the computer laboratory. Disponível em: http://ru6.cti.gr/Publications/1009.pdf Acesso: 10/set/2006.

3. BOEREE, C. G., Personality theories: Carl Jung. Disponível em: http://webspace. ship.edu/cgboer/jung.html Acesso: 10/dez/2007.

4. BOURAS, C.; HORNIG, G.; TRIANTAFILLOU, V.; TSIATSOS, TH. Architectures supporting e-learning through collaborative virtual environments: the case of INVITE. Disponível em: http://ru6.cti.gr/Publications Acesso: 15/set/2006.

5. CANESSA, E.; FONDA, C.; RADICELLA, S.M. Virtual Laboratory strategies for development. Disponível em: http://www.ictp.trieste.it Acesso: 05/out/2005.

6. CASAS, L. A. A. Contribuições para a modelagem de um ambiente inteligente de educação baseado em realidade virtual. 1999. Tese de Doutorado. UFSC, Santa Catarina.

7. CERNIAN, O.; HAMBURG, H.; MANCAS, D., VLADUT, G. The role of virtual Laboratories in Education. 4-th European Conference E-COMM-LINE, Bucharest, Romenia. September 25-26, 2003.

8. CHEE, Y.S.; HOOI, C.M., C-VISIONS: Socialized learning through Collaborative, Virtual, Interactive Simulations. Proceedings of CSCL 2002, pg. 687-696, Hillsdale, NJ, USA.

9. CHURCHILL, E.F., SNOWDON, D.N., MUNRO, A.J. (eds) Collaborative virtual environments: digital places and spaces for interaction. Springer-verlang. 2001. 
10. CODATA. UNESCO: The emergence of virtual laboratories: towards new policies and strategies for knowledge handling. $17^{\text {th }}$ international CODATA Conference. Oct. 2000.

11. DILLENBOURG, $P$. What do you mean by 'collaborative learning' ?. In: Dillenbourg, P. (Ed) Collaborative-learning: Cognitive and Computational Approaches. (pg. 1-19), Pergamon Press. UK, 1999.

12. EARNSHAW, R. A.; LAMOTTE, W.; CHAMPNESS, N,; CHILTON, N.; DIAS, M.; MATOS, J. M. Visinet III-3D Visualisation over Networks. Telepresence and shared virtual environments (CHAINS). pp. 3-35. TEN IBC B3007, 1997.

13. FROITZHEIM, K.; SIMIONI, M. Developing a toolkit for virtual laboratory builders and participants. ESF-IIASA-NSF Workgroup. 3-5 December 1999, Laxenburg, Austria.

14. GARDNER, H. E. Inteligências múltiplas: a teoria na prática. Trad. Maria A. V. Veronese. Porto Alegre. Editora Artes Médicas. 1995.

15. GIL, A. C. Como elaborar projetos de pesquisa. Editora Atlas. São Paulo, 2002.

16. GILES, E.; PITRE, S.; WOMACK, S., Multiple intelligences and learning styles: from emerging perspectives on learning, teaching and technology. University of Georgia. Disponível em: http://projects.coe.ugga.edu Acesso: 25/ago/2007.

17. GOOD, T. E.; BROPHY, J. Psicologia educativa contemporânea. México. MacGraw Hill Interamericana Editores, 1997.

18. GOODYEAR, P. Psychological foundations for networked learning. In: Networked learning. Christine, pg. 49-75. Springer, 2001.

19. GUIMARÃES, E.; MAFFEIS, A.; PEREIRA, J.; RUSSO, B.; CARDOZO, E.; BERGERMAN, M.; MAGALHÃES, M.F. REAL: A virtual laboratory for mobile robot experiments. IEEE Transactions on Education, Vol. 46, N. 1, February, 2003.

20. HARASIM, L. M. Online education: an environment for collaboration and intellectual amplification. In; L. M. Harasim (ed). Online education: Perspectives on a new environment. New York: Praeger, 1990. 
21. HOFMAN, H.G. Virtual reality therapy. Scientific American, vol. 291, issue 2, pg. 58, August, 2004.

22. HOLLADAY. A. Learning strategies and technology.

Disponível em: http://ed.uab.edu/ed630/p1.html

Acesso: 15/jun/2000.

23. ISDALE, J. What is virtual reality ? A web-based introduction.

Disponível em: http://www.isx.com/ jisdale/whatisvr.html Acesso: 28/set/2007.

24. JONASSEN, D. Computer mediated communication. In: Computers in the classroom: Mindtools for critical thinking, Jonassen, David. pg. 147-183. Prentice Hall, 1995.

25. KHALIFA, M.; LAM, R., Web-based learning: effects on learning process and outcome. IEEE Transactions on Education, Vol. 45, N. 4, November, 2002.

26. KIRNER, C.; TORI, R. (ed.), Realidade Virtual: conceitos e tendências. Editora Mania de Livro. São Paulo, pg. 4-46, 2004.

27. KNAPP, F.; MIRZADEH, S. Radionuclide production. Chapter 10. pg.135-150. In: WAGNER, H. N.; Principles of Nuclear Medicine. Second edition. W.B.Saunders Company. Philadelphia. USA. pg. 11-55. 2001.

28. KOSCHMAN, T. Dewey's contribution to the foundations of CSCL research. Computer Support for Collaborative Learning (CSCL 2002). USA, CO.

29. LAISTER, J.; KOUBEK, A. $3^{\text {rd }}$ Generation learning platform requirements and motivation for collaborative learning. EURODL - European Journal of Open Distance Learning. Dec. 2001.

30. LANGER, E. J. Mindfullness. Perseus Books, Reading, Massachusetts. USA. pg. 11-178. 1989.

31. LANGER, E. J. The Power of Mindful Learning. Perseus Books. Reading. Massachusetts. USA. pg. 20-103. 1997.

32. LOCK, A.; PETERS, C.; Handbook of Human Symbolic Evolution, (ed.), Blackwell Publishers Ltd, Massachussets, USA. pg. 469-479. 1999. 
33. OLIVEIRA, R., SANTOS, D. Preparações radiofarmacêuticas e suas aplicações. In: Revista brasileira de ciências farmacêuticas. Vol. 42, n.2, abr/jun., 2006.

34. RICHARDSON, R. J. Pesquisa social: métodos e técnicas. 3a. Ed. São Paulo: Editora Atlas, pg. 17-143. 1999.

35. RIVARD, J. D. Selected topics on technology, teaching and learning. Nedham Heights, MA, Simon and Schuster. pg. 21-45. 1996.

36. RODRIGUES, L.C.R.; KUBO, M. M.; RODELLO, I. A.; SEMENTILLE, A. C.; BREGA, J. R. F. Ambientes Virtuais Distribuídos. In: KIRNER, C.; TORI, R. (Org.). Realidade Virtual - Conceitos e Tendências. São Paulo: 2004, v. 01.

37. ROMISZOWSKI, A. J. Computer mediated communication. In: Instructional development paradigms. Educational Technology Publications Inc., USA, pg. 419. 1997.

38. SAHA, G. Fundamentals of nuclear pharmacy. Fourth edition. Springer-Verlag Science Business Media, Inc. New York, pg. 12-97. 1998.

39. SANTAELLA, L. Matrizes da linguagem e pensamento. Sonora, visual e verbal. São Paulo, lluminuras. pg. 55-57. 2001.

40. Sementille, A. C. A Utilização da Arquitetura Corba na Construção de Ambientes Virtuais Distribuídos. 1999. Tese de doutorado em Física Aplicada, USP, São Carlos.

41. SHUELL, T. Designing instructional computing systems for meaningful learning. New York. Springer-verlag. pg. 34-58. 1992.

42. SMITH, M. K. Howard Gardner and multiple intelligences.

Disponível em: http://www.infed.org/thinkers/gardner.htm Acesso: 05/set/2006.

43. STAHL, G. Meaning and interpretation in collaboration. In: Designing for changed in networked learning environments. Wasson, B., pg. 523-532. Kluwer academic. UK. 2003.

44. TAYLOR, R. (ed) The computer in the school: tutor, tool, tutee. Teachers College Press, New York. pg. 3-89.1980. 
45. THALMANN, D., PANDZIC, I. S., CAPIN, T. K. Avatar in network virtual environments. England. Willey, pg. 15-36. 1999.

46. THALMANN, D. The role of virtual humans in virtual environment technology and interfaces. Disponível em: http://www.epfl.ch Acesso: 20/ago/2004.

47. THRALL, J., ZIESSMAN, H.; Medicina Nuclear. Trad. Maria Expósito Penas. Editora Guanabara Koogan. S.A., Rio de Janeiro. pg. 15-48. 2003.

48. TUBIS, M.; WOLF, W. Radiopharmacy. John Wiley \& Sons, Inc. New York. USA. pg. 8-23. 1976.

49. UNESCO Report. The emergence of virtual laboratories: towards new policies and strategies for knowledge handling Disponível em: http://www.codata.org.2000. Acesso: 03/ago/2006.

50. VIGOTSKI, L. S. A formação social da mente. O desenvolvimento dos processos psicológicos superiores. Trad.: José Cipolla Neto. São Paulo, Editora Martins Fontes, pg. 25-131. 1998.

51. VIGOTSKI, L. S. Pensamento e linguagem. Trad.: Jefferson Luiz Camargo. São Paulo, Editora Martins Fontes, pg. 9-97.1999.

52. VIRRAD GROUP. The VirRAD mission statement.

Disponível em: http://www.virrad.eu.org Acesso: 18/set/2006.

53. WILCOX, S. K. Web developer's guide to 3D avatars. New York: Willey, pg. 1449. 1998.

54 WOOLFOLK, A. Psicologia educativa. Sexta edición. México, Prentice Hall Hispanoamericana, pg. 37-69. 1996.

55. YIN, R. K. Estudo de caso: planejamento e métodos. 2. Ed. Porto Alegre, Editora Bookman, pg. 23-87. 2001.

56. YOUNGBLUT, C. Educational uses of virtual reality technology. IDA-Institute for Defense Analyses, IDA Document D-2128, January, pg. 5-17. 1998. 